UNESP- Universidade Estadual Paulista

"Júlio de Mesquita Filho"

unesp

Faculdade de Medicina de Botucatu

Departamento de Clínica Médica

Laboratório Experimental da Clínica Médica

\title{
INFLUÊNCIA DO TEMPO DE EXPOSIÇÃO À OBESIDADE SOBRE A FUNÇÃO CARDÍACA DE RATOS
}

André Soares Leopoldo

BOTUCATU - 2010 
André Soares Leopoldo

\title{
INFLUÊNCIA DO TEMPO DE EXPOSIÇÃO À OBESIDADE SOBRE A FUNÇÃO CARDÍACA DE RATOS
}

\author{
Tese apresentada à Faculdade de \\ Medicina, Universidade Estadual \\ Paulista "Júlio de Mesquita Filho" \\ Campus de Botucatu, para obtenção do \\ título de Doutor em Fisiopatologia em \\ Clínica Médica "Ciências da Saúde"
}

Orientador: Prof. Dr. Antonio Carlos Cicogna 
FICHA CATALOGRÁFICA ELABORADA PELA SEÇÃO TÉCNICA DE AQUISIÇÃO E TRATAMENTO DA INFORMAÇÃO

DIVISÃO TÉCNICA DE BIBLIOTECA E DOCUMENTẢČ̃̃O - CAMPUS DE BOTUCATU - UNESP BIBLIOTECÁRIA RESPONSÁVEL: Selma Maria de Jesus

\section{Leopoldo, André Soares. \\ Influência do tempo de exposição à obesidade sobre a função cardíaca de ratos / André Soares Leopoldo. - Botucatu, 2010.}

Tese (doutorado) - Faculdade de Medicina de Botucatu, Universidade

Estadual Paulista, 2010

Orientador: Antonio Carlos Cicogna

Assunto CAPES: 40101053

1. Coração - Doenças 2. Obesidade - Estudos experimentais

Palavras-chave: Colágeno; Dieta hiperlipídica; Função cardíaca; Obesidade; Trânsito de $\mathrm{Ca}^{+2}$ 
Dedico este trabalho às pessoas que foram as principais responsáveis por mais esta conquista:

À memória do meu pai, Paulo Rodolfo Leopoldo, exemplo e referência, que me ensinou os valores e princípios que regem a minha vida! Aे minha querida mãe, pelo amor, dedicação e presença constante na minha vida. Muitas palavras seriam insuficientes para demonstrar todo meu amor e gratidão!

A todos os meus familiares que me mostraram que FAMÍLIA é o que há de mais precioso na vida. Tenho certeza que não teria chegado até aqui, sem a presença de vocês. Sou eternamente grato a vocês!

À minha querida esposa e companheira desta trajetória, Ana Paula, pelo apoio e paciência nos momentos de maior dificuldade.

É impossível mensurar o quanto você é fundamental para a minha vida. Nunca se esqueça, você é a pessoinha da minha vida. Te amo!

Amar não é olhar um para o outro, é olhar juntos na mesma direção. (Antoine de Saint-Exupéry) 
A Deus pelas pessoas notáveis que colocou em meu caminho e permitiram a realização desta conquista.

Ao Prof. Dr. Antonio Carlos Cicogna, pela amizade e por tudo que tem me ensinado. Sem dúvida uma das coisas que mais me impressiona no Senhor é o seu entusiasmo em aprender, algo contagiante.

Foi uma honra tê-lo como orientador!

Ao Prof. Dr. Carlos Roberto Padovani pelo estímulo e auxílio imensurável do início ao término da construção desta tese, pessoa admirável, sempre disposto a ajudar em todos os momentos. Muito obrigado por tudo!

Ao amigo, Mario Mateus Sugizaki, pela oportunidade e respeito. Dizer obrigado é pouco para uma gratidão que, com palavras, dificilmente seria traduzida.

Pensar é o trabalho mais pesado que há, e, talvez, seja essa a razão para tão poucas pessoas se dediquem a tal tarefa" (Henry Ford) 
Aos AMIGOS que pude encontrar nestes anos de Laboratório, obrigado pela ajuda, compreensão e carinho dispensados no decorrer desta longa caminhada. Existem amigos que são passageiros, mas o mais importante, são aqueles que permanecem para sempre.

Aos companheiros do Lab. CIC, André Nascimento, Dijon, Silvio, Danielle, Paulo, Carlos, Paulinha, Adriana, Albano, Carolina, Loreta e Olga. Obrigado por contribuirem sempre de maneira positiva. Vocês são muito especiais!

A toda galera do Laboratório Experimental, Renata, Lidiane, Fabiana, Marcelo, Ricardo, Paula, Aline, Cristiana, Sandro, Maria Tereza, Marcos, Paula Schmidt, Rosangela, Juliana, Camila Bonomo, Daniele, Camila, Natasha, Fernanda, Miriane e Regiane. Obrigado pela amizade e convívio gostoso!

Á Sandrinha, a quem tenho uma admiração especial pelo seu exemplo de integridade, 6om fumor e alegria de viver. Valeu, amiga!

Às Profas. Dra. Célia Regina Nogueira e Maeli Dal Pai Silva, pela amizade e apoio contínuo em todos os momentos deste trabalho.

Aos Profs. Drs. Katashi Okoshi e Leonardo Zornoff pela atenção e valiosas sugestões que contribuíram para o aprimoramento deste trabalho. 
Aos amigos do Laboratório Experimental de Clínica Médica, José Carlos Georgette, Mário Bruno, Sueli Clara, José Aparecido, Ângelo, Rogério Monteiro, Elenize Jamas Pereira, Vitor Souza, Antonio Carlos de Lalla, Camila Renata Corrêa e Corina Julieta Corrêa, pela colaboração e sincera amizade. Vocês são essenciais!

Aos funcionários do Departamento de Clínica Médica, Ana Maria Mengue, Alexandre Luís Loureiro, Renato Borges Pereira, Elisangela Aparecida da Silva, Laura Andrade Câmara e Bruno José Fajiolli, pela atenção e prontidão em ajudar. Muito obrigado!

Aos funcionários da secretaria da Pós-graduação, Regina Célia Spadin, Nathanael Pinheiro Salles, Janete Aparecida Herculano $\mathcal{N}$ unes Silva, Andrea Paula Longo Devidé, e Lílian Cristina $\mathcal{N a d a l}$ Bianchi $\mathcal{N}$ unes, que com muita competência, paciência e 6om humor auxiliaram na solução de problemas.

Obrigado pelo apoio!

Ao Beto da Comissão de Ética em Experimentação Animal, por sua gentileza e prontidão em me auxiliar em inúmeras situações.

Obrigado pelo apoio e boa vontade!

Às funcionárias do ponto de apoio da FAPESP, sempre prontas a ajudar. Muito obrigado!

À Fundação de Amparo à Pesquisa do Estado de São Paulo pela concessão da bolsa de Doutorado e por viabilizar a realização deste estudo. Muito obrigado!

A todos, que de forma direta ou indireta, colaboraram para a concretização desta tese. Muito obrigado! 
"O valor das coisas não está no tempo em que elas duram, mas na intensidade com que acontecem. Por isso existem momentos inesquecíveis, coisas inexplicáveis e pessoas incomparáveis". 


\section{RESUMO}

A obesidade é uma doença crônica metabólica caracterizada pelo acúmulo excessivo de tecido adiposo. O excesso de gordura acarreta diversas anormalidades cardíacas, as quais se relacionam com a duração e intensidade da obesidade. Os períodos prolongados de obesidade promovem disfunção diastólica do ventrículo esquerdo, e, ocasionalmente disfunção sistólica e insuficiência cardíaca. A obesidade experimental por dietas hiperlipídicas tem sido utilizada como alternativa para o esclarecimento das causas e conseqüências da obesidade humana. Diversos modelos experimentais mostram que a obesidade acarreta disfunção cardíaca, a qual pode estar relacionada com alterações no trânsito de $\mathrm{Ca}^{+2}$ intracelular e nos níveis de colágeno miocárdico. Em razão da carência de estudos que avaliaram a relação entre a função cardíaca e a duração da obesidade, o objetivo deste estudo foi testar as seguintes hipóteses: o aumento do tempo de exposição à obesidade intensifica a disfunção miocárdica e reduz a capacidade de enchimento e ejeção do coração; o incremento da disfunção do músculo cardíaco é decorrente de maior redução do fluxo de cálcio pelo canal L do sarcolema e menor atividade da $\mathrm{Ca}^{+2}$ ATPase do retículo sarcoplasmático (Serca2a); e, o prejuízo funcional in vivo e in vitro, acentuado pelo tempo, é resultante do aumento dos níveis de colágeno miocárdico. Ratos Wistar machos, com 30 dias, foram distribuídos em dois grupos: controle $(C ; n=110)$ e obeso $(\mathrm{Ob} ; \mathrm{n}=110)$. Os ratos $\mathrm{C}$ receberam ração padrão para roedores e os $\mathrm{Ob}$ um ciclo de quatro rações hiperlipídicas por períodos de 15, 30 e 45 semanas. A gordura corporal total foi realizada pela somatória dos depósitos epididimal, retroperitoneal, visceral e a obesidade definida pelo índice de adiposidade. Os perfis nutricionais e metabólicos também foram avaliados nestes animais. O processo de remodelação cardíaca foi avaliado por meio de análises estruturais e funcionais. A estrutura foi analisada in vivo por meio do ecocardiograma e post mortem por estudos macroscópicos e microscópicos. A função cardíaca do ventrículo esquerdo foi analisada in vivo por meio do ecocardiograma e in vitro utilizando o músculo papilar isolado do ventrículo esquerdo (VE). A comparação dos seis grupos experimentais foi realizada pela técnica de análise de variância para o esquema de dois fatores (dieta e tempo), complementada com teste de comparações múltiplas de Bonferroni. O nível de significância considerado para todas as variáveis foi de 5\%. A obesidade acarretou intolerância à glicose, hiperinsulinemia, hiperleptinemia e resistência à insulina após 15, 30 e 45 semanas. No entanto, foram observadas algumas alterações pontuais, como hipercolesterolemia e hipertrigliceridemia. A obesidade não alterou o comportamento da pressão arterial sistólica e da lipoproteína de alta intensidade ao longo do tempo. O estudo macroscópico post mortem 
mostrou que a obesidade acarretou aumento dos pesos do coração e das câmaras cardíacas nos momentos 15 e 30 semanas. Entretanto, este processo hipertrófico não foi constatado após 45 semanas de obesidade. A obesidade promoveu aumento da massa e das espessuras diastólicas do septo interventricular e da parede posterior do VE após 15, 30 e 45 semanas. No entanto, a obesidade acarretou elevação da espessura relativa do VE na $30^{\mathrm{a}}$ e $45^{\mathrm{a}}$ semana. A análise ecocardiográfica mostrou que o tempo de exposição à obesidade intensificou a hipertrofia do VE. A área seccional transversa do miócito do VE foi elevada após 45 semanas de obesidade. A obesidade não promoveu variações no colágeno intersticial do VE em todos os períodos de tratamento; entretanto, houve aumento de colágeno no músculo papilar de ratos obesos após 45 semanas. O tempo de exposição à obesidade aumentou proporcionalmente os níveis de colágeno do VE. A função cardíaca in vivo mostrou que obesidade acarretou aumento das frações de encurtamento endo e mesocárdico e diminuição do estresse sistólico e razão E/A após 30 semanas. O tempo de exposição à obesidade influenciou somente parâmetros ecocardiográficos sistólicos. A obesidade promoveu disfunção miocárdica, após 15 semanas, visualizada pela diminuição da TD após a realização das manobras inotrópicas e lusitrópicas. No entanto, a duração da obesidade não modificou a função cardíaca in vitro. A função do canal L e a atividade da Serca2a foram preservadas em todos os momentos de avaliação. Em conclusão, o tempo de exposição à obesidade não intensifica a disfunção cardíaca, a atividade do canal L e da Serca2a e promove aumento do colágeno miocárdico. A elevação dos níveis de colágeno não acarreta prejuízo da função cardíaca in vivo e in vitro.

Palavras-chave: obesidade; dieta hiperlipídica; função cardíaca; trânsito de $\mathrm{Ca}^{+2}$; colágeno miocárdico 


\section{ABSTRACT}

Obesity is a chronic metabolic disease characterized by excessive accumulation of adipose tissue. Excess fat causes many cardiac abnormalities, which correlate with the duration and intensity of obesity. Prolonged periods of obesity promote left ventricular (LV) diastolic dysfunction, and occasionally systolic dysfunction and heart failure. Experimental models for high-fat diets have been used as an alternative to the explanation of causes and consequences of human obesity. Several experimental models have shown that obesity leads to cardiac dysfunction, which may be related to changes in intracellular calcium $\left(\mathrm{Ca}^{2+}\right)$ handling and in myocardial collagen. Due to the lack of studies that evaluated the relationship between cardiac function and the duration of obesity, the objective of the current study was to test the following hypothesis: the increased time of exposure to obesity intensifies the myocardial dysfunction and reduces the ability of filling and ejection of heart ; the elevation in functional impairment in vivo and in vitro is enhanced by time due to increased levels of myocardial collagen, and the dysfunction of heart muscle over time is due to greater reduction of calcium flow through L-type $\mathrm{Ca}^{2+}$ channel and lower activity of $\mathrm{Ca}^{2+}$-ATPase of sarcoplasmic reticulum (Serca2a). Thirty-day-old male Wistar rats were assigned to one of two groups $(\mathrm{n}=110$ each): control $(\mathrm{C})$ and obese $(\mathrm{Ob})$. The $\mathrm{C}$ group was fed a standard diet and $\mathrm{Ob}$ group was fed cycles of four high-fat diets for 15, 30 and 45 weeks. The total body fat was measured from the sum of the individual fat pad weights (epididymal, retroperitoneal and visceral) and the obesity defined by adiposity index. The cardiac remodeling process was assessed by structural and functional analysis. The nutritional and metabolic profiles of these animals were also evaluated. The structure was analyzed in vivo by echocardiography and post-death for macroscopic and microscopic studies. The LV cardiac function was assessed in vivo by echocardiography and in vitro using isolated papillary muscle from the LV. A comparison of six experimental groups was performed by two-way (diet and time of exposure) analysis of variance (ANOVA) and complemented by Bonferroni's posthoc test for specific differences. The significance level for all variables was 5\%. Obesity promoted glucose intolerance, hyperinsulinemia, hyperleptinemia and insulin resistance after 15, 30 and 45 weeks. However, we observed some specific changes, such as hypercholesterolemia and hypertriglyceridemia. Obesity did not alter the systolic blood pressure and high-density lipoprotein behavior over time. The post-death macroscopic study showed that obesity led to an increase in heart weight and heart chambers at 15 and 30 weeks. However, this hypertrophic process was not observed after 45 weeks of obesity. Obesity increased the LV mass and interventricular septum and 
posterior wall thickness in diastole after 15, 30 and 45 weeks. However, obesity has led to an increase in LV relative wall thickness in the $30^{\text {th }}$ and $45^{\text {th }}$ weeks. The echocardiographic analysis showed that the time of exposure to obesity increased the LV hypertrophy. LV crosssectional area myocyte was elevated after 45 weeks of obesity. Obesity did not promote changes in LV interstitial collagen in all periods of treatment; however, there was an increase in interstitial collagen deposition of obese papillary muscle after 45 weeks. The time of exposure to obesity increased proportionally the LV collagen levels. Cardiac function in vivo showed that obesity led to an increased in endocardial and midwall fractional shortening and a reduction in wall systolic stress and early peak transmitral flow velocity to late peak transmitral flow velocity ratio (E/A) after 30 weeks. The time of exposure to obesity influenced only echocardiographic systolic parameters. Obesity promoted myocardial dysfunction after 15 weeks, viewed by the decrease in TD after inotropic and lusitropic maneuvers. However, the duration of obesity did not modify cardiac function in vitro. L-type channel function and Serca2a activity have been preserved at all times of evaluation. In conclusion, the time of exposure to obesity not enhances cardiac dysfunction, the activity of the L channel and Serca2a and promotes increased myocardial collagen. The accumulation of collagen does not cause damage of cardiac function in vivo and in vitro.

Keywords: obesity, high-fat diet, cardiac function, $\mathrm{Ca}^{2+}$, collagen. 


\section{LISTA DE QUADROS}

Quadro 1- Composição de macro e micronutrientes das rações $(\%)$.......................................26

Quadro 2- Perfil de aminoácidos das rações $(\%)$...................................................................27

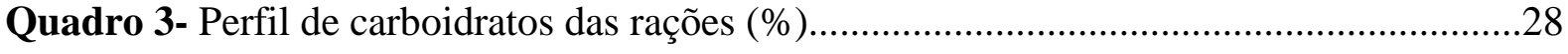

Quadro 4- Perfil de ácidos graxos saturados e insaturados das rações (\%)............................29 


\section{LISTA DE FIGURAS}

Figura 1. Evolução semanal do peso corporal................................................................... 48

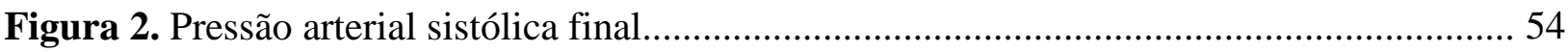

Figura 3. Área glicêmica obtida no teste de tolerância à glicose................................................ 55

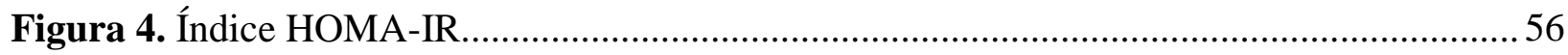

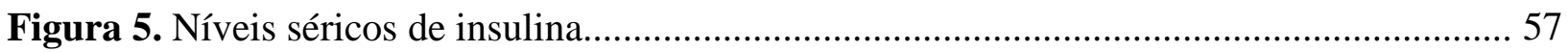

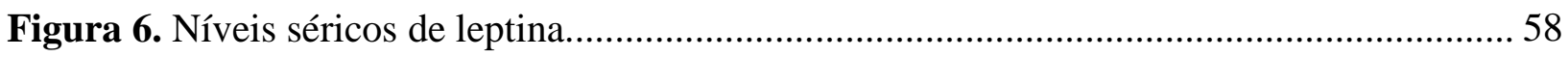

Figura 7. Área seccional transversa dos miócitos em fragmentos do ventrículo esquerdo......... 64

Figura 8. Secções transversas subendocárdicas do ventrículo esquerdo................................. 65

Figura 9. Área seccional transversa dos miócitos em fragmentos do músculo papilar............... 66

Figura 10. Secções transversas subendocárdicas do músculo papilar...................................... 67

Figura 11. Fração de colágeno intersticial do ventrículo esquerdo......................................... 68

Figura 12. Secções transversas subendocárdicas do ventrículo esquerdo................................ 69

Figura 13. Fração de colágeno intersticial do músculo papilar.............................................. 70

Figura 14. Secções transversas subendocárdicas do músculo papilar..................................... 71

Figura 15. Curva da tensão de repouso.......................................................................... 76

Figura 16. Potenciação pós-pausa.................................................................................... 79

Figura 17. Efeitos da elevação da concentração de cálcio extracelular................................... 82

Figura 18. Efeitos da elevação da freqüência de estímulo................................................... 85

Figura 19. Efeitos do bloqueio dos canais L de cálcio com diltiazem................................... 88

Figura 20. Efeitos do bloqueio da Serca2a com ácido ciclopiazônico..................................... 91 


\section{LISTA DE TABELAS}

Tabela 1. Perfil nutricional no momento inicial de obesidade ............................................. 49

Tabela 2. Perfil nutricional dos animais após 15,30 e 45 semanas....................................... 52

Tabela 3. Estrutura cardíaca in vivo após 15, 30 e 45 semanas............................................ 60

Tabela 4. Estrutura macroscópica cardíaca post mortem .................................................... 62

Tabela 5. Função cardíaca in vivo após 15, 30 e 45 semanas................................................ 73

Tabela 6. Contração isométrica basal.............................................................................. 75

Tabela 7. Potenciação pós-pausa................................................................................. 78

Tabela 8. Elevação da concentração de cálcio extracelular............................................... 81

Tabela 9. Elevação da freqüência cardíaca................................................................... 84

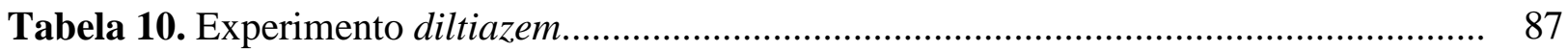

Tabela 11. Experimento ácido ciclopiazônico....................................................................... 90

Tabela 12. Teor de água nos tecidos cardíaco, pulmonar e hepático.................................... 92 


\section{SUMÁRIO}

Lista de Quadros

Lista de Figuras

Lista de Tabelas

Resumo

Abstract

1.

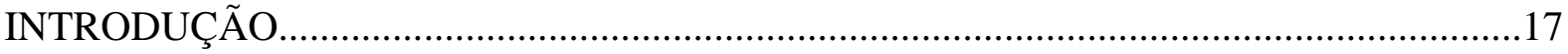

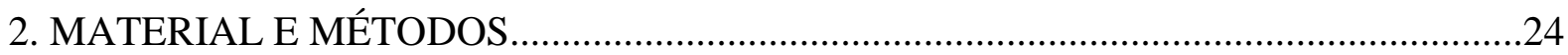

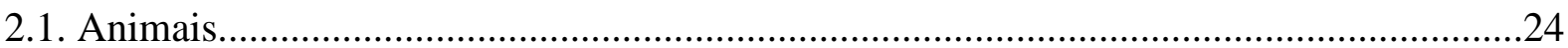

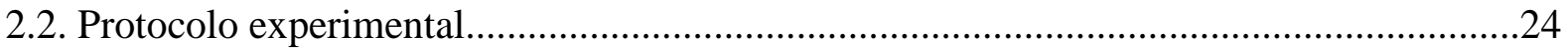

2.2.1. Composição das rações padrão e hiperlipídica...................................................25

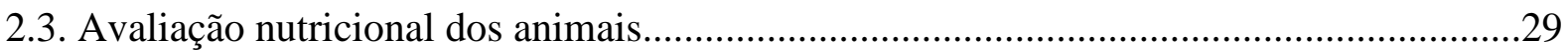

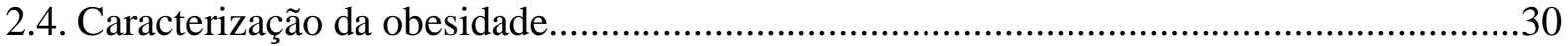

2.5. Determinação do momento inicial de obesidade................................................................31

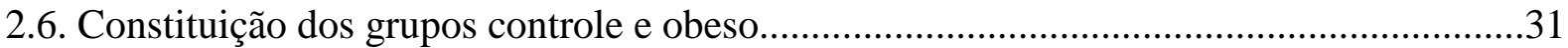

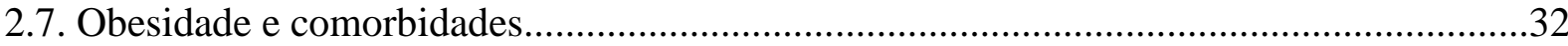

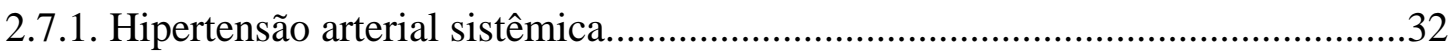

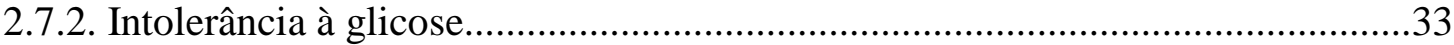

2.7.3. Resistência sistêmica à insulina.......................................................................33

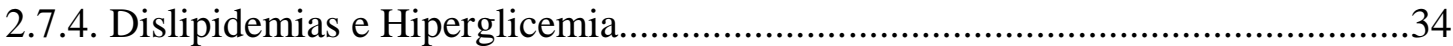

2.7.5. Hiperinsulinemia e Hiperleptinemia...................................................................34

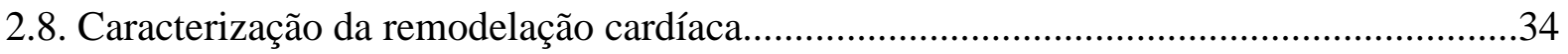

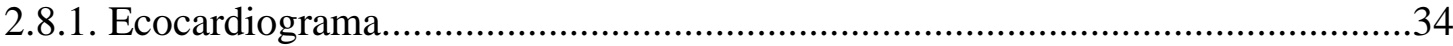

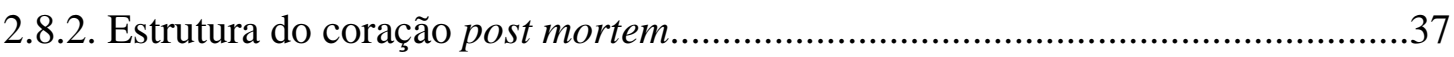

2.8.2.1 Área seccional transversa do miócito e determinação da fração de

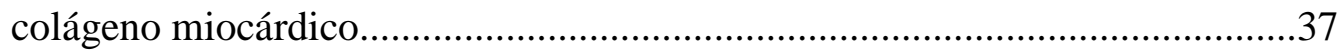

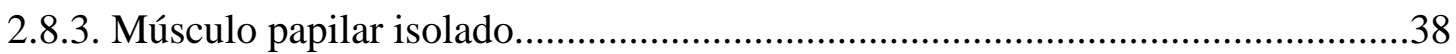

2.8.3.1. Parâmetros funcionais................................................................... 
2.8.3.2.1- Protocolo funcional em condição basal. .42

2.8.3.2.1.1- Curva de tensão-comprimento.........................................43

2.8.3.2.2- Manobras inotrópicas e lusitrópicas...............................................43

2.8.3.2.2.1- Potenciação pós-pausa......................................................43

2.8.3.2.2.2- Elevação da concentração de cálcio extracelular...............43

2.8.3.2.2.3- Elevação da freqüência cardíaca........................................44

2.8.3.2.2.4- Experimento diltiazem..................................................44

2.8.3.2.2.5- Experimento ácido ciclopiazônico...................................45

2.9. Determinação do teor de água nos tecidos cardíaco, pulmonar e hepático.......................46

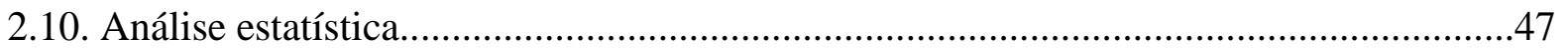

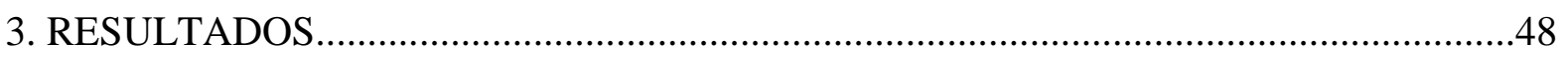

3.1. Caracterização do momento inicial de obesidade..............................................................48

3.2. Comparação entre os grupos controles e obesos após 15, 30 e 45 semanas.......................50

3.2.1. Composição dos grupos controle e obeso.......................................................50

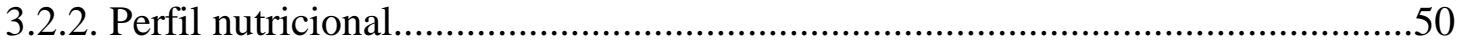

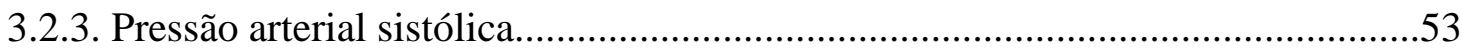

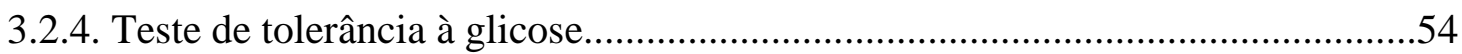

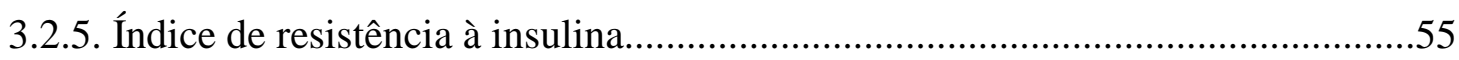

3.2.6. Análise sérica dos hormônios insulina e leptina.................................................56

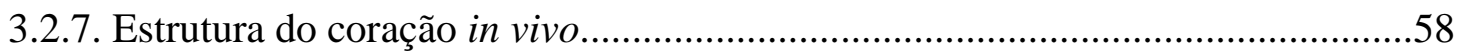

3.2.8. Estrutura do coração post mortem.................................................................61

3.2.8.1. Análise macroscópica........................................................................61

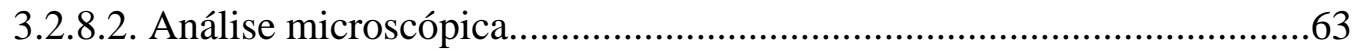

3.2.8.2.1- Área seccional transversa do miócito....................................63

3.2.8.2.2- Determinação da fração de colágeno miocárdico....................68

3.2.9- Avaliação da função cardíaca in vivo.....................................................72

3.2.10- Avaliação da função cardíaca in vitro...................................................74

3.2.10.1- Condição basal.....................................................................74

3.2.10.1.1- Curva de tensão-comprimento............................................75

3.2.10.2- Potenciação pós-pausa............................................................76 
3.2.10.3- Elevação da concentração de cálcio extracelular. .79

3.2.10.4- Elevação da freqüência cardíaca.........................................82

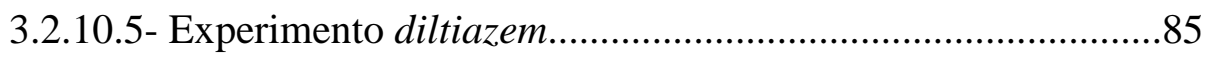

3.2.10.6- Experimento ácido ciclopiazônico.......................................88

3.2.11. Determinação do teor de água nos tecido cardíaco, pulmonar e hepático. .91

4. DISCUSSÃO. .93

4.1- Modelo experimental de obesidade. .93

4.2- Obesidade e remodelação cardíaca. 101

4.2.1- Influência da obesidade sobre a estrutura cardíaca. .102

4.2.2- Influência da obesidade sobre a função cardíaca. .107

5. CONCLUSÃO. 116

6. REFERÊNCIAS 117 


\section{INTRODUÇÃO}

A obesidade é uma doença complexa caracterizada pelo acúmulo excessivo de tecido adiposo. $^{(1)}$ A incidência e prevalência da obesidade no mundo têm aumentado progressivamente nas últimas décadas, ${ }^{(2)}$ sendo considerada atualmente, uma epidemia global e um importante problema de saúde pública, que afeta tanto países desenvolvidos quanto subdesenvolvidos. ${ }^{(3-5)} \mathrm{O}$ número de indivíduos com sobrepeso atinge mais de um bilhão de pessoas, sendo que, mais de $30 \%$ desta população é obesa. ${ }^{(6)}$ Além disso, um fato marcante é o aumento na prevalência de obesidade nos diversos subgrupos populacionais para quase todos os países latino-americanos. Nos últimos anos, pôde se perceber uma intensa migração no foco das pesquisas realizadas por diversos grupos de pesquisadores da América Latina, o que demonstra a crescente importância da obesidade como tema de investigações científicas. ${ }^{(7)}$ Apesar de ter sido acumulado até o momento um relativo conhecimento sobre a distribuição da obesidade, dentro do contexto da transição nutricional, muito ainda se faz necessário, sobretudo, no campo da prevenção e intervenção populacional. ${ }^{(7)}$

No Brasil, as mudanças demográficas, sócio-econômicas e epidemiológicas ao longo do tempo permitiram que ocorresse a chamada transição nutricional, com diminuição progressiva da desnutrição e aumento da obesidade. ${ }^{(8-10)}$ Segundo a Pesquisa de Orçamentos Familiares do Instituto Brasileiro de Geografia e Estatística, ${ }^{(11)}$ aproximadamente 40 milhões de pessoas no Brasil apresentam sobrepeso e, deste grupo, 10,5 milhões são obesos. A previsão é que $35 \%$ da população adulta brasileira será obesa em 2025, refletindo-se no aumento de custos e cuidados para a saúde pública. ${ }^{(11)}$

Estudos que avaliaram as conseqüências da obesidade para a saúde humana têm mostrado que a etiologia da obesidade é complexa. Enquanto alguns autores sugerem que o fator genético contribui para o desenvolvimento da obesidade, muitos trabalhos enfatizam que 
a prevalência desta doença na população ocorre devido aos chamados fatores ambientais, em especial à dieta e o sedentarismo. ${ }^{(6,12)} \mathrm{O}$ aumento do consumo de energia, a redução na prática de atividade física ou a combinação de ambos têm levado a um balanço calórico positivo com conseqüente aumento da gordura corporal. ${ }^{(13)}$ Dentro desse contexto, a obesidade se consolidou como agravo nutricional associado a uma alta incidência de morbidades, como câncer, resistência à insulina, diabetes mellitus tipo 2, dislipidemias e doenças cardiovasculares, ${ }^{(6,14,15)}$ influenciando desta maneira, no perfil de mortalidade das populações, e, conseqüentemente, reduzindo a expectativa de vida. ${ }^{(16-20)}$

Diversas pesquisas mostram que a obesidade aumenta o risco de mortalidade por doenças cardiovasculares em torno de 20 a $30 \%$ em homens. ${ }^{(13,21)}$ Estudos longitudinais mostram que a obesidade per se predispõe às diversas anormalidades cardiovasculares, como a doença arterial coronariana ${ }^{(22)}$ e, eventualmente, pode ocasionar insuficiência cardíaca. ${ }^{(23-25)}$

Embora a obesidade possa acarretar falência cardíaca, existem informações controversas, principalmente, sobre a função sistólica em humanos obesos na presença ${ }^{(26-30)}$ ou ausência de comorbidades. ${ }^{(5,23,31-40)}$ As pesquisas clínicas, realizadas por ecocardiograma, mostram que indivíduos obesos apresentam disfunção diastólica do ventrículo esquerdo (VE). ${ }^{(5,26-28,32,34-36,38,39)}$ Apenas um trabalho encontrou função diastólica preservada no VE, verificando alteração no desempenho diastólico somente no ventrículo direito. ${ }^{(33)}$ Os estudos que avaliaram a performance sistólica na obesidade mostram desempenho preservado, ${ }^{(30,31,33,36,37)}$ aumentado ${ }^{(32,34,35,38)}$ ou diminuído; ${ }^{(5,27,29,39,40)}$ a razão para esta discrepância, provavelmente, está relacionada às técnicas utilizadas para avaliar a função sistólica. ${ }^{(5)}$ Outro fator que poderia interferir nos resultados seria a intensidade da obesidade; entretanto, alguns autores encontraram fração de ejeção normal ou até mesmo elevada em indivíduos com obesidade mórbida. ${ }^{(28,35,38,41-43)}$ 
A duração da obesidade humana têm sido freqüentemente associada às anormalidades na função cardíaca. ${ }^{(23,34,39,44)}$ Os períodos prolongados de obesidade promovem disfunção diastólica do ventrículo esquerdo, e, ocasionalmente disfunção sistólica e insuficiência cardíaca. ${ }^{(23-25,45)}$ Segundo Alpert et al, ${ }^{(23)}$ a duração da obesidade mórbida foi determinante para a alteração na função cardíaca; estes autores relatam uma correlação positiva entre a duração da obesidade mórbida e disfunção sistólica e diastólica. Outro estudo observou que os valores da fração de ejeção foram reduzidos em indivíduos obesos e inversamente relacionados com índice de massa corporal e a duração da obesidade. ${ }^{(46)}$

Os estudos que envolvem obesos humanos, provavelmente, poderiam responder às diversas dúvidas em relação às disfunções cardiovasculares, mecanismos envolvidos e tratamentos clínicos. No entanto, estas pesquisas apresentam limitações éticas, financeiras e dificuldades no controle das variáveis que poderiam interferir nos resultados. ${ }^{(47)}$ A obesidade experimental, utilizando modelos genéticos ${ }^{(48-50)}$ ou manipulações dietéticas, ${ }^{(51-54)}$ é uma alternativa para o estudo da obesidade, comorbidades e mecanismos oriundos do excesso de gordura corporal. Dentro desse contexto, esses modelos experimentais também são importantes para o estabelecimento de tratamentos terapêuticos, que terão como desfecho final a aplicabilidade na obesidade clínica. ${ }^{(55)}$ A obesidade experimental por meio de dietas com alta densidade energética representa um modelo mais realista e apropriado para o estudo das causas e consequiências da obesidade humana. ${ }^{(47)}$ Estudos epidemiológicos mostram uma correlação significantemente positiva entre o consumo de dieta rica em gordura e incidência de obesidade; ${ }^{(47,56,57)}$ entretanto, o impacto destas dietas na estrutura e função cardíaca em modelos experimentais de obesidade é controverso devido às diferenças na composição dos lipídios, em ácidos graxos saturados e insaturados. ${ }^{(55)}$

As pesquisas experimentais que promovem obesidade, por dietas hiperlipídicas, apresentam resultados inconsistentes em relação à função cardíaca. Trabalhos têm mostrado 
que ratos obesos induzidos por dieta hiperlipídica, durante um período de 11 a 12 semanas, não apresentaram alterações na função cardíaca visualizada por meio de diferentes técnicas, como o ecocardiograma ${ }^{(51)}$ e coração isolado. ${ }^{(58)}$ Entretanto, Relling et al ${ }^{(52)}$ verificaram em ratos Sprague-Dawley, que obesidade induzida por dieta hiperlípidica, durante 12 semanas, acarretou disfunção contrátil no cardiomiócito após elevação da concentração de cálcio e frequiência de estímulo. Outros pesquisadores também observaram depressão do desempenho mecânico do miócito em condições basais e após elevação da concentração de cálcio $\left(\mathrm{Ca}^{+2}\right)$, em ratos alimentados com uma dieta hiperlipídica durante 12 semanas. ${ }^{(59)}$ Pesquisas recentes em nosso laboratório ${ }^{(60,61)}$ mostraram que a obesidade em ratos Wistar, induzida por um ciclo de dietas hiperlipídicas por 15 semanas e adição de sacarose por 3 semanas, não acarretou alterações mecânicas no músculo papilar isolado do ventrículo esquerdo em situação basal; entretanto, após a realização de manobras inotrópicas e lusitrópicas, foi observado disfunção miocárdica. Portanto, os resultados da literatura em relação à função cardíaca em modelos experimentais de obesidade não são consistentes. A discrepância nos resultados encontrados poderia ser devido às diferenças nas técnicas utilizadas, na intensidade e na duração da obesidade. Além disso, nestes estudos, o tipo de ácidos graxos utilizados na dieta hiperlipídica, saturado ou insaturado, não descrito pelos autores, pode ter influenciado a função cardíaca. Há diversas evidências que a utilização de dietas ricas em gorduras, especialmente as saturadas, estão associadas com aumento do risco de disfunções cardiovasculares; ${ }^{(62-64)}$ entretanto, os resultados sobre a influência dos ácidos graxos mono ou polinsaturados na função são conflitantes, não alterando ou melhorando o desempenho cardíaco. $^{(65-69)}$

A disfunção cardíaca em diversos modelos experimentais ${ }^{(70-73)}$ tem sido freqüentemente relacionada com anormalidades na homeostase de $\mathrm{Ca}^{+2}$ intracelular miocárdico, as quais podem estar associadas principalmente com alterações na expressão ou 
na função das proteínas envolvidas no trânsito de $\mathrm{Ca}^{+2}$ miocárdico. Contudo, a relação entre disfunção cardíaca e ciclo de $\mathrm{Ca}^{+2}$ intracelular é pouco estudada na obesidade. ${ }^{(50,52,59,74)}$

$\mathrm{O}$ trânsito de $\mathrm{Ca}^{+2}$ intracelular é um dos principais mecanismos reguladores da contração e relaxamento miocárdico. ${ }^{(75,76)}$ A contração cardíaca inicia-se a nível celular, com a fase de despolarização do potencial de ação, o que causa abertura dos canais de $\mathrm{Ca}^{+2}$ do tipo $\mathrm{L}$ com conseqüente influxo de $\mathrm{Ca}^{+2}$ do meio extracelular para o interior da célula através destes canais. ${ }^{(76)} \mathrm{O}$ influxo de $\mathrm{Ca}^{+2}$ promove aumento da concentração de $\mathrm{Ca}^{+2}$ livre no citosol o que desencadeia a liberação de grande quantidade de $\mathrm{Ca}^{+2}$ a partir do retículo sarcoplasmático (RS) por meio de um mecanismo conhecido como liberação de $\mathrm{Ca}^{+2}$ induzida por $\mathrm{Ca}^{+2}{ }^{(77)} \mathrm{O}$ aumento do $\mathrm{Ca}^{+2}$ citosólico possibilita a ligação desse íon com troponina $\mathrm{C}$ (TnC) e a interação actina-miosina. A intensidade da contração depende da quantidade e da sensibilidade dos miofilamentos ao $\mathrm{Ca}^{+2}$.

A entrada dos íons cálcio pelos canais L dentro dos cardiomiócitos é bem descrita na literatura como sendo o evento inicial do processo acoplamento excitação-contração. ${ }^{(78,79)}$ Alterações na quantidade ou função dos canais L têm sido implicadas em uma variedade de doenças cardiovasculares, como fibrilação atrial, insuficiência cardíaca e isquemia crônica. ${ }^{(80-}$ 82) Diversos modelos experimentais mostram que o canal $L$ exerce papel fundamental na performance cardíaca e, qualquer defeito na função deste canal, pode conseqüentemente, acarretar disfunção cardíaca; ${ }^{(83-85)}$ entretanto, não foram encontrados estudos que avaliaram a participação deste canal na deterioração funcional induzida pela obesidade.

Após o evento excitação-contração, inicia-se o relaxamento miocárdico à custa da diminuição da quantidade de $\mathrm{Ca}^{+2}$ citosólico. A remoção rápida dos íons $\mathrm{Ca}^{+2}$ para dentro do RS ou, alternativamente, a extrusão desses para o meio extracelular são essenciais para o relaxamento. O processo de recaptura de $\mathrm{Ca}^{+2}$ para o interior do $\mathrm{RS}$ é realizado pela $\mathrm{Ca}^{+2}$ ATPase do retículo sarcoplasmático (Serca2a). Em humanos, é descrito que a Serca2a remove 
70 a $80 \%$ dos íons $\mathrm{Ca}^{+2 .(86)}$ entretanto, em ratos esta proteína é responsável pela recaptura de 92\%.(75) Diversos modelos experimentais mostram que a disfunção cardíaca pode estar associada com aterações nos níveis e/ou atividade da Serca2a. ${ }^{(87-89)}$ Entretanto, a participação da Serca2a na disfunção cardíaca decorrente da obesidade não está esclarecida. Relling et $\mathrm{al}^{(52)}$ utilizando ratos submetidos à dieta hiperlipídica, por 12 semanas, mostraram que a obesidade, não acompanhada de comorbidades, promoveu prejuízo da função dos cardiomiócitos, aumento da expressão protéica da Serca2a e da fosfolambam (PLB) e diminuição dos níveis de PLB fosforilado; entretanto, os autores não avaliaram a atividade da Serca2a nestes animais.

A remodelação cardíaca em diversos modelos experimentais, ${ }^{(90-92)}$ assim como na obesidade, pode também apresentar alterações na matriz extracelular, principalmente nos níveis de colágeno. O colágeno, em situação estável, contribui para a manutenção da estrutura e função cardíaca. ${ }^{(93)}$ Entretanto, em resposta a estímulos desencadeados por agentes mecânicos ou neuro-hormonais, o colágeno pode sofrer alterações com possível ocorrência de fibrose intersticial, ${ }^{(94)}$ e prejudicar o movimento miofibrilar. ${ }^{(95,96)}$ A obesidade experimental ainda carece de informações sobre a relação entre função cardíaca e os níveis de colágeno intersticial. ${ }^{(51,97)}$ Carroll e Tyagi ${ }^{(97)}$ verificaram aumento da expressão protéica de colágeno tipo I e III em coelhos obesos após 12 semanas; entretanto, estes autores não avaliaram a função cardíaca. Outro pesquisador ${ }^{(51)}$ mostrou que a obesidade não promove disfunção cardíaca e alterações na fração de colágeno intersticial após 12 semanas. Pesquisa recente em nosso laboratório mostrou que ratos obesos, submetidos a um ciclo de dietas hiperlipídicas por 15 semanas e adição de sacarose por 3 semanas, apresentaram aumento da rigidez miocárdica e aumento de colágeno intersticial. ${ }^{(59)}$ Silva et $\mathrm{al}^{(98)}$ verificaram, em animais obesos alimentados com dieta hiperlipídica, aumento dos níveis protéicos de colágeno III após 
45 semanas e diminuição da expressão proteíca de colágeno I após 30 e 45 semanas. Estes autores não avaliaram a função cardíaca destes ratos.

Em razão da carência de estudos que avaliaram a relação entre função cardíaca e duração da obesidade, o objetivo deste estudo foi testar as seguintes hipóteses:

1) o aumento do tempo de exposição à obesidade intensifica a disfunção miocárdica e reduz a capacidade de enchimento e ejeção do coração;

2) o incremento da disfunção do músculo cardíaco é decorrente da maior redução do fluxo de cálcio pelo canal L do sarcolema e menor atividade da Serca2a;

3) o prejuízo funcional in vivo e in vitro, acentuado pelo tempo, é resultante do aumento dos níveis de colágeno miocárdico. 


\section{MATERIAL E MÉTODOS}

\section{1- Animais}

No presente estudo foram utilizados 220 ratos Wistar machos, com 30 dias de idade, provenientes do Biotério do Laboratório Experimental do Departamento da Clínica Médica, Faculdade de Medicina de Botucatu, Universidade Estadual Paulista "Júlio de Mesquita Filho" - UNESP, São Paulo, Brasil. Os animais foram mantidos no biotério de origem sob as seguintes condições: gaiolas individuais de polipropileno com tampas de arame cromado forradas com maravalha de Pinus esterilizada, temperatura ambiente $\left(24 \pm 2^{\circ} \mathrm{C}\right)$, umidade controlada $(55 \pm 5 \%)$ e ciclos de iluminação de 12 horas. Os procedimentos experimentais foram realizados de acordo com o "Guide for the Care and Use of Laboratory Animals" publicado pelo "U.S. National Institutes of Health"(99) e aprovados pela Comissão de Ética em Experimentação Animal da Faculdade de Medicina de Botucatu - UNESP.

\section{2- Protocolo Experimental}

Os ratos foram randomizados em dois grupos: alimentados com dietas normocalórica (DN, $n=110)$ ou hipercalórica $(\mathrm{DH}, \mathrm{n}=110)$. Os ratos $\mathrm{DN}$ receberam ração padrão para roedores (RC Focus 1765, Agroceres ${ }^{\circledR}$, Rio Claro, São Paulo, Brasil) e os DH um ciclo de quatro rações hiperlipídicas (RC Focus 2413, 2414, 2415 e 2416, Agroceres ${ }^{\circledR}$, Rio Claro, São Paulo, Brasil), por períodos de 15, 30 e 45 semanas. As rações hiperlipídicas foram alternadas a cada 24 horas. Os ratos DN e DH receberam 50 g de ração e após 24 horas a quantidade não ingerida foi mensurada. A oferta de água foi ad libitum.

As rações idealizadas no Laboratório Experimental de Músculo Papilar Isolado do Departamento de Clínica Médica, Faculdade de Medicina de Botucatu, UNESP, foram adaptadas a partir de modelo dietético utilizado anteriormente pelo grupo. ${ }^{(100)}$ 


\subsection{1- Composição das rações padrão e hiperlipídica}

A ração padrão RC Focus 1765 foi composta pelos seguintes ingredientes: fosfato bicálcico, óleo de soja degomado, cloreto de sódio, milho moído, aditivo antioxidante, farelo de soja, farelo de trigo, farinha de carne e ossos, farinha de peixe, suplemento mineral e vitamínico. As quatro rações hiperlipídicas RC Focus 2413, 2414, 2415 e 2416 apresentaram a mesma composição nutricional, com exceção dos aditivos flavorizantes, queijo, bacon, chocolate ou baunilha, respectivamente; as rações foram constituídas de cloreto de sódio, caseína, soro de leite em pó, concentrado protéico de soja, milho integral moído, farinha de bolacha, fosfato bicálcico, carbonato de cálcio, óleo de milho, aditivos emulsificante e antioxidante, suplemento mineral e vitamínico.

A composição de macro e micronutrientes das rações padrão e hiperlipídica, mensurada pela empresa Agroceres ${ }^{\circledR}$, Rio Claro, São Paulo, Brasil, está apresentada no Quadro 1. Os perfis de aminoácidos, carboidratos e ácidos graxos, avaliados no Laboratório de Bioquímica de Microrganismos e Plantas do Departamento de Tecnologia - Faculdade de Ciências Agrárias e Veterinárias, UNESP, Jaboticabal, SP, Brasil, estão apresentado nos Quadros 2, 3 e 4, respectivamente. 
Quadro 1- Composição de macro e micronutrientes das rações (\%)

\begin{tabular}{ccc} 
& \multicolumn{2}{c}{ Rações } \\
\cline { 2 - 3 } Componentes & Padrão & Hiperlipídica \\
\hline Proteína & 22,0 & 20,0 \\
Carboidrato & 42,7 & 26,4 \\
Gordura & 4,0 & 20,0 \\
Vitaminas e Minerais & 11,3 & 12,1 \\
Fibras & 8,0 & 9,0 \\
Umidade & 12,0 & 12,5 \\
Calorias (Kcal/g) & $\mathbf{2 , 9 5}$ & $\mathbf{3 , 6 5}$ \\
\% Calorias da proteína & 29,8 & 21,9 \\
\% Calorias do carboidrato & 57,9 & 28,9 \\
\% Calorias da gordura & 12,3 & 49,2 \\
\hline
\end{tabular}


Quadro 2- Perfil de aminoácidos das rações (\%)

\begin{tabular}{|c|c|c|}
\hline \multirow[b]{2}{*}{ Aminoácidos } & \multicolumn{2}{|c|}{ Rações } \\
\hline & Padrão & Hiperlipídica \\
\hline Ácido Aspártico & 10,81 & 9,92 \\
\hline Ácido Glutâmico & 20,12 & 18,99 \\
\hline Serina & 5,23 & 5,06 \\
\hline Glicina & 4,48 & 4,32 \\
\hline Histidina & 2,50 & 2,43 \\
\hline Arginina & 7,47 & 7,07 \\
\hline Treonina & 3,38 & 4,01 \\
\hline Alanina & 4,53 & 4,69 \\
\hline Prolina & 5,93 & 5,80 \\
\hline Tirosina & 3,34 & 3,48 \\
\hline Valina & 5,05 & 5,33 \\
\hline Metionina & 1,89 & 2,43 \\
\hline Cistina & 1,63 & 1,85 \\
\hline Isoleucina & 4,22 & 4,38 \\
\hline Leucina & 7,78 & 7,96 \\
\hline Fenilalanina & 5,01 & 5,01 \\
\hline Lisina & 5,62 & 6,59 \\
\hline Triptofano & 1,01 & 0,68 \\
\hline
\end{tabular}


Quadro 3- Perfil de carboidratos das rações (\%)

\begin{tabular}{ccc}
\hline & \multicolumn{2}{c}{ Rações } \\
\cline { 2 - 3 } Carboidratos & Padrão & Hiperlipídica \\
\hline Raffinose & 1,74 & 0,81 \\
Maltose & 1,07 & 1,60 \\
Glicose Livre & 0,82 & 1,63 \\
Glicose & 46,58 & 42,37 \\
Frutose Livre & 0,62 & 0,96 \\
Frutose & 20,93 & 16,46 \\
Sacarose & 8,83 & 11,57 \\
Lactose & 0,65 & 4,48 \\
Fucose & 0,17 & 0,15 \\
Arabinose & 5,55 & 6,78 \\
Galactose & 4,55 & 6,08 \\
Xilose & 5,47 & 4,27 \\
Rhamnose & 0,22 & 0,26 \\
Manose & 2,80 & 2,58 \\
\hline
\end{tabular}


Quadro 4- Perfil de ácidos graxos saturados e insaturados das rações (\%)

\begin{tabular}{|c|c|c|}
\hline \multirow[b]{2}{*}{ Ácidos graxos } & \multicolumn{2}{|c|}{ Rações } \\
\hline & Padrão & Hiperlipídica \\
\hline Capróico (c6:0) & 0,00 & 0,02 \\
\hline Caprílico (c8:0) & 0,03 & 0,03 \\
\hline Cáprico (c10:0) & 0,02 & 0,05 \\
\hline Láurico (c12:0) & 0,33 & 0,25 \\
\hline Mirístico (c14:0) & 0,30 & 0,33 \\
\hline Palmítico (c16:0) & 16,56 & 15,09 \\
\hline Heptadecanóico (c17:0) & 0,02 & 0,08 \\
\hline Esteárico (c18:0) & 3,90 & 4,36 \\
\hline Palmitoléico (c16:1) & 0,06 & 0,15 \\
\hline Oléico (c18:1n9c) & 27,96 & 37,94 \\
\hline Linoléico (c18:2n6c) & 47,10 & 40,83 \\
\hline$\alpha$-Linolênico (c18:3n3c) & 3,72 & 0,87 \\
\hline Ácidos Graxos Saturados & 21,16 & 20,21 \\
\hline Ácidos Graxos Insaturados & 78,84 & 79,79 \\
\hline
\end{tabular}

\section{3- Avaliação nutricional dos animais}

O perfil nutricional foi determinado pela análise de ingestão calórica, eficiência alimentar, peso e gordura corporal, índice de adiposidade, lipídios, glicemia e proteína sérica. A ingestão calórica foi calculada pela seguinte fórmula: ingestão alimentar semanal multiplicada pelo valor energético de cada ração ( $\mathrm{g}$ x kcal). Com a finalidade de analisar a capacidade do animal converter a energia consumida em peso corporal, foi calculada a eficiência alimentar (EA), dividindo-se o ganho total de peso corporal dos animais (g) pela energia total ingerida (Kcal). O peso corporal dos animais foi aferido semanalmente, 
utilizando-se uma balança digital Mettler® modelo Spider 2 (Toledo do Brasil Indústria de Balanças Ltda, São Bernardo do Campo, São Paulo, Brasil). A quantidade de gordura corporal total foi determinada pela somatória dos depósitos de gordura epididimal, retroperitoneal e visceral. O índice de adiposidade foi calculado, dividindo-se a gordura corporal total pelo peso corporal final, multiplicado por $100 .{ }^{(101)}$ Para análise do perfil glicêmico, lipídico e protéico, os ratos foram colocados em jejum por 12 a 15 horas, anestesiados com pentobarbital sódico (50 mg/kg/IP, Cristália ${ }^{\circledR}$ Produtos Químicos Farmacêuticos Ltda, Itapira, São Paulo, Brasil) e eutanasiados por decapitação. A seguir, as amostras de sangue foram coletadas em tubos Falcon, centrifugadas a 3000 rpm por 10 minutos (Eppendorf ${ }^{\circledR}$ Centrifuge 5804-R, Hamburg, Germany) e armazenadas em freezer à $-80^{\circ} \mathrm{C}$ (Thermo Fisher Scientific LLC, Asheville, NC, USA). As concentrações séricas de glicose, triacilglicerol, colesterol total, lipoproteínas de alta (HDL) e baixa (LDL) densidade, e proteínas foram determinadas utilizando-se kits específicos $\left(\mathrm{CELM}^{\circledR}\right.$, Barueri, São Paulo, Brasil) e analisadas pelo método enzimático colorimétrico automatizado (Technicon, RA-XT ${ }^{\mathrm{TM}}$ System, Global Medical Instrumentation, Minnesota, USA). Os níveis de ácidos graxos não-esterificados (NEFA) foram avaliados utilizando kit colorimétrico (WAKO NEFA-C, Wako Pure Chemical Industries, Osaka, Japan) pelo método de Johnson \& Peters. ${ }^{(102)}$

\section{4- Caracterização da obesidade}

A obesidade nos animais ao final dos períodos de 15, 30 e 45 semanas de tratamento foi determinada utilizando-se o índice de adiposidade. Diversos estudos têm utilizado este índice como ferramenta para avaliar a quantidade de gordura corporal em roedores. ${ }^{(51,58,103,104)}$ Este método de baixo custo é facilmente realizado, pois permite avaliar os depósitos de gordura corporal de maneira precisa e consistente. 


\section{5- Determinação do momento inicial da obesidade}

O momento do início da obesidade foi determinado aferindo-se semanalmente o peso corporal dos animais. Na terceira semana de tratamento, observou-se aumento significante do peso corporal no grupo DH em relação ao DN. Com a finalidade de verificar se a diferença do peso corporal entre os grupos era resultante de um maior índice de adiposidade nos ratos DH, foram eutanasiados 19 animais de cada grupo para a determinação da gordura corporal. Como o grupo DH apresentou índice de adiposidade estatisticamente maior do que o DN, a terceira semana de tratamento foi considerada como o início da obesidade no grupo DH.

\section{6- Constituição dos grupos controle e obeso}

Após 15, 30 e 45 semanas do início da obesidade, os grupos de animais que receberam ração padrão e hiperlipídica foram denominados como controle (C) e obeso (Ob), respectivamente, e alocados em seis sub-grupos: $\mathrm{C}_{15}, \mathrm{C}_{30}, \mathrm{C}_{45}, \mathrm{Ob}_{15}, \mathrm{Ob}_{30}$ e $\mathrm{Ob}_{45}$.

$\mathrm{Na}$ experimentação biológica, em especial estudos experimentais, mesmo quando mantidas as condições laboratoriais semelhantes, não está assegurada uma homogeneidade de resposta. Neste sentido, os ratos submetidos à ração padrão e hiperlipídica poderiam apresentar, em maior ou menor escala, características comuns, como, por exemplo, o índice de adiposidade. Estudo publicado previamente ${ }^{(105)}$ mostrou que este fato pode conduzir a erro de classificação, ou seja, animais submetidos à ração padrão poderiam ser classificados como controle, quando na realidade, exibem características de animais obesos, ou vice versa. Por essa razão, tornou-se necessário estabelecer um critério que separasse os animais em dois grupos distintos de acordo com o índice de adiposidade. Com essa finalidade, foi construído um intervalo de $95 \%$ de confiança (IC) para a média do índice de adiposidade dos ratos controle e obeso. Foi adotado como ponto de separação (PS) entre os grupos, o ponto médio entre o limite superior do $\mathrm{C}_{15}$ e o limite inferior do $\mathrm{Ob}_{15}$; a partir deste ponto foram excluídos 
do grupo $\mathrm{C}_{15}$ os animais com índice de adiposidade acima do PS e do grupo $\mathrm{Ob}_{15}$ os animais com índice de adiposidade abaixo do PS. O mesmo procedimento foi realizado para os grupos $\mathrm{C}_{30} ; \mathrm{Ob}_{30} ; \mathrm{C}_{45} \mathrm{e} \mathrm{Ob}_{45}$.

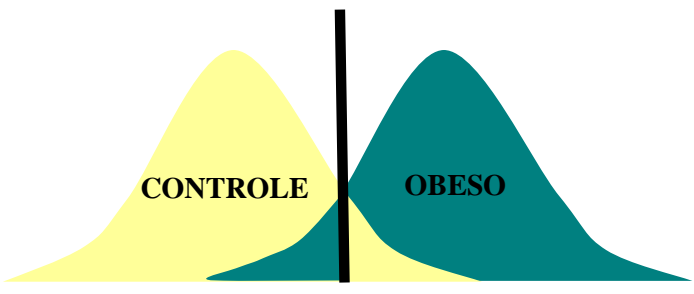

PS

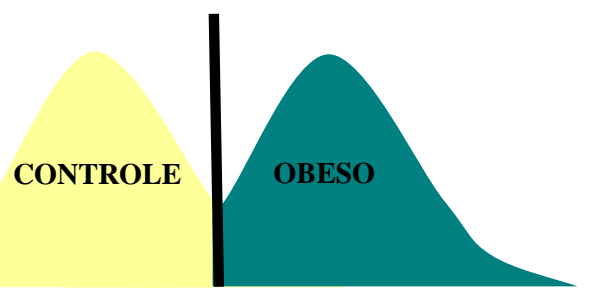

PS

Representação esquemática do critério utilizado para composição dos grupos controle e obeso

\section{7- Obesidade e comorbidades}

As alterações no perfil cardiovascular, metabólico e hormonal, como hipertensão arterial sistêmica, intolerância à glicose, resistência sistêmica à insulina, dislipidemias, hiperglicemia, hiperinsulinemia e hiperleptinemia, ${ }^{(51,52,103,106-112)}$ que podem estar frequentemente associadas à obesidade, foram avaliadas em todos os sub-grupos.

\subsection{1- Hipertensão arterial sistêmica}

Como os animais obesos podem apresentar hipertensão arterial sistêmica, ${ }^{(106-112)}$ foi mensurada a pressão arterial sistólica (PAS). A PAS foi aferida indiretamente por pletismografia de cauda, utilizando-se electro-sphygmomanometer, Narco Bio-System ${ }^{\circledR}$, modelo 709-0610 (International Biomedical, Inc, USA); este método não permite avaliar a pressão arterial diastólica. Com a finalidade de produzir vasodilatação da artéria caudal, os ratos foram previamente aquecidos, à temperatura de $40^{\circ} \mathrm{C}$ por 5 minutos, em uma caixa de madeira $(50 \times 40 \mathrm{~cm})$ forrada com maravalha de Pinus autoclavada. Após o aquecimento, foi acoplado o sensor e o manguito em torno da cauda do animal. O manguito foi insuflado até 
atingir pressão de $200 \mathrm{mmHg}$ e, posteriormente, desinsuflado. As pulsações arteriais foram registradas em polígrafo Gould RS 3200 (Gould Instrumenta Valley View, Ohio, USA).

\subsection{2- Intolerância à glicose}

Como os animais obesos podem apresentar níveis glicêmicos normais em condições basais, foi analisado o perfil glicêmico após uma sobrecarga de glicose. ${ }^{(52,109,111)}$ A partir deste teste foi possível constatar se os ratos obesos desenvolveram intolerância à glicose, isto é, apresentavam níveis de glicemia elevados em relação ao grupo C após sobrecarga de glicose. As coletas de sangue, na artéria caudal, foram realizadas na condição basal após um período de jejum de 6 horas e após administração intraperitoneal de glicose $25 \%$ (Sigma-Aldrich, ${ }^{\circledR} \mathrm{St}$ Louis, MO, USA), equivalente a $2 \mathrm{~g} / \mathrm{kg}$. As amostras sanguíneas foram coletadas nos momentos 0 , considerado condição basal, e após 15, 30, 60, 90 e 120 minutos da infusão da glicose. A mensuração dos níveis glicêmicos foi realizada com glicosímetro portátil AccuChek Go Kit (Roche Diagnostic Brazil Ltda, São Paulo, Brasil). A intolerância à glicose foi avaliada pelo perfil da curva e área glicêmica.

\subsection{3- Resistência sistêmica à insulina}

Como os animais obesos podem apresentar resistência à ação da insulina, ${ }^{(51,52,109,111,112)}$ foi analisado o índice HOMA-IR (homeostatic model assessment), baseado nas concentrações séricas de glicose e insulina de jejum. Este índice é freqüentemente utilizado na literatura para avaliar resistência à insulina. ${ }^{(51,113)} \mathrm{O}$ cálculo do HOMA-IR foi realizado pela seguinte fórmula: concentração de insulina $(\mu \mathrm{U} / \mathrm{mL})$ multiplicada pelos níveis glicêmicos $(\mathrm{mM} / \mathrm{L})$ dividida por $22,5 .^{(114)}$ 


\subsection{4- Dislipidemias e Hiperglicemia}

Como os animais obesos podem apresentar alterações do perfil lipídico e glicêmico, ${ }^{(51,106,109,110)}$ foram avaliadas as concentrações séricas de glicose, triacilglicerol, colesterol total, lipoproteínas de alta e baixa densidade e ácidos graxos não-esterificados (NEFA). A metodologia utilizada foi descrita no item 2.3, referente à avaliação nutricional dos animais.

\subsection{5- Hiperinsulinemia e Hiperleptinemia}

Como os animais obesos podem apresentar hiperinsulinemia e hiperleptinemia, (51,52,109-111) foram analisados os níveis séricos destes hormônios. As concentrações hormonais foram determinadas pelo método de ELISA utilizando-se kits específicos (Linco Research Inc, St. Louis, MO, USA). A leitura foi realizada com auxílio de leitor de micro-placa (Spectra MAX 190, Molecular Devics, Sunnyvale, CA, USA).

\section{8- Caracterização da remodelação cardíaca}

Como a obesidade pode acarretar remodelação cardíaca, ${ }^{(51-53,54,58,60)}$ o coração foi analisado por meio de estudos estruturais e funcionais. A estrutura foi avaliada in vivo por meio do ecocardiograma e post mortem por análises macroscópicas e microscópicas. A função do ventrículo esquerdo (VE) foi analisada in vivo por meio do ecocardiograma e in vitro utilizando o músculo papilar isolado do VE. Os métodos utilizados para análise da remodelação cardíaca estão descritos abaixo:

\subsection{1- Ecocardiograma}

A ecocardiografia Doppler (ECO) é um método versátil, seguro, indolor, não invasivo e importante para análises seriais, ${ }^{(115)}$ oferecendo informações sobre a estrutura e a função 
cardíaca em roedores. ${ }^{(116)}$ É um processo que causa menos alterações fisiológicas do que técnicas invasivas, como a hemodinâmica. ${ }^{(117)}$ Esta metodologia permite avaliar o desempenho do coração in situ, portanto, sujeito às variações de pré-carga, pós-carga, contratilidade e freqüência cardíaca.

A análise ecocardiográfica foi realizada após 15, 30 e 45 semanas de tratamento. Os ratos foram anestesiados com cloridrato de ketamina $\left(50 \mathrm{mg} / \mathrm{kg} / \mathrm{IP}\right.$; Dopalen ${ }^{\circledR}$, Sespo Indústria e Comércio Ltda - Divisão Vetbrands, Jacareí, São Paulo, Brasil) e cloridrato de xilazina (1,0 mg/kg/IP; Anasedan ${ }^{\circledR}$, Sespo Indústria e Comércio Ltda - Divisão Vetbrands, Jacareí, São Paulo, Brasil). Após anestesia e tricotomia da face anterior do tórax, os animais foram posicionados em decúbito lateral esquerdo. O exame foi realizado pelo Prof. Dr. Katashi Okoshi, segundo técnica já consolidada em nosso laboratório, ${ }^{(118)}$ utilizando-se aparelho Philips ${ }^{\circledR}$ HDI 5000 (Philips Electronics North America Corporation, New York, USA) equipado com transdutor eletrônico de $12 \mathrm{MHz}$. A mensuração das estruturas cardíacas foi realizada a partir de imagens obtidas em modo monodimensional (M), com o feixe de ultrasom orientado pela imagem bidimensional e o transdutor posicionado na região paraesternal eixo menor. A imagem do ventrículo esquerdo (VE) foi obtida posicionando o cursor do modo-M logo abaixo do plano da valva mitral entre os músculos papilares; as imagens da aorta e do átrio esquerdo foram obtidas ao nível da valva aórtica. As seguintes estruturas do VE foram analisadas: diâmetros sistólico e diastólico (DSVE e DDVE; mm), espessuras sistólica e diastólica da parede posterior (ESPP e EDPP; mm) e do septo interventricular (ESSIV e EDSIV; mm). O DDVE, a EDPP e a EDSIV foram medidos no momento correspondente ao diâmetro máximo da cavidade; o DSVE, a ESPP e a ESSIV foram analisadas no menor diâmetro. A partir das medidas citadas foram realizados os cálculos da espessura relativa da parede (ERelVE), da massa (g) e do índice de massa (mg/g) do VE; a ERelVE foi calculada pela razão EDPP/DDVE e a massa pela seguinte fórmula: $\{[(\mathrm{DDVE}+$ 
EDPP + EDSIV) ${ }^{3}-$ DDVE $\left.\left.^{3}\right] \times 1,04\right\} / 1000$, onde o valor de 1,04 indica a densidade específica do miocárdio. O índice de massa do VE foi calculado normalizando a massa pelo peso corporal final $(\mathrm{PCF})(\mathrm{g})$. A mensuração das estruturas cardíacas foi realizada com o auxílio de um paquímetro, utilizando-se a média aritmética de cinco ciclos cardíacos consecutivos.

O desempenho sistólico do VE foi mensurado pelos seguintes índices: fração de encurtamento endocárdico $(\Delta \mathrm{D}$ endo; \%) e mesocárdico $(\Delta \mathrm{D}$ meso; \%), velocidade de encurtamento da parede posterior (VEPP; mm/s), volume sistólico (VS; mL), débito (DC; $\mathrm{mL} / \mathrm{min}$ ) e índice cardíaco (ICA; $\mathrm{mL} / \mathrm{min} / \mathrm{g}$ ) e estresse sistólico (mmHg). As $\Delta \mathrm{D}$ endo e $\Delta \mathrm{D}$ meso foram calculadas, respectivamente, pelas seguintes fórmulas: [(DDVE - DSVE) / DDVE] $x 100 \%$ e $\{[($ DDVE $+1 / 2$ EDPP $+1 / 2$ EDSIV $)-($ DSVE $+1 / 2$ ESPP $+1 / 2$ ESSIV $)] /$ $($ DDVE $+1 / 2$ EDPP $+1 / 2$ EDSIV) $\} \times 100 \%$. A VEPP foi mensurada pela tangente máxima do encurtamento sistólico da parede posterior. O VS foi medido pela seguinte fórmula: volume diastólico final - volume sistólico final. O DC foi calculado multiplicando-se o VS pela frequiência cardíaca e o ICA pela razão entre o DC/PCF. O estresse sistólico foi calculado pela seguinte fórmula: PAS x (DSVE/2)/ESPP.

A função diastólica do VE foi analisada pelos seguintes parâmetros: velocidades do fluxo transvalvar mitral correspondente à fase de enchimento inicial (onda $\mathrm{E} ; \mathrm{cm} / \mathrm{s}$ ) e tardia conseqüente à contração atrial (onda $\mathrm{A} ; \mathrm{cm} / \mathrm{s}$ ), relação onda $\mathrm{E} / \mathrm{onda} \mathrm{A}$, tempos de desaceleração da onda E (TDE; ms) e de relaxamento isovolumétrico (TRIV; ms). As ondas E e A foram medidas no momento de maior velocidade dos fluxos transvalvar. Para a obtenção dos fluxos relacionados à função diastólica, o transdutor foi posicionado na região correspondente a ponta do coração na imagem denominada quatro câmaras. O TRIV foi mensurado na imagem denominada cinco câmaras. As medidas de velocidade e tempo foram realizadas em tempo real utilizando-se o monitor do ecocardiógrafo. 


\subsection{2- Estrutura do coração post mortem}

As análises estruturais, macro e microscópica post mortem, permitem identificar a presença de remodelação cardíaca a nível atrial e ventricular. ${ }^{(119-121)}$ A remodelação a nível macroscópico, que identifica a presença ou ausência de hipertrofia, foi determinada pela análise dos seguintes parâmetros: peso total do coração, do átrio, dos ventrículos esquerdo e direito, e das respectivas relações com o comprimento da tíbia. A remodelação do VE e do músculo papilar a nível microscópico foi avaliada pela mensuração da área seccional transversa do miócito (AST; $\mu \mathrm{m}^{2}$ ) e pela determinação da fração de colágeno miocárdica $(\%)$. As metodologias utilizadas estão descritas abaixo:

\subsubsection{1- Área seccional transversa do miócito e determinação da fração de colágeno miocárdica}

As análises da área seccional transversa do miócito e a determinação de fração de colágeno miocárdica foram realizadas utilizando amostras do ventrículo esquerdo e do músculo papilar. Após toracotomia mediana, o coração foi rapidamente removido e amostras da parede anterior do VE e músculo papilar foram retiradas a $6 \mathrm{~mm}$ do ápice. Os fragmentos foram colocados em solução de formol a $10 \%$ por $24 \mathrm{~h} \cdot{ }^{(121)}$ As amostras foram submetidas a cortes histológicos de $5 \mu \mathrm{m}$ de espessura e posteriormente processadas de acordo com as técnicas descritas abaixo.

As análises das áreas seccionais transversas do VE e do músculo papilar foram realizadas pelas técnicas de Reticulina de Gomori e Hematoxilina-eosina (HE), respectivamente. Na técnica de Reticulina de Gomori, o fragmento do VE foi imerso em permanganato de potássio $1 \%$, ácido oxálico $3 \%$, alúmen de ferro $1 \%$, prata amoniacal, formol $10 \%$, cloreto de ouro $0,2 \%$ e hiposulfito de sódio $2 \%$ e posteriormente, corado pelo ácido púrico. Na técnica de Hematoxilina-eosina, as amostras do músculo papilar foram 
lavadas em água corrente por 24 h, transferidas para solução de etanol 70\%, inclusas em blocos de parafina e coradas com hematoxilina-eosina. A técnica de Reticulina de Gomori ${ }^{(122)}$ permitiu mensurar de forma mais precisa a área transversa do miócito do VE. O cálculo das áreas seccionais dos miócitos foi realizado mensurando-se 50 a 70 células por amostra. Os miócitos analisados, localizados na camada subendocárdica, apresentaram forma arredondada e núcleo centralizado. As áreas seccionais transversas dos miócitos (AST; $\mu \mathrm{m}^{2}$ ) foram utilizadas como indicador do tamanho celular.

A determinação da fração de colágeno (\%) foi realizada segundo a técnica de Picrosirius Red. Nesta metodologia foi mensurado o colágeno intersticial, sendo excluído o colágeno perivascular. Os fragmentos do ventrículo esquerdo e do músculo papilar foram lavados em água corrente por 24 horas, transferidos para etanol $70 \%$ diluído em água, inclusos em blocos de parafina e corados com solução de Picrosirius Red. A quantificação da fração de colágeno intersticial foi realizada utilizando-se 30 a 40 campos por fragmento. $\mathrm{O}$ tecido colágeno foi identificado pela coloração vermelha.

Os cortes histológicos, realizados para a análise da AST e fração de colágeno total, foram ampliados 40 vezes com o auxílio de microscópio (Leica DM LS, modelo DXC-151ª, LEICA Mikroskopie \& System GmbH Wetzlar, Germany) acoplado a uma câmera de vídeo, que envia imagens digitais a um computador dotado de programa de análises (Image Pro-plus, Media Cybernetics, Silver Spring, Maryland, USA).

\subsection{3- Músculo papilar isolado}

A técnica que utiliza o músculo papilar isolado do ventrículo esquerdo, realizada rotineiramente em nosso laboratório, ${ }^{(123-125)}$ avalia a função mecânica do miocárdico in vitro. Esta preparação permite detectar alterações precoces na contração e no relaxamento do músculo cardíaco, ${ }^{(123)}$ independente das variações da pós-carga, pré-carga, freqüência 
cardíaca, influência hormonal e substrato energético, o que é difícil de ser obtido na avaliação do coração in vivo. Além disso, como a adaptação do organismo à obesidade pode causar efeitos indiretos no coração, o estudo com músculo papilar isolado tem a vantagem de possibilitar a análise direta da função miocárdica. $\mathrm{O}$ estudo funcional do músculo papilar isolado do ventrículo esquerdo foi realizado conforme técnica descrita abaixo.

Os animais foram anestesiados, eutanasiados por decapitação e submetidos à toracotomia mediana. Os corações foram rapidamente removidos e colocados em solução de Krebs-Henseleit $^{(126)}$ com a seguinte composição em mM: $118,5 \mathrm{NaCl} ; 4,69 \mathrm{KCl} ; 2,5 \mathrm{CaCl}_{2}$; $1,16 \mathrm{MgSO}_{4} ; 1,18 \mathrm{KH}_{2} \mathrm{PO}_{4} ; 5,50$ glicose e $24,88 \mathrm{NaCO}_{3}$, mantidos à temperatura de $28^{\circ} \mathrm{C}$, previamente oxigenada durante 10 minutos com $95 \%$ de oxigênio $\left(\mathrm{O}_{2}\right)$ e $5 \%$ de dióxido de carbono $\left(\mathrm{CO}_{2}\right)$. Após permanecerem aproximadamente 1 minuto na solução, os corações foram retirados e o ventrículo direito dissecado com a finalidade de expor o septo interventricular; este foi dividido a fim de permitir a exposição adequada dos dois músculos papilares, anterior e posterior, do ventrículo esquerdo. Os músculos papilares foram cuidadosamente dissecados, mantendo-se nas suas extremidades segmentos da parede ventricular. Esses fragmentos foram presos a anéis de aço inoxidável com diâmetro interno de 3,8 a 4,2 mm; a fixação dos anéis nestes fragmentos tem como finalidade evitar a lesão da extremidade dos músculos papilares. Estes, após terem suas extremidades presas aos anéis, foram rapidamente transferidos para câmara de vidro contendo a mesma solução de KrebsHenseleit descrita acima, continuamente oxigenada com $95 \%$ de $\mathrm{O}_{2}$ e $5 \%$ de $\mathrm{CO}_{2}$ e mantida à temperatura de $28^{\circ} \mathrm{C}$, graças ao uso de banho circulante (Refrigerating/Heating $-20^{\circ} \mathrm{C}$ to $150^{\circ} \mathrm{C}$, PolyScience Division of Preston Industries, Inc., Niles, IL, USA). O músculo papilar foi posicionado verticalmente e sua extremidade inferior acoplada a um fio de aço inoxidável, 0,38 mm de diâmetro, conectado a um transdutor de força (Grass FT03 Force Displacement Transducer, GRASS Technologies, An Astro-Med, Inc. Product Group, West Warwick, RI, 
USA). O fio de aço atravessava uma fenda, preenchida por mercúrio, existente no assoalho da câmara de vidro. A porção superior tendinosa do músculo papilar foi conectada a um fio de aço, semelhante ao anterior, que estava ligado à extremidade do braço longo de uma alavanca isotônica de metal. Sobre esta extremidade existia um micrômetro (L.S. Starrett. Co. Athol. Mass. $\mathrm{n}^{\circ} 463$, USA.) que controlava a extensão dos movimentos da alavanca, permitindo ajustar o comprimento de repouso do músculo papilar. $\mathrm{Na}$ extremidade do braço curto da alavanca foi suspenso, por fio de aço, semelhante aos anteriores, um peso de 5,0 $\mathrm{g}$, denominado pré-carga, que tinha por finalidade promover o estiramento inicial do músculo papilar. A alavanca era constituída de alumínio ou bronze, rígida e leve, sendo a razão entre os braços longo e curto de 4:1.

Os músculos papilares foram estimulados 12 vezes por minuto $(0,2 \mathrm{~Hz})$ por meio de eletrodos de platina tipo agulha (Grass E8, GRASS Technologies, An Astro-Med, Inc. Product Group, West Warwick, RI, USA), posicionados paralelamente ao eixo longitudinal dos músculos. Os eletrodos foram acoplados a estimulador elétrico (Grass S48, GRASS Technologies, Na Astro-Med, Ic. Product Group, West Warwick, RI, USA) que emitia estímulos em onda quadrada de 5 mili-segundos. A voltagem de estímulo utilizada foi de 12 a 15 volts, aproximadamente, $10 \%$ acima do valor mínimo necessário para provocar resposta mecânica máxima do músculo. $\mathrm{O}$ pH da solução foi entre 7,38 a 7,42 e a pressão parcial de oxigênio da solução foi mantida entre 550 a $600 \mathrm{mmHg}$.

Após um período de 60 minutos, durante os quais os músculos contraíram contra a pré-carga sem desenvolverem força, contração isotônica, foi colocado uma carga adicional de 50 g, denominada pós-carga, na extremidade do braço curto da alavanca. A carga total, précarga acrescida da pós-carga, impedia que os músculos encurtassem, passando os mesmos a desenvolverem somente força, contração isométrica. O excessivo estiramento muscular que poderia ser causado pela adição da pós-carga foi evitado pelo micrômetro que impedia a 
movimentação da alavanca. Após a estabilização do músculo em contração isométrica, este foi progressivamente estirado, por meio do micrômetro, até a força desenvolvida atingir o seu valor máximo. O comprimento de estiramento da fibra muscular associado à força ou tensão máxima desenvolvida, em contração isométrica, denominou-se Lmax. Após atingir o Lmax, o músculo foi novamente colocado em contração isotônica durante 5 minutos. A seguir, o músculo papilar foi recolocado em contração isométrica para determinação final de Lmax. O registro das variáveis foi iniciado após verificar-se que o músculo permaneceu estável em contração isométrica durante 15 minutos.

\subsubsection{1- Parâmetros funcionais}

Os seguintes parâmetros mecânicos foram analisados de um curva obtida em contração isométrica: tensão máxima desenvolvida $\left(\mathrm{TD}, \mathrm{g} / \mathrm{mm}^{2}\right.$ ), tensão de repouso (TR, $\left.\mathrm{g} / \mathrm{mm}^{2}\right)$, velocidade máxima de variação da tensão desenvolvida (+dT/dt, $\left.\mathrm{g} / \mathrm{mm}^{2} / \mathrm{s}\right)$ e velocidade máxima de variação de decréscimo da tensão desenvolvida (-dT/dt, g/mm²/s). A curva de contração isométrica que foi obtida durante os experimentos está representada abaixo.

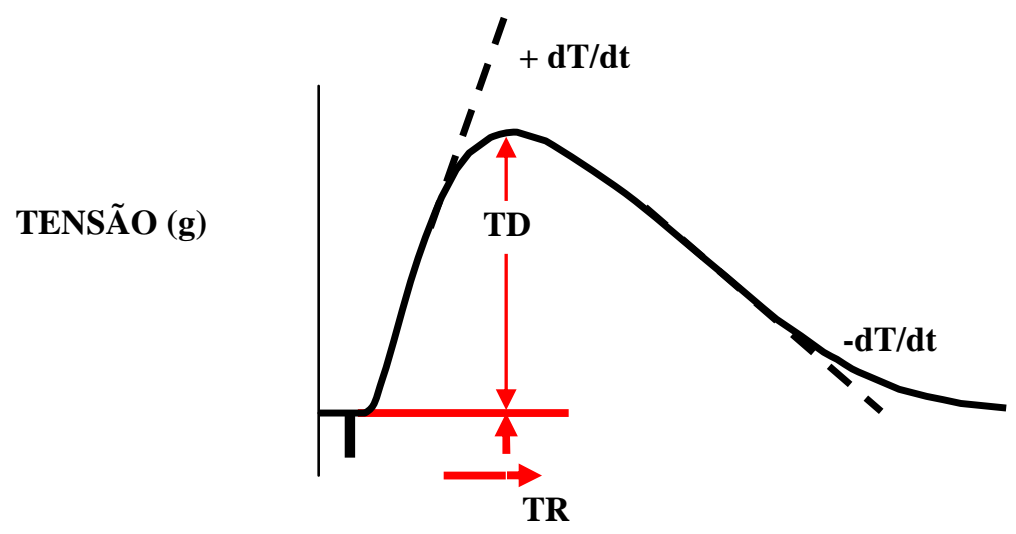

Representação esquemática da curva de contração isométrica.

As contrações isométricas foram registradas em um sistema de aquisição de dados computadorizado (AcqKnowledge ${ }^{\circledR}$ MP100, Biopac Systems, Inc, Santa Barbara, CA, USA). 
A análise das curvas permitiu determinar os valores dos parâmetros mecânicos. Os valores da $\mathrm{TD}, \mathrm{TR},+\mathrm{dT} / \mathrm{dt}$ e -dT/dt foram divididos pela área seccional do músculo papilar. Este processo de normalização permitiu comparar o desempenho de músculos de diferentes tamanhos. Os dados obtidos são apresentados em valores absolutos $\left(\mathrm{g} / \mathrm{mm}^{2}\right)$.

\subsubsection{2- Protocolo funcional}

O desempenho mecânico dos músculos papilares em contração isométrica foi analisado sob condição basal e após diferentes manobras inotrópicas e lusitrópicas. Essas foram utilizadas com a finalidade de identificar alterações da contração e do relaxamento que poderiam não ser observadas em condições basais. Além disso, as mesmas poderiam auxiliar no entendimento dos possíveis mecanismos relacionados com as alterações da função mecânica do miocárdio. As manobras mais freqüentemente utilizadas são: potenciação póspausa, variação da concentração de cálcio extracelular e alteração da freqüência de estímulo cardíaco, que permitem verificar a participação do trânsito de $\mathrm{Ca}^{+2}$ intracelular na patogênese da disfunção do miocárdio.

\subsubsection{1- Protocolo funcional em condição basal}

A obtenção dos dados em condição basal foi realizada com concentração de cálcio de 2,5 mM na solução de Krebs-Henseleit. Além disso, nesta concentração de cálcio também foi obtida a curva entre tensão de repouso e variações de comprimento diastólico do músculo (curva de tensão-comprimento). 


\subsection{1- Curva de tensão-comprimento}

A relação entre a tensão de repouso (TR) e o comprimento diastólico do músculo foi analisada pela curva tensão-comprimento. O comportamento da curva permite inferir a rigidez miocárdica do músculo papilar. Com essa finalidade, a TR foi analisada em comprimentos musculares correspondentes a 90\%, 92\%, 94\%, 96\%, 98\% e 100\% de Lmáx. A análise do comportamento da TR em relação a variações no comprimento do músculo foi realizada pelo modelo de regressão potencial, sendo que esta variável foi expressa em valores logarítimos.

\subsubsection{2- Manobras inotrópicas e lusitrópicas}

As seguintes manobras inotrópicas e lusitrópicas miocárdicas com efeitos positivos e negativos foram realizadas:

\subsection{1- Potenciação pós-pausa}

O potenciação pós-pausa (PPP) é um instrumento utilizado para estudar a função de liberação e armazenamento de cálcio pelo retículo sarcoplasmático. ${ }^{(127-129)}$ Além disso, esta manobra permite analisar indiretamente o trocador $\mathrm{Na}^{+} / \mathrm{Ca}^{+2}$. A relação entre PPP e a função miocárdica foi realizada com concentração de cálcio de $0,5 \mathrm{mM}$ na solução de KrebsHenseleit e após períodos de repouso de 10, 30 e 60 segundos com intervalos de 5 minutos entre cada elevação. Os períodos crescentes tiveram como finalidade disponibilizar maiores quantidades de cálcio citosólico e, portanto, intensificar a magnitude do desempenho do músculo cardíaco.

\subsection{2- Elevação da concentração de cálcio extracelular}

A elevação da concentração de cálcio intracelular acarreta aumento do fluxo desse íon por meio dos canais lentos de $\mathrm{Ca}^{+2}$ e pela troca $\mathrm{Na}^{+} / \mathrm{Ca}^{+2}$, o que permite, também como PPP, 
avaliar os mecanismos relacionados com o transporte de cálcio intracelular e a função miocardíca. ${ }^{(130)}$ A elevação da concentração de cálcio na solução de Krebs-Henseleit foi realizada com aumentos sequenciais de $\mathrm{Ca}^{+2}$ de 0,5 para 1,0, 1,5, 2,0 e 2,5 mM com intervalos de 5 minutos entre cada concentração.

\subsection{3- Elevação da freqüência cardíaca}

A relação entre frequiência de contração e função cardíaca permite avaliar o trânsito de cálcio intracelular e o acoplamento excitação-contração. ${ }^{(131)}$ Esta manobra foi realizada com concentração de cálcio de $1,0 \mathrm{mM}^{(132)}$ na solução de Krebs-Henseleit e após aumentos seqüenciais da frequência de estímulo de 0,1 para $0,2,0,5,0,7,1,0$ e 2,0 Hz, com intervalos de 5 minutos entre cada elevação.

Além das manobras inotrópicas e lusitrópicas positivas descritas acima, o trânsito de $\mathrm{Ca}^{+2}$ intracelular miocárdico foi avaliado por meio de dois experimentos farmacológicos, denominados diltiazem e ácido ciclopiazônico. Estes experimentos utilizaram bloqueadores específicos de ação inotrópica e lusitrópica negativa, que diminuem a entrada e a recaptura de $\mathrm{Ca}^{+2}$ intracelular. ${ }^{(83,133-135)}$

\subsection{4- Experimento diltiazem}

O diltiazem (Diltiazem Hydrochoride, Sigma ${ }^{\circledR}$-Aldrich, St Louis, MO, USA) é um bloqueador específico dos canais lentos sarcolemais da classe das benzotiazepinas. ${ }^{(136-139)}$ Os canais L no coração contêm subunidades $\alpha 1$ c que são altamente sensíveis ao diltiazem, o que resulta em diminuição da entrada de cálcio miocárdico. ${ }^{(139)}$ Neste experimento, os músculos foram avaliados em elevação seqüencial de $\mathrm{Ca}^{+2}$ de 0,5 para 1,0, 1,5, 2,0 e 2,5 mM com ausência ou presença do bloqueador. A dose de diltiazem diluída em água ultrapura e o 
tempo de exposição ao bloqueador para a realização do experimento foram, respectivamente, $10^{-4} \mathrm{M}$ e 60 minutos. Os dados obtidos foram expressos em porcentagem média de bloqueio.

\subsection{5- Experimento ácido ciclopiazônico}

O ácido ciclopiazônico (Penicillium cyclopium, Sigma ${ }^{\circledR}$-Aldrich, St Louis, MO, USA) é um bloqueador específico da ATPase de cálcio do retículo sarcoplasmático (Serca2a) que diminui a recaptura de cálcio intracelular miocárdico. ${ }^{(140-142)}$ Esta droga foi preparada em solução estoque de $20 \mathrm{mM}$ diluída em dimetil sulfóxido (DMSO), o que permitiu obter uma concentração final de $10 \mu \mathrm{M}$; o DMSO presente era menor que $0,5 \%$. A dose e o tempo de exposição ao bloqueador para a realização do experimento foram, respectivamente, $30 \mu \mathrm{M}$ e 120 minutos. Neste experimento, os músculos papilares foram avaliados em elevação seqüencial de $\mathrm{Ca}^{+2}$ de 0,5 para 1,0, 1,5, 2,0 e 2,5 mM com ausência ou presença do bloqueador.

As ações dos bloqueadores, diltiazem e ácido ciclopiazônico, sobre a função mecânica do músculo papilar foram analisadas da seguinte forma: porcentagem (\%) média de bloqueio das drogas foi igual ao valor da TD na concentração de $0,5 \mathrm{mM}$ de cálcio intracelular com bloqueador em relação ao valor da TD na concentração de $0,5 \mathrm{mM}$ de cálcio intracelular sem bloqueador. Este cálculo foi realizado pela seguinte fórmula: $\Delta(\%)=(\mathrm{M} 2-$ M1)/M1x100, onde M1 é o valor na concentração de cálcio extracelular, como por exemplo, 0,5 mM e M2 é o valor em resposta à concentração de diltiazem ou ácido ciclopiazônico nesta mesma concentração. Os dados obtidos foram expressos em porcentagem média de bloqueio.

Após o término das manobras de avaliação mecânica do músculo papilar, os mesmos foram retirados da preparação e usados para a avaliação da área seccional. Os parâmetros morfológicos utilizados para caracterizar os músculos papilares foram: comprimento (mm), 
peso $(\mathrm{mg})$ e área seccional $\left(\mathrm{mm}^{2}\right)$. O comprimento in vitro, $\left(\mathrm{L}_{\text {máx }}\right)$ foi medido com auxílio de um catetômetro Gartner (Gartner Scientific Corporation, Chicago, USA). A porção muscular entre os anéis de aço foi cortada, submetida à secagem com papel filtro e pesada. Considerando-se que o músculo papilar tem forma cilíndrica, uniforme e peso específico aproximadamente unitário, a área seccional foi calculada dividindo-se o peso pelo comprimento determinado em Lmáx.

Os músculos papilares dissecados inadequadamente ou que apresentaram comportamento funcional fora do padrão de normalidade foram excluídos do estudo. $\mathrm{O}$ desempenho mecânico foi considerado inadequado quando os valores das variáveis obtidas em contração isométrica apresentaram afastamento superior a dois desvios padrão da média, ou seja, cujo escore em valor absoluto foi superior a 1,96. Os músculos papilares que apresentaram área seccional entre 0,5 e $1,7 \mathrm{~mm}^{2}$ foram utilizados no experimento.

\section{9- Determinação do teor de água nos tecidos cardíaco, pulmonar e hepático}

Em razão da obesidade poder acarretar aumento na volemia corporal dos ratos, ${ }^{(143)} \mathrm{o}$ que poderia promover acúmulo de líquido nos tecidos, foi realizada a avaliação do teor de água tecidual nas amostras de ventrículos esquerdo e direito, átrio, pulmão e fígado. Após a remoção do tecido, realizou-se a pesagem in natura. Em seguida, as amostras foram submetidas à secagem em estufa (Kamp Metalúrgica, Duque de Caxias, Rio de Janeiro, Brasil), sob temperatura de $55 \pm 5^{\circ} \mathrm{C}$, por um período de 48 horas. A determinação do teor de água foi expressa em valores relativos e calculada pela seguinte fórmula: [(PN-PS)/PN] x $100 \%$, onde PN representa o peso in natura e o PS o peso seco. 


\subsection{0- Análise estatística}

O perfil nutricional, as comorbidades associadas à obesidade e as análises macro, micro e funcionais referentes à remodelação cardíaca foram expressas por meio de medidas descritivas de posição e variabilidade. ${ }^{(144)} \mathrm{A}$ comparação dos seis grupos experimentais $\left(\mathrm{C}_{15}\right.$, $\mathrm{Ob}_{15}, \mathrm{C}_{30}, \mathrm{Ob}_{30}, \mathrm{C}_{45} \mathrm{e} \mathrm{Ob}_{45}$ ) foi realizada pela técnica de análise de variância (ANOVA) para o esquema de dois fatores independentes (dieta e tempo), complementada com teste de comparações múltiplas de Bonferroni. ${ }^{(145)}$

A comparação do perfil glicêmico entre os grupos, visualizado tanto pelo teste de tolerância à glicose, foi realizada pela análise de variância (ANOVA) no modelo de medidas repetidas para esquema de dois fatores independentes e complementada com o teste de comparações múltiplas de Bonferroni.

As variáveis relacionadas ao estudo funcional do músculo papilar em condição basal e após a realização das diferentes manobras inotrópicas e lusitrópicas foram estudadas pela ANOVA no modelo de medidas repetidas para esquema de dois fatores independentes ${ }^{(146)}$ e complementada com o teste de comparações múltiplas de Student-Newman-Keuls. A comparação das variações percentuais nos grupos após a ação dos bloqueadores foi realizada pela ANOVA no modelo de medidas repetidas para esquema de dois fatores independentes e complementada com o teste de comparações múltiplas de Student-Newman-Keuls.

A comparação entre as curvas de regressão da TR em relação à variação de comprimento do músculo foi realizada pelo teste do coeficiente angular e da constante de regressão linear. ${ }^{(147)} \mathrm{O}$ nível de significância considerado para todas as variáveis foi de $5 \%$. 


\section{RESULTADOS}

\section{1- Caracterização do momento inicial de obesidade}

O peso corporal foi semelhante nas duas primeiras semanas de tratamento em ambos os grupos $\mathrm{C}$ e $\mathrm{Ob}$; entretanto, após a $3^{\mathrm{a}}$ semana de tratamento, o peso corporal dos animais $\mathrm{Ob}$ foi significativamente maior que os C (Figura 1). Neste momento, o maior peso corporal dos Ob foi associado ao aumento do índice de adiposidade, caracterizando o momento inicial de obesidade $\left(\mathrm{C}_{0}\right.$ e $\left.\mathrm{Ob}_{0}\right)$ (Figura 1; Tabela 1$)$.

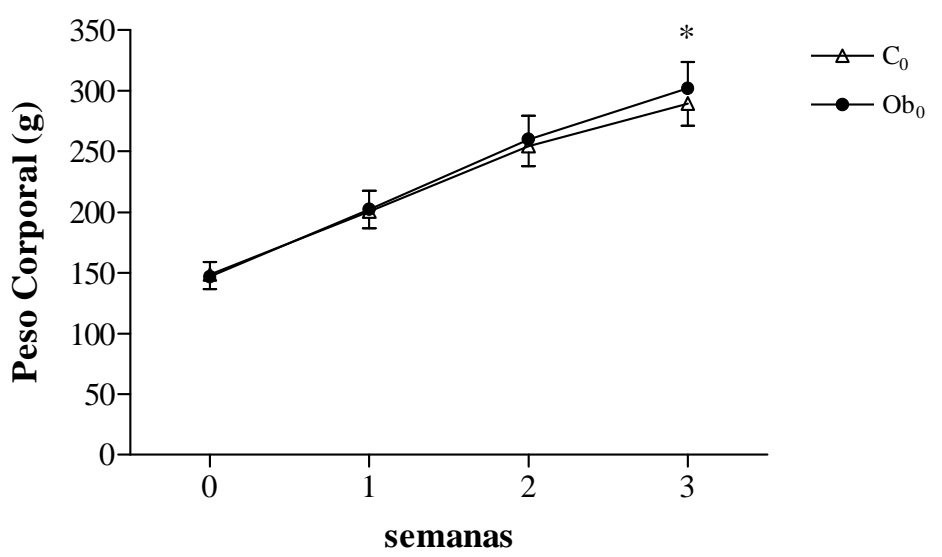

Figura 1. Evolução semanal do peso corporal dos animais controle $\left(\mathrm{C}_{0}, \mathrm{n}=19\right)$ e obeso $\left(\mathrm{Ob}_{0}, \mathrm{n}=19\right)$. Dados expressos em média \pm desvio padrão. ANOVA para o modelo de medidas repetidas em grupos independentes e complementada com o teste post-hoc de Bonferroni. * $\mathrm{p}<0,05$ vs $\mathrm{C}_{0}$.

A Tabela 1 mostra o perfil nutricional e a pressão arterial dos animais $\mathrm{C}_{0}$ e $\mathrm{Ob}_{0} . \mathrm{O}$ peso corporal final, o ganho de peso, os depósitos de gordura epididimal e visceral, a gordura corporal total e o índice de adiposidade foram maiores no $\mathrm{Ob}_{0}$ do que no $\mathrm{C}_{0}$. Não houve diferença significativa entre os grupos no peso corporal inicial, no depósito de gordura retroperitoneal, na pressão arterial sistólica final e na ingestão calórica. Durante o período 
experimental, os animais $\mathrm{Ob}_{0}$ ingeriram menor quantidade de ração que os $\mathrm{C}_{0}$, porém, a eficiência alimentar foi maior nos animais $\mathrm{Ob}_{0}$ do que no $\mathrm{C}_{0}$.

Tabela 1. Perfil nutricional no momento inicial de obesidade

\begin{tabular}{ccc}
\hline & \multicolumn{2}{c}{ Grupos } \\
\cline { 2 - 3 } Variáveis & $\mathbf{C}_{\mathbf{0}}(\mathbf{n}=\mathbf{1 9})$ & $\mathbf{O b}_{\mathbf{0}}(\mathbf{n}=\mathbf{1 9})$ \\
\hline PCI (g) & $148 \pm 12$ & $147 \pm 12$ \\
PCF (g) & $290 \pm 18$ & $302 \pm 22^{*}$ \\
Ganho de peso (g) & $142 \pm 15$ & $155 \pm 17^{*}$ \\
Epididimal (g) & $4,6 \pm 0,8$ & $5,6 \pm 1,2^{*}$ \\
Retroperitoneal (g) & $5,4 \pm 1,5$ & $6,4 \pm 1,7$ \\
Visceral (g) & $4,1 \pm 1,0$ & $4,9 \pm 0,9^{*}$ \\
Gordura corporal total (g) & $14 \pm 3$ & $17 \pm 3^{*}$ \\
Índice de adiposidade (\%) & $4,9 \pm 1,0$ & $5,6 \pm 0,9^{*}$ \\
PAS (mmHg) & $127 \pm 8$ & $131 \pm 14$ \\
Ingestão alimentar (g/dia) & $26 \pm 2$ & $22 \pm 2^{*}$ \\
Ingestão calórica (kcal/dia) & $77 \pm 5$ & $80 \pm 7$ \\
Eficiência alimentar (\%) & $8,7 \pm 0,6$ & $9,2 \pm 0,71^{*}$ \\
\hline
\end{tabular}

Dados expressos em média \pm desvio-padrão. PCI: peso corporal inicial; PCF: peso corporal final; PAS: pressão arterial sistólica. Dados expressos em média \pm desvio padrão. $\mathrm{C}_{0}$ : controle; $\mathrm{Ob}_{0}$ : obeso. Teste " $t$ " de Student para amostras independentes. * $\mathrm{p}<0,05$ vs $\mathrm{C}_{0}$. 


\section{2- Comparação entre os grupos controles e obesos após 15, 30 e 45 semanas}

\subsection{1- Composição dos grupos controle e obeso}

Os grupos 15, 30 e 45 semanas, após a aplicação do critério, foram constituídos, respectivamente de $\mathrm{C}_{15}, \mathrm{n}=18, \mathrm{Ob}_{15}, \mathrm{n}=18, \mathrm{C}_{30}, \mathrm{n}=17, \mathrm{Ob}_{30}, \mathrm{n}=20, \mathrm{C}_{45}, \mathrm{n}=20$ e $\mathrm{Ob}_{45}, \mathrm{n}=15$.

\subsection{2- Perfil nutricional}

A Tabela 2 mostra o perfil nutricional dos animais $\mathrm{C}_{15}, \mathrm{C}_{30}, \mathrm{C}_{45}, \mathrm{Ob}_{15}, \mathrm{Ob}_{30}$, e $\mathrm{Ob}_{45}$. A comparação entre os três momentos, fixados os grupos, mostrou que o PCI, a ingestão alimentar e calórica, os depósitos de gordura epididimal, retroperitoneal, visceral, a gordura corporal total, o índice de adiposidade, os valores séricos de glicose e de HDL foram semelhantes entre os grupos controles ao longo do tempo. Entretanto, o tempo de exposição ao tratamento acarretou nos grupos controles alterações no PCF, no ganho de peso, na eficiência alimentar, nos níveis de triglicérides, colesterol, LDL, proteína e NEFA. Enquanto o tempo aumentou os níveis de LDL nos animais controles $\left(\mathrm{C}_{45}>\mathrm{C}_{30}>\mathrm{C}_{15}\right)$, a eficiência alimentar foi diminuída $\left(\mathrm{C}_{45}<\mathrm{C}_{30}<\mathrm{C}_{15}\right)$. O PCF e a proteína foram maiores no $\mathrm{C}_{45} \mathrm{em}$ relação ao $\mathrm{C}_{15}$, enquanto que o colesterol total foi elevado no $\mathrm{C}_{30}$ e no $\mathrm{C}_{45}$ em relação ao $\mathrm{C}_{15}$. $\mathrm{O}$ ganho de peso e as dosagens séricas de triglicérides e NEFA foram maiores no $\mathrm{C}_{45} \mathrm{em}$ relação ao $\mathrm{C}_{30}$ e $\mathrm{C}_{15}$. Nos animais obesos, o tempo de exposição ao tratamento não foi capaz de promover alterações no PCI, na ingestão alimentar e calórica, no depósito de gordura epididimal, nos níveis séricos de glicose, triglicérides, colesterol, HDL, LDL e proteína. Entretanto, o tempo acarretou aumento no PCF e no ganho de peso dos animais $\mathrm{Ob}_{30}$ e $\mathrm{Ob}_{45}$ em relação ao $\mathrm{Ob}_{15}$. A duração da obesidade também elevou o depósito visceral e a quantidade de gordura corporal total nos animais $\mathrm{Ob}_{45}$ em relação ao $\mathrm{Ob}_{15}$ e $\mathrm{Ob}_{30}$. Enquanto o depósito de gordura retroperitoneal foi menor nos animais $\mathrm{Ob}_{15}$ em relação ao $\mathrm{Ob}_{45}$, o índice de adiposidade e os níveis de NEFA foram elevados nos animais $\mathrm{Ob}_{45}$ em relação ao $\mathrm{Ob}_{30}$. $\mathrm{O}$ 
tempo influenciou a eficiência alimentar da mesma forma que nos animais controles, diminuindo ao longo do tempo $\left(\mathrm{Ob}_{15}>\mathrm{Ob}_{30}>\mathrm{Ob}_{45}\right)$.

A comparação entre os dois grupos, fixados os momentos, mostrou que o PCF, o ganho de peso, a ingestão calórica, os depósitos de gordura epididimal, retroperitoneal e visceral, a gordura corporal total e o índice de adiposidade foram maiores nos grupos $\mathrm{Ob}$ em relação aos respectivos controles nos três períodos de tratamento. A ingestão alimentar foi menor nos grupos $\mathrm{Ob}$ em relação aos $\mathrm{C}$ em todos os momentos de avaliação. O PCI, os níveis de glicose e de HDL não sofreram alterações do tempo, uma vez que, não houve diferença significativa entre os dois grupos. A eficiência alimentar, os níveis de colesterol, proteína e NEFA foram maiores no $\mathrm{Ob}$ do que no $\mathrm{C}$ no momento 15 semanas. Enquanto os valores de triglicérides foram elevados no $\mathrm{Ob}_{30}$ em relação ao $\mathrm{C}_{30}$, os níveis de $\mathrm{LDL}$ foram diminuídos nos animais $\mathrm{Ob}_{30}$ e $\mathrm{Ob}_{45}$ em relação aos respectivos controles. 
Tabela 2. Perfil nutricional dos animais após 15, 30 e 45 semanas

Tratamento

\begin{tabular}{|c|c|c|c|c|}
\hline \multirow[b]{2}{*}{ Variáveis } & \multirow[b]{2}{*}{ Grupos } & \\
\hline & & 15 sem & 30 sem & 45 sem \\
\hline \multirow{2}{*}{ PCI (g) } & $\mathbf{C}$ & $289 \pm 23^{\mathrm{Aa}}$ & $294 \pm 13^{\mathrm{Aa}}$ & $289 \pm 19^{\mathrm{Aa}}$ \\
\hline & Ob & $299 \pm 28^{\mathrm{Aa}}$ & $301 \pm 22^{\mathrm{Aa}}$ & $298 \pm 19^{\mathrm{Aa}}$ \\
\hline \multirow{2}{*}{ PCF (g) } & $\mathbf{C}$ & $484 \pm 31^{\mathrm{Aa}}$ & $516 \pm 49^{\mathrm{ABa}}$ & $544 \pm 39^{\mathrm{Ba}}$ \\
\hline & Ob & $531 \pm 46^{\mathrm{Ab}}$ & $568 \pm 47^{\mathrm{Bb}}$ & $588 \pm 39^{\mathrm{Bb}}$ \\
\hline \multirow{2}{*}{ Ganho de Peso (g) } & $\mathbf{C}$ & $195 \pm 22^{\mathrm{Aa}}$ & $222 \pm 43^{\mathrm{Aa}}$ & $255 \pm 34^{\mathrm{Ba}}$ \\
\hline & $\mathbf{O b}$ & $232 \pm 35^{\mathrm{Ab}}$ & $267 \pm 35^{\mathrm{Bb}}$ & $290 \pm 32^{\mathrm{Bb}}$ \\
\hline \multirow{2}{*}{ Ingestão alimentar (g/dia) } & $\mathbf{C}$ & $27 \pm 2^{\mathrm{Aa}}$ & $27 \pm 2^{\mathrm{Aa}}$ & $27 \pm 2^{\mathrm{Aa}}$ \\
\hline & Ob & $24 \pm 2^{\mathrm{Ab}}$ & $25 \pm 2^{\mathrm{Ab}}$ & $24 \pm 2^{\mathrm{Ab}}$ \\
\hline \multirow{2}{*}{ Ingestão Calórica (Kcal/dia) } & $\mathbf{C}$ & $79 \pm 5^{\mathrm{Aa}}$ & $79 \pm 6^{\mathrm{Aa}}$ & $81 \pm 5^{\mathrm{Aa}}$ \\
\hline & $\mathbf{O b}$ & $89 \pm 9^{\mathrm{Ab}}$ & $91 \pm 8^{\mathrm{Ab}}$ & $88 \pm 7^{\mathrm{Ab}}$ \\
\hline \multirow{2}{*}{ Eficiência alimentar (\%) } & $\mathbf{C}$ & $2,4 \pm 0,2^{\mathrm{Aa}}$ & $1,3 \pm 0,2^{\mathrm{Ba}}$ & $1,1 \pm 0,1^{\mathrm{C}}$ \\
\hline & $\mathbf{O b}$ & $2,5 \pm 0,3^{\mathrm{Ab}}$ & $1,4 \pm 0,2^{\mathrm{Ba}}$ & $1,1 \pm 0,1^{\mathrm{C}}$ \\
\hline \multirow{2}{*}{ Epididimal (g) } & $\mathbf{C}$ & $7,9 \pm 1,4^{\mathrm{Aa}}$ & $7,0 \pm 2,3^{\mathrm{Aa}}$ & $6,7 \pm 2^{\mathrm{Aa}}$ \\
\hline & $\mathbf{O b}$ & $12 \pm 3^{\mathrm{Ab}}$ & $11 \pm 2^{\mathrm{Ab}}$ & $13 \pm 3^{\mathrm{Ab}}$ \\
\hline \multirow[b]{2}{*}{ Retroperitoneal (g) } & $\mathbf{C}$ & $7,8 \pm 1,5^{\mathrm{Aa}}$ & $8,6 \pm 2,4^{\mathrm{Aa}}$ & $11 \pm 2^{\mathrm{Aa}}$ \\
\hline & $\mathbf{O b}$ & $16 \pm 6^{\mathrm{Ab}}$ & $17 \pm 4^{\mathrm{ABb}}$ & $21 \pm 5^{\mathrm{Bb}}$ \\
\hline \multirow{2}{*}{ Visceral (g) } & $\mathbf{C}$ & $6,1 \pm 1,0^{\mathrm{Aa}}$ & $5,8 \pm 2,5^{\mathrm{Aa}}$ & $7,0 \pm 1,4^{\mathrm{Aa}}$ \\
\hline & $\mathbf{O b}$ & $11 \pm 4^{\mathrm{Ab}}$ & $11 \pm 3^{\mathrm{Ab}}$ & $13 \pm 3^{\mathrm{Bb}}$ \\
\hline \multirow{2}{*}{ Gordura corporal total (g) } & $\mathbf{C}$ & $22 \pm 3^{\mathrm{Aa}}$ & $21 \pm 6^{\mathrm{Aa}}$ & $24 \pm 4^{\mathrm{Aa}}$ \\
\hline & $\mathbf{O b}$ & $39 \pm 13^{\mathrm{Ab}}$ & $39 \pm 8^{\mathrm{Ab}}$ & $46 \pm 7^{\mathrm{Bb}}$ \\
\hline \multirow{2}{*}{ Índice de Adiposidade (\%) } & C & $4,5 \pm 0,5^{\mathrm{Aa}}$ & $4,1 \pm 0,1^{\mathrm{Aa}}$ & $4,5 \pm 0,7^{\mathrm{Aa}}$ \\
\hline & $\mathbf{O b}$ & $7,2 \pm 1,8^{\mathrm{ABb}}$ & $6,8 \pm 1,1^{\mathrm{Ab}}$ & $7,9 \pm 1,1^{\mathrm{Bb}}$ \\
\hline
\end{tabular}


Tabela 2. Perfil nutricional dos animais após 15, 30 e 45 semanas "continua"

\begin{tabular}{|c|c|c|c|c|}
\hline \multirow{2}{*}{ Glicose basal (mg/dl) } & $\mathbf{C}$ & $91 \pm 7^{\mathrm{Aa}}$ & $90 \pm 7^{\mathrm{Aa}}$ & $93 \pm 7^{\mathrm{Aa}}$ \\
\hline & Ob & $96 \pm 9^{\mathrm{Aa}}$ & $94 \pm 6^{\mathrm{Ab}}$ & $95 \pm 8^{\mathrm{Aa}}$ \\
\hline \multirow{2}{*}{ Triglicérides (mg/dl) } & $\mathbf{C}$ & $63 \pm 18^{\mathrm{Aa}}$ & $52 \pm 8^{\mathrm{Aa}}$ & $87 \pm 20^{\mathrm{Ba}}$ \\
\hline & Ob & $76 \pm 16^{\mathrm{Aa}}$ & $79 \pm 15^{\mathrm{Ab}}$ & $81 \pm 27^{\mathrm{Aa}}$ \\
\hline \multirow{2}{*}{ Colesterol (mg/dl) } & $\mathbf{C}$ & $57 \pm 10^{\mathrm{Aa}}$ & $73 \pm 10^{\mathrm{Ba}}$ & $86 \pm 19^{\mathrm{Ba}}$ \\
\hline & Ob & $71 \pm 12^{\mathrm{Ab}}$ & $70 \pm 11^{\mathrm{Aa}}$ & $80 \pm 11^{\mathrm{Aa}}$ \\
\hline \multirow{2}{*}{ HDL (mg/dl) } & $\mathbf{C}$ & $23 \pm 3^{\mathrm{Aa}}$ & $25 \pm 3^{\mathrm{Aa}}$ & $28 \pm 4^{\mathrm{Aa}}$ \\
\hline & Ob & $26 \pm 7^{\mathrm{Aa}}$ & $26 \pm 4^{\mathrm{Aa}}$ & $24 \pm 6^{\mathrm{Aa}}$ \\
\hline \multirow{2}{*}{ LDL (mg/dl) } & $\mathbf{C}$ & $13 \pm 3^{\mathrm{Aa}}$ & $17 \pm 4^{\mathrm{Ba}}$ & $24 \pm 7^{\mathrm{Ca}}$ \\
\hline & Ob & $14 \pm 3^{\mathrm{Aa}}$ & $14 \pm 3^{\mathrm{Ab}}$ & $16 \pm 3^{\mathrm{Ab}}$ \\
\hline \multirow{2}{*}{ Proteína (g/dL) } & $\mathbf{C}$ & $6,1 \pm 0,4^{\mathrm{Aa}}$ & $6,3 \pm 0,3^{\mathrm{ABa}}$ & $6,5 \pm 0,3^{\mathrm{Ba}}$ \\
\hline & Ob & $6,5 \pm 0,3^{\mathrm{Ab}}$ & $6,4 \pm 0,3^{\mathrm{Aa}}$ & $6,8 \pm 0,2^{\mathrm{Aa}}$ \\
\hline \multirow{2}{*}{ NEFA (mmol/L) } & $\mathbf{C}$ & $0,43 \pm 0,08^{\mathrm{Aa}}$ & $0,40 \pm 0,06^{\mathrm{Aa}}$ & $0,54 \pm 0,09^{\mathrm{Ba}}$ \\
\hline & Ob & $0,50 \pm 0,08^{\mathrm{ABb}}$ & $0,44 \pm 0,07^{\mathrm{Aa}}$ & $0,53 \pm 0,08^{\mathrm{Ba}}$ \\
\hline
\end{tabular}

Dados expressos em média \pm desvio-padrão. C: grupo controle submetido à dieta normocalórica por $15(\mathrm{C} ; \mathrm{n}=18)$, $30(\mathrm{C} ; \mathrm{n}=17)$ e $45(\mathrm{C} ; \mathrm{n}=20)$ semanas de tratamento; Ob: grupo obeso submetido à dieta hipercalórica por $15(\mathrm{Ob}$; $\mathrm{n}=18), 30(\mathrm{Ob} ; \mathrm{n}=20)$ e $45(\mathrm{Ob} ; \mathrm{n}=15)$ semanas de tratamento; PCI: peso corporal inicial; PCF: peso corporal final; HDL: lipoproteína de alta intensidade; LDL: lipoproteína de baixa intensidade; NEFA: ácidos graxos nãoesterificados. Letra maiúscula indica comparação entre os momentos fixado o grupo; letra minúscula indica comparação entre os grupos fixado o momento. Letras diferentes indicam diferença significativa $(p<0,05)$. Análise de variância (ANOVA) para o esquema de dois fatores, complementada com o teste de comparações múltiplas de Bonferroni.

\subsection{3- Pressão arterial sistólica}

A Figura 2 mostra o resultado da pressão arterial sistólica final realizado nos animais $\mathrm{C}_{15}, \mathrm{C}_{30}, \mathrm{C}_{45}, \mathrm{Ob}_{15}, \mathrm{Ob}_{30}$, e $\mathrm{Ob}_{45}$. A comparação entre os três momentos, fixados os grupos, mostrou que o tempo de exposição ao tratamento acarretou aumento somente da PAS no grupo $\mathrm{C}_{45}$ em relação ao $\mathrm{C}_{30}$. A obesidade não promoveu alterações na PAS ao longo do tempo. Além disso, a pressão arterial sistólica final foi semelhante entre os grupos controles e obesos. 


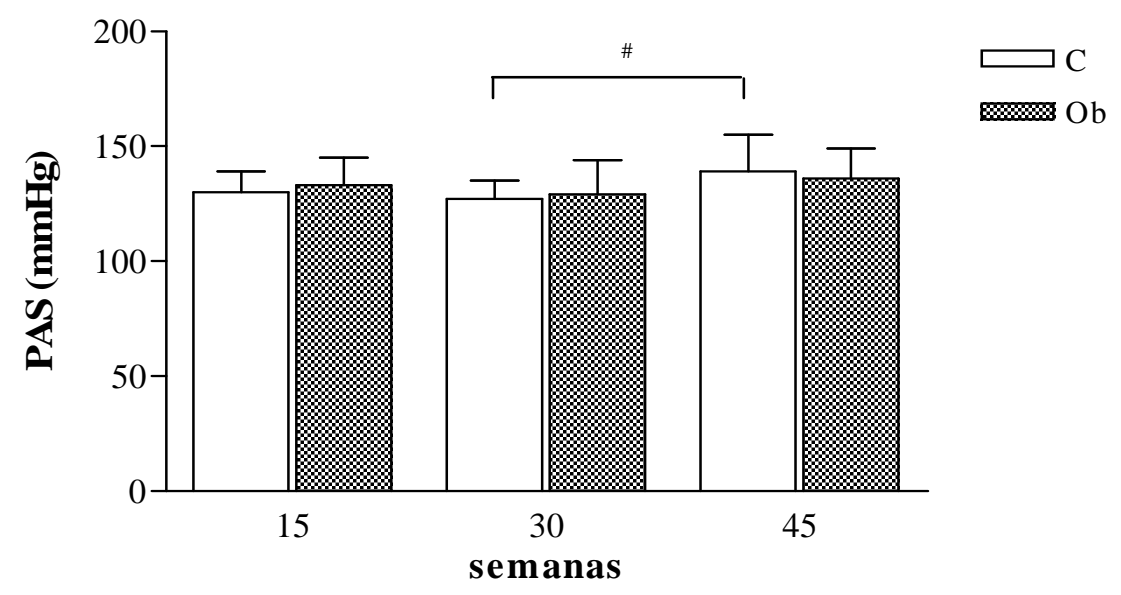

Figura 2. Pressão arterial sistólica final dos animais controle $\left(\mathrm{C}_{15}, \mathrm{n}=18 ; \mathrm{C}_{30}, \mathrm{n}=17 ; \mathrm{C}_{45}, \mathrm{n}=20\right)$ e obeso $\left(\mathrm{Ob}_{15}\right.$, $\left.\mathrm{n}=18 ; \mathrm{Ob}_{30}, \mathrm{n}=20 ; \mathrm{Ob}_{45}, \mathrm{n}=15\right)$ submetidos a 15,30 e 45 semanas de tratamento. Dados expressos em média \pm desvio-padrão. Análise de variância (ANOVA) para o esquema de dois fatores, complementada com o teste posthoc de Bonferroni. Não houve diferença estatística entre os grupos controle e obeso. ${ }^{\#}$ p $<0,05$ vs intra-grupo.

\subsection{4- Teste de tolerância à glicose}

A Figura 3 ilustra o resultado da área glicêmica do teste de tolerância à glicose realizado nos animais $\mathrm{C}_{15}, \mathrm{C}_{30}, \mathrm{C}_{45}, \mathrm{Ob}_{15}, \mathrm{Ob}_{30}$, e $\mathrm{Ob}_{45}$. $\mathrm{O}$ tempo de tratamento promoveu aumento da área glicêmica somente no grupo $C_{45}$ em relação ao $C_{30}\left(C_{45}>C_{30}\right)$; entretanto, não houve alteração na variável no grupo obeso. As áreas glicêmicas foram maiores nos grupos $\mathrm{Ob}_{15}, \mathrm{Ob}_{30}$, e $\mathrm{Ob}_{45}$ em relação aos seus respectivos grupos controles. 


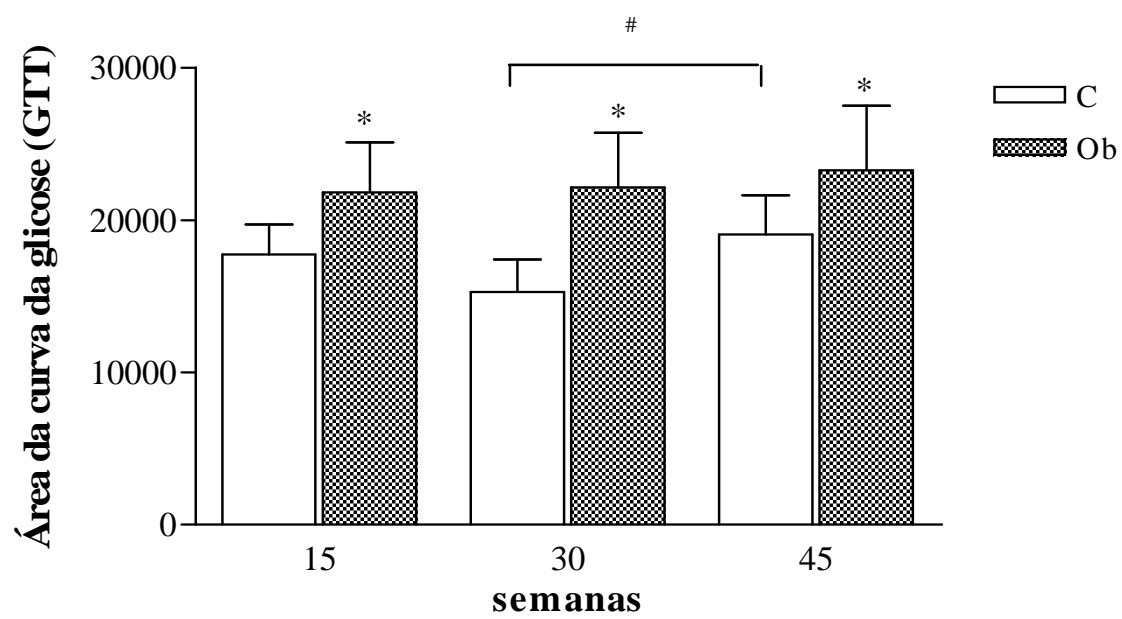

Figura 3. Área glicêmica obtida no teste de tolerância à glicose realizado nos animais controle $\left(\mathrm{C}_{15}, \mathrm{n}=14 ; \mathrm{C}_{30}\right.$, $\left.\mathrm{n}=13 ; \mathrm{C}_{45}, \mathrm{n}=10\right)$ e obeso $\left(\mathrm{Ob}_{15}, \mathrm{n}=14 ; \mathrm{Ob}_{30}, \mathrm{n}=15 ; \mathrm{Ob}_{45}, \mathrm{n}=\right.$ 10) submetidos a 15,30 e 45 semanas de tratamento. Dados expressos em média \pm desvio-padrão. Análise de variância (ANOVA) para o esquema de dois fatores, complementada com o teste post-hoc de Bonferroni. * p $<0,05$ vs C. ${ }^{\#} \mathrm{p}<0,05$ vs intra-grupo.

\subsection{5- Índice de resistência à insulina}

A Figura 4 mostra o resultado do índice HOMA-IR nos grupos $\mathrm{C}_{15}, \mathrm{C}_{30}, \mathrm{C}_{45}, \mathrm{Ob}_{15}$, $\mathrm{Ob}_{30}$, e $\mathrm{Ob}_{45}$. O índice HOMA-IR foi maior nos grupos $\mathrm{Ob}_{15}, \mathrm{Ob}_{30}$ e $\mathrm{Ob}_{45}$ em relação aos seus respectivos grupos controles. A duração da obesidade acarretou aumento do índice HOMA-IR nos animais $\mathrm{Ob}_{45}$ em relação aos $\mathrm{Ob}_{15}$ e $\mathrm{Ob}_{30}$. Entretanto, não foram observadas alterações deste índice entre os grupos controle ao longo do tempo. 


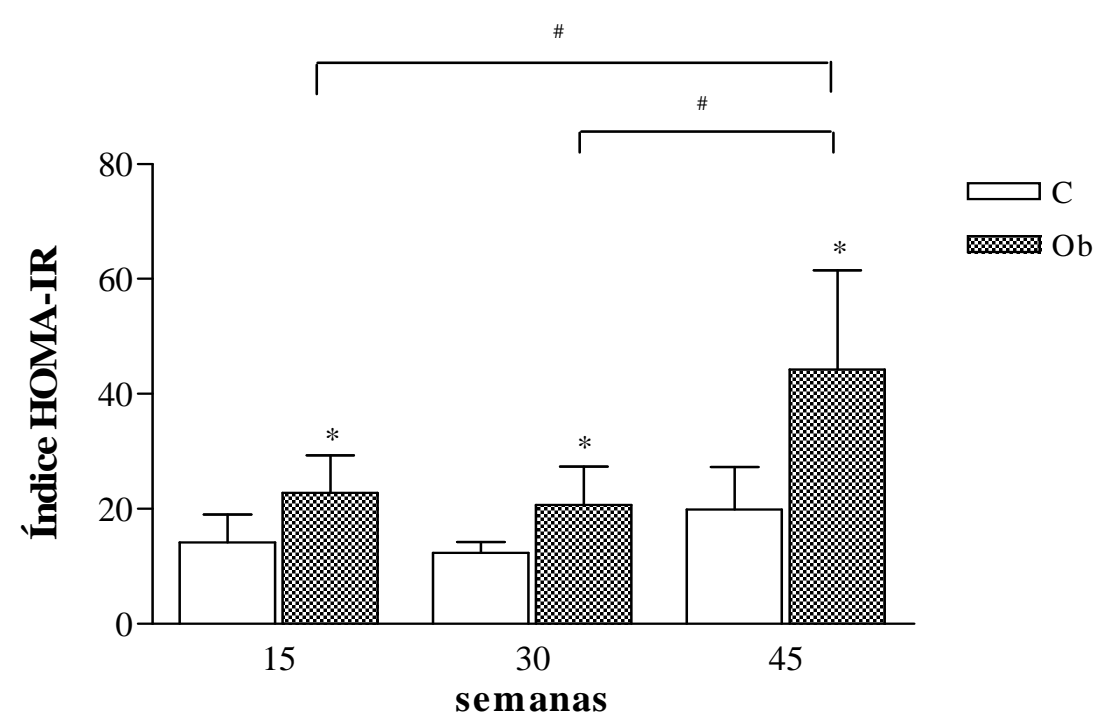

Figura 4. Índice HOMA-IR dos animais controle $\left(\mathrm{C}_{15}\right.$, $\mathrm{C}_{30}$ e $\left.\mathrm{C}_{45}\right)$ e obeso $\left(\mathrm{Ob}_{15}, \mathrm{Ob}_{30}\right.$ e $\left.\mathrm{Ob}_{45}\right)$ submetidos a 15,30 e 45 semanas de tratamento. $n=10$ animais por grupo. Dados expressos em média \pm desvio padrão. Análise de variância (ANOVA) para o esquema de dois fatores, complementada com o teste post-hoc de Bonferroni.* $\mathrm{p}<0,05$ vs C. ${ }^{\#} \mathrm{p}<0,05$ vs intra-grupo.

\subsection{6- Análise sérica dos hormônios insulina e leptina}

As Figuras 5 e 6 ilustram os resultados séricos de insulina e de leptina realizados nos grupos $\mathrm{C}_{15}, \mathrm{C}_{30}, \mathrm{C}_{45}, \mathrm{Ob}_{15}, \mathrm{Ob}_{30}$, e $\mathrm{Ob}_{45}$, respectivamente. A Figura 5 mostra que a insulina aumentou nos animais $\mathrm{Ob}_{45}$ em relação ao $\mathrm{Ob}_{15}$ e $\mathrm{Ob}_{30}$. Entretanto, não foi observado alteração nos níveis de insulina entre os grupos controles ao longo do tempo. A comparação entre os grupos, fixados os momentos, mostrou que os níveis de insulina sérica foram maiores nos grupos $\mathrm{Ob}_{30}$ e $\mathrm{Ob}_{45}$ em relação aos respectivos controles; além disso, não foi possível mostrar diferença estatística no grupo $\mathrm{Ob}_{15}$ em relação ao $\mathrm{C}_{15}(\mathrm{p}=0,051)$.

O tempo de exposição à obesidade promoveu aumento da leptina nos grupos $\mathrm{Ob}_{45} \mathrm{e}$ $\mathrm{Ob}_{30}$ em relação ao $\mathrm{Ob}_{15}$ e; entretanto não foi possível mostrar diferença estatística entre os grupos $\mathrm{Ob}_{30}$ versus $\mathrm{Ob}_{45}(\mathrm{p}=0,10)$. Nos animais controles, o tempo não promoveu alterações nos níveis de leptina. A comparação entre os grupos, fixados os momentos, mostra que os 
níveis séricos de leptina foram maiores nos grupos obesos em relação aos respectivos grupos controles ao longo do tempo (Figura 6).

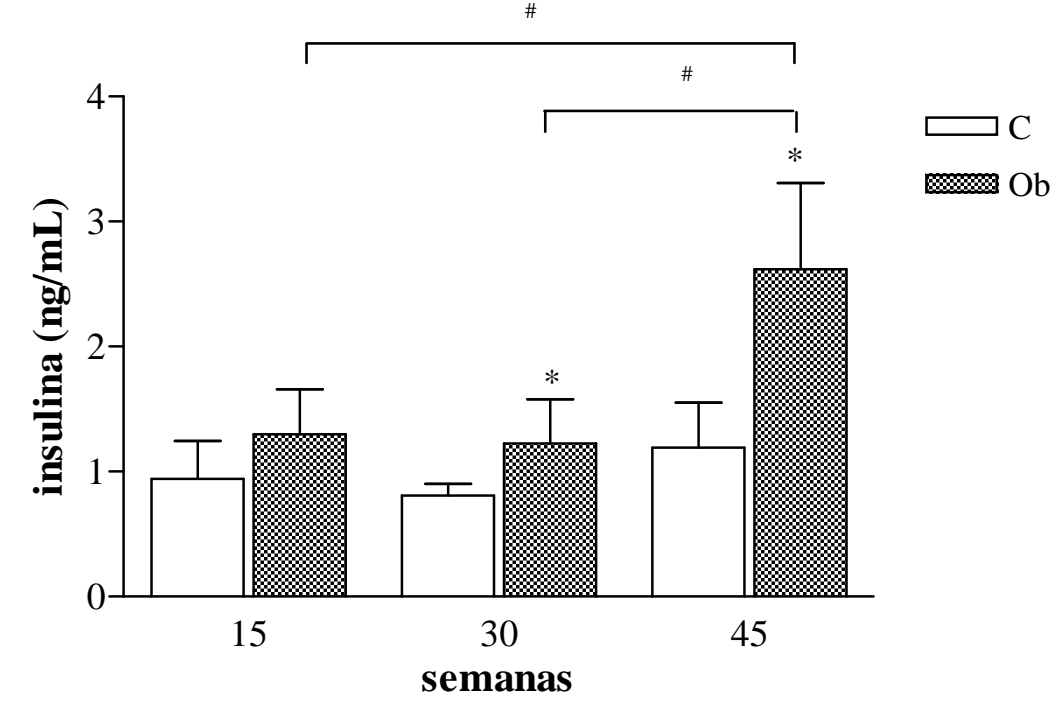

Figura 5. Níveis séricos de insulina dos animais controle $\left(\mathrm{C}_{15}, \mathrm{C}_{30}\right.$ e $\left.\mathrm{C}_{45}\right)$ e obeso $\left(\mathrm{Ob}_{15}, \mathrm{Ob}_{30}\right.$ e $\left.\mathrm{Ob}_{45}\right)$ submetidos a 15,30 e 45 semanas de tratamento. $n=10$ animais por grupo. Dados expressos em média \pm desvio-padrão. Análise de variância (ANOVA) para o esquema de dois fatores, complementada com o teste post-hoc de Bonferroni. * $\mathrm{p}<0,05$ vs C. ${ }^{\#} \mathrm{p}<0,05$ vs intra-grupo. 


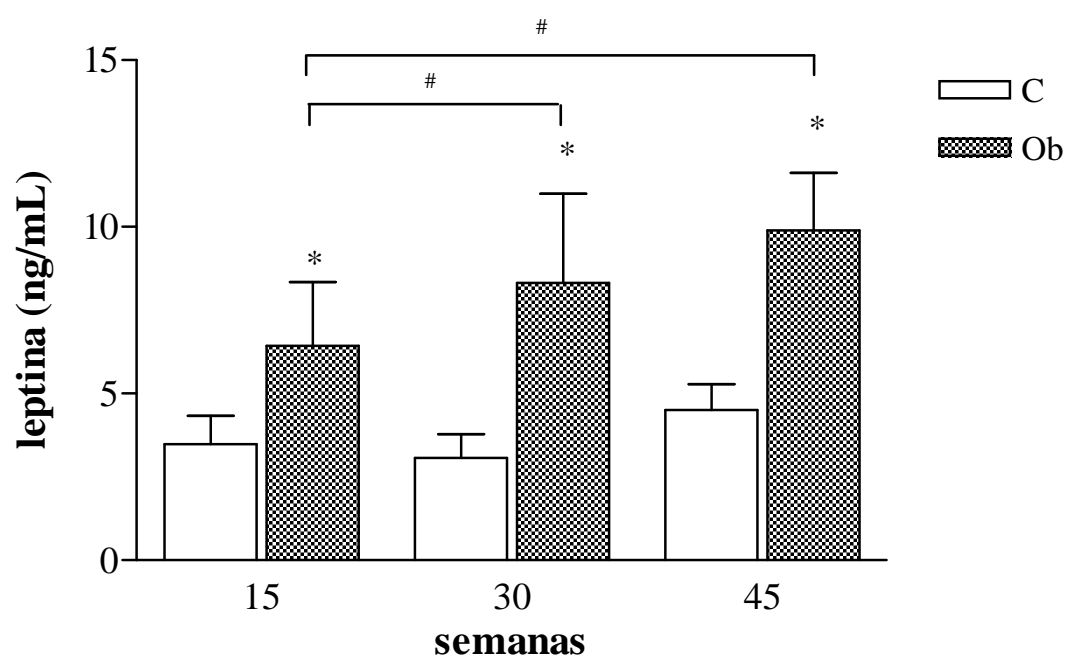

Figura 6. Níveis séricos de leptina dos animais controle $\left(\mathrm{C}_{15}, \mathrm{C}_{30}\right.$ e $\left.\mathrm{C}_{45}\right)$ e obeso $\left(\mathrm{Ob}_{15}, \mathrm{Ob}_{30}\right.$ e $\left.\mathrm{Ob}_{45}\right)$ submetidos a 15 , 30 e 45 semanas de tratamento. $n=10$ animais por grupo. Dados expressos em média \pm desvio-padrão. Análise de variância (ANOVA) para o esquema de dois fatores, complementada com o teste post-hoc de Bonferroni.* $\mathrm{p}<0,05$ vs C. ${ }^{\#} \mathrm{p}<0,05$ vs intra-grupo.

\subsection{7- Estrutura do coração in vivo}

A estrutura cardíaca in vivo dos animais $\mathrm{C}_{15}, \mathrm{C}_{30}, \mathrm{C}_{45}, \mathrm{Ob}_{15}, \mathrm{Ob}_{30}$, e $\mathrm{Ob}_{45}$, realizada por meio do ecocardiograma, está apresentada na Tabela 3. A comparação entre os três momentos, fixados os grupos, mostrou que o DDVE, AE, AE/AO e o índice de massa do VE foram semelhantes entre os grupos controles ao longo do tempo. Entretanto, o tempo de exposição ao tratamento acarretou nos grupos controles alterações na relação DDVE/PCF, no DSVE, na EDPP, na EDSIV, na ESPP, na ERelVE, no AO e na massa do VE. A EDSIV e a espessura relativa da parede do $\mathrm{VE}$ aumentaram no grupo $\mathrm{C}$ ao longo do tempo $\left(\mathrm{C}_{45}>\mathrm{C}_{30}>\right.$ $\mathrm{C}_{15}$ ). Enquanto o tempo diminuiu a relação DDVE/PCF nos animais $\mathrm{C}_{45}$ em relação aos $\mathrm{C}_{30} \mathrm{e}$ $\mathrm{C}_{15}$, a EDPP foi elevada nos grupos $\mathrm{C}_{45}$ e $\mathrm{C}_{30}$ em relação ao $\mathrm{C}_{15}$. A ESPP e o diâmetro da aorta foram maiores no grupo $\mathrm{C}_{45}$ em relação ao $\mathrm{C}_{15}$. Além disso, enquanto o DSVE foi maior no grupo $\mathrm{C}_{30}$ em relação ao $\mathrm{C}_{45}$, a massa do $\mathrm{VE}$, após 15 semanas de tratamento foi menor em relação ao $\mathrm{C}_{45}$. Nos animais obesos, o tempo de exposição ao tratamento não foi capaz de promover alterações no DDVE, na ESPP, no AE, no AO, na relação AE/AO, na massa e no 
índice de massa do VE. Entretanto, acarretou aumento na EDPP, na EDSIV e na espessura relativa da parede do $\mathrm{VE}\left(\mathrm{Ob}_{45}>\mathrm{Ob}_{30}>\mathrm{Ob}_{15}\right)$. Enquanto a duração da obesidade diminuiu a relação DDVE/PCF nos animais $\mathrm{Ob}_{15}$ em relação aos $\mathrm{Ob}_{30}$ e $\mathrm{Ob}_{45}$, o DSVE foi maior no grupo $\mathrm{Ob}_{15}$ em relação ao $\mathrm{Ob}_{30}$ e $\mathrm{Ob}_{45}$.

A comparação entre os dois grupos, fixados os momentos, mostrou que enquanto o EDSIV foi maior nos grupos $\mathrm{Ob}$ em relação aos respectivos controles nos três períodos de tratamento, a relação DDVE/PCF foi diminuída ao longo do tempo entre os grupos. O DSVE e o índice de massa do VE foram menores no grupo $\mathrm{Ob}_{30}$ em relação ao $\mathrm{C}_{30}$. A obesidade, após 15 e 45 semanas, promoveu aumento da EDPP e da massa do VE em relação aos respectivos controles. Além disso, os animais $\mathrm{Ob}_{15}$ e $\mathrm{Ob}_{30}$ apresentaram maiores ESPP em relação ao $\mathrm{C}_{15}$ e $\mathrm{C}_{30}$, respectivamente. As espessuras relativas da parede do $\mathrm{VE}$ foram aumentadas nos grupos $\mathrm{Ob}$ nos momentos 30 e 45 semanas em relação aos respectivos controles. O DDVE, os diâmetros do átrio e aorta e a relação AE/AO não sofreram alterações do tempo, uma vez que, não houve diferença significativa entre os dois grupos. 
Tabela 3. Estrutura cardíaca in vivo após 15, 30 e 45 semanas

\section{Tratamento}

\begin{tabular}{|c|c|c|c|c|}
\hline Variáveis & Grupos & 15 sem & 30 sem & 45 sem \\
\hline \multirow{2}{*}{ PCF (g) } & $\mathbf{C}$ & $484 \pm 31^{\mathrm{Aa}}$ & $516 \pm 49^{\mathrm{ABa}}$ & $544 \pm 39^{\mathrm{Ba}}$ \\
\hline & Ob & $531 \pm 46^{\mathrm{Ab}}$ & $568 \pm 47^{\mathrm{Bb}}$ & $588 \pm 39^{\mathrm{Bb}}$ \\
\hline \multirow{2}{*}{ DDVE (mm) } & $\mathbf{C}$ & $8,5 \pm 0,4^{\mathrm{Aa}}$ & $8,7 \pm 0,5^{\mathrm{Aa}}$ & $8,3 \pm 0,3^{\mathrm{Aa}}$ \\
\hline & Ob & $8,9 \pm 0,3^{\mathrm{Aa}}$ & $8,5 \pm 0,4^{\mathrm{Aa}}$ & $8,5 \pm 0,3^{\mathrm{Aa}}$ \\
\hline \multirow{2}{*}{ DDVE/PCF (mm/kg) } & $\mathbf{C}$ & $19 \pm 1^{\mathrm{Aa}}$ & $18 \pm 2^{\mathrm{Aa}}$ & $16 \pm 1^{\mathrm{Ba}}$ \\
\hline & Ob & $16 \pm 1^{\mathrm{Ab}}$ & $14 \pm 1^{\mathrm{Bb}}$ & $14 \pm 1^{\mathrm{Bb}}$ \\
\hline \multirow{2}{*}{ DSVE (mm) } & $\mathbf{C}$ & $4,6 \pm 0,5^{\mathrm{ABa}}$ & $4,7 \pm 0,4^{\mathrm{Aa}}$ & $4,2 \pm 0,5^{\mathrm{Ba}}$ \\
\hline & $\mathbf{O b}$ & $4,8 \pm 0,3^{\mathrm{Aa}}$ & $4,1 \pm 0,4^{\mathrm{Bb}}$ & $4,2 \pm 0,3^{\mathrm{Ba}}$ \\
\hline \multirow{2}{*}{$\operatorname{EDPP}(\mathbf{m m})$} & $\mathbf{C}$ & $1,37 \pm 0,07^{\mathrm{Aa}}$ & $1,51 \pm 0,04^{\mathrm{Ba}}$ & $1,59 \pm 0,11^{\mathrm{Ba}}$ \\
\hline & $\mathbf{O b}$ & $1,45 \pm 0,06^{\mathrm{Ab}}$ & $1,58 \pm 0,05^{\mathrm{Ba}}$ & $1,72 \pm 0,09^{\mathrm{Cb}}$ \\
\hline \multirow{2}{*}{ EDSIV (mm) } & $\mathbf{C}$ & $1,40 \pm 0,06^{\mathrm{Aa}}$ & $1,52 \pm 0,04^{\mathrm{Ba}}$ & $1,61 \pm 0,11^{\mathrm{Ca}}$ \\
\hline & Ob & $1,48 \pm 0,05^{\mathrm{Ab}}$ & $1,59 \pm 0,04^{\mathrm{Bb}}$ & $1,72 \pm 0,09^{\mathrm{Cb}}$ \\
\hline \multirow{2}{*}{$\operatorname{ESPP}(\mathbf{m m})$} & $\mathbf{C}$ & $2,5 \pm 0,2^{\mathrm{Aa}}$ & $2,7 \pm 0,2^{\mathrm{ABa}}$ & $2,9 \pm 0,2^{\mathrm{Ba}}$ \\
\hline & $\mathbf{O b}$ & $2,8 \pm 0,2^{\mathrm{Ab}}$ & $3,0 \pm 0,2^{\mathrm{Ab}}$ & $2,9 \pm 0,2^{\mathrm{Aa}}$ \\
\hline \multirow{2}{*}{ ERelVE (mm) } & $\mathbf{C}$ & $0,161 \pm 0,004^{\mathrm{Aa}}$ & $0,174 \pm 0,007^{\mathrm{Ba}}$ & $0,191 \pm 0,012^{\mathrm{Ca}}$ \\
\hline & $\mathbf{O b}$ & $0,163 \pm 0,009^{\mathrm{Aa}}$ & $0,186 \pm 0,010^{\mathrm{Bb}}$ & $0,204 \pm 0,010^{\mathrm{Cb}}$ \\
\hline \multirow{2}{*}{$\mathrm{AE}(\mathbf{m m})$} & $\mathbf{C}$ & $5,4 \pm 0,4^{\mathrm{Aa}}$ & $5,7 \pm 1,0^{\mathrm{Aa}}$ & $6,0 \pm 0,5^{\mathrm{Aa}}$ \\
\hline & $\mathbf{O b}$ & $5,8 \pm 0,3^{\mathrm{Aa}}$ & $5,8 \pm 0,4^{\mathrm{Aa}}$ & $5,9 \pm 0,4^{\mathrm{Aa}}$ \\
\hline \multirow{2}{*}{$\mathrm{AO}(\mathbf{m m})$} & $\mathbf{C}$ & $4,0 \pm 0,1^{\mathrm{Aa}}$ & $4,1 \pm 0,2^{\mathrm{ABa}}$ & $4,3 \pm 0,2^{\mathrm{Ba}}$ \\
\hline & $\mathbf{O b}$ & $4,2 \pm 0,2^{\mathrm{Aa}}$ & $4,2 \pm 0,2^{\mathrm{Aa}}$ & $4,3 \pm 0,2^{\mathrm{Aa}}$ \\
\hline \multirow{2}{*}{ AE/AO } & $\mathbf{C}$ & $1,33 \pm 0,08^{\mathrm{Aa}}$ & $1,39 \pm 0,12^{\mathrm{Aa}}$ & $1,40 \pm 0,11^{\mathrm{Aa}}$ \\
\hline & $\mathbf{O b}$ & $1,39 \pm 0,08^{\mathrm{Aa}}$ & $1,39 \pm 0,11^{\mathrm{Aa}}$ & $1,38 \pm 0,08^{\mathrm{Aa}}$ \\
\hline
\end{tabular}


Tabela 3. Estrutura cardíaca in vivo após 15, 30 e 45 semanas "continua"

\begin{tabular}{|c|c|c|c|c|}
\hline \multirow{2}{*}{ Massa VE (g) } & $\mathbf{C}$ & $0,85 \pm 0,11^{\mathrm{Aa}}$ & $0,99 \pm 0,12^{\mathrm{ABa}}$ & $1,00 \pm 0,13^{\mathrm{Ba}}$ \\
\hline & Ob & $1,00 \pm 0,07^{\mathrm{Ab}}$ & $1,02 \pm 0,10^{\mathrm{Aa}}$ & $1,12 \pm 0,12^{\mathrm{Ab}}$ \\
\hline \multirow{2}{*}{ Índice de Massa VE (mg/g) } & $\mathbf{C}$ & $1,88 \pm 0,24^{\mathrm{Aa}}$ & $2,08 \pm 0,29^{\mathrm{Aa}}$ & $1,96 \pm 0,27^{\mathrm{Aa}}$ \\
\hline & $\mathbf{O b}$ & $1,75 \pm 0,18^{\mathrm{Aa}}$ & $1,68 \pm 0,15^{\mathrm{Ab}}$ & $1,81 \pm 0,17^{\mathrm{Aa}}$ \\
\hline
\end{tabular}

Dados expressos em média \pm desvio-padrão. C: grupo controle submetido à dieta normocalórica por 15 ( $\mathrm{n}=7), 30$ $(n=7)$ e $45(n=10)$ semanas de tratamento; Ob: grupo obeso submetido à dieta hipercalórica por $15(n=7), 30(n=10)$ e $45(n=7)$ semanas de tratamento; DDVE e DSVE: diâmetros diastólico e sistólico do ventrículo esquerdo (VE); PCF: peso corporal final; EDPP: espessura diastólica da parede posterior do VE; EDSIV: espessura diastólica do septo ventricular; ESPP: espessura sistólica da parede posterior; ERelVE: espessura relativa da parede do VE; AE: diâmetro do átrio esquerdo; AO: diâmetro da aorta. Letra maiúscula indica comparação entre os momentos fixado o grupo; letra minúscula indica comparação entre os grupos fixado o momento. Letras diferentes indicam diferença significativa $(\mathrm{p}<0,05)$. Análise de variância (ANOVA) para o esquema de dois fatores, complementada com o teste de comparações múltiplas de Bonferroni.

\subsection{8- Estrutura do coração post mortem}

\subsubsection{1- Análise macroscópica}

A Tabela 4 mostra a estrutura macroscópica cardíaca post mortem dos ratos $\mathrm{C}_{15}, \mathrm{C}_{30}$, $\mathrm{C}_{45}, \mathrm{Ob}_{15}, \mathrm{Ob}_{30}$, e $\mathrm{Ob}_{45}$. A comparação entre os três momentos, fixados os grupos, mostrou que os pesos do coração, VE, VD, átrio e as relações coração/Tíbia e VE/Tíbia foram semelhantes entre os grupos controles nos três momentos. O comprimento da tíbia, as relações VD/Tíbia e AT/Tíbia apresentaram comportamento diferente entre os grupos controles. Enquanto o comprimento da tíbia foi maior no grupo $C_{45}$ em relação aos $C_{15}$ e $C_{30}$, a relação VD/Tíbia foi diminuída nos animais $\mathrm{C}_{30}$ e $\mathrm{C}_{45}$ em relação ao $\mathrm{C}_{15}$. $\mathrm{O}$ tempo de exposição ao tratamento também promoveu diminuição na relação AT/Tíbia no grupo $\mathrm{C}_{45}$ em relação ao $\mathrm{C}_{15}$. Nos animais obesos, o tempo de exposição à obesidade não foi capaz de promover alterações nos pesos do coração, do VE e do VD. O comprimento da tíbia aumentou nos animais obesos ao longo do tempo $\left(\mathrm{Ob}_{45}>\mathrm{Ob}_{30}>\mathrm{Ob}_{15}\right)$. A duração da obesidade acarretou aumento do AT no grupo $\mathrm{Ob}_{15}$ em relação $\mathrm{Ob}_{30}$. As relações coração/Tíbia, VE/Tíbia e 
AT/Tíbia foram maiores nos animais $\mathrm{Ob}_{15}$ do que os animais $\mathrm{Ob}_{30}$ e $\mathrm{Ob}_{45}$. Além disso, o tempo acarretou diminuição da relação VD/Tíbia no grupo $\mathrm{Ob}_{45}$ em relação aos $\mathrm{Ob}_{15}$ e $\mathrm{Ob}_{30}$.

A comparação entre os dois grupos, fixados os momentos, mostrou que os pesos do coração, do VD e a relação VD/Tíbia foram maiores no Ob do que no C nos momentos 15 e 30 semanas. A obesidade após 15 semanas acarretou aumento nos pesos do VE, do AT, nas relações coração/Tíbia, VE/Tíbia e AT/Tíbia em relação ao respectivo controle. Entretanto, na $30^{\mathrm{a}}$ semana não foi possível mostrar diferença estatística nos pesos do VE $(\mathrm{p}=0,07)$, do AT $(\mathrm{p}=0,09)$ e na relação coração/Tíbia $(\mathrm{p}=0,052)$ entre os grupos. O comprimento da tíbia não sofreu influência do tempo, uma vez que, não houve diferença estatística entre os dois grupos nos três momentos de avaliação.

Tabela 4. Estrutura macroscópica cardíaca post mortem

Tratamento

\begin{tabular}{|c|c|c|c|c|}
\hline Variáveis & Grupos & 15 sem & 30 sem & 45 sem \\
\hline \multirow{2}{*}{ PCF (g) } & $\mathbf{C}$ & $484 \pm 31^{\mathrm{Aa}}$ & $516 \pm 49^{\mathrm{ABa}}$ & $544 \pm 39^{\mathrm{Ba}}$ \\
\hline & $\mathbf{O b}$ & $531 \pm 46^{\mathrm{Ab}}$ & $568 \pm 47^{\mathrm{Bb}}$ & $588 \pm 39^{\mathrm{Bb}}$ \\
\hline \multirow{2}{*}{ Tíbia (cm) } & $\mathbf{C}$ & $4,4 \pm 0,1^{\mathrm{Aa}}$ & $4,5 \pm 0,1^{\mathrm{Aa}}$ & $4,6 \pm 0,1^{\mathrm{Ba}}$ \\
\hline & $\mathbf{O b}$ & $4,4 \pm 0,1^{\mathrm{Aa}}$ & $4,5 \pm 0,1^{\mathrm{Ba}}$ & $4,7 \pm 0,2^{\mathrm{Ca}}$ \\
\hline \multirow{2}{*}{ Coração (g) } & $\mathbf{C}$ & $1,19 \pm 0,11^{\mathrm{Aa}}$ & $1,17 \pm 0,09^{\mathrm{Aa}}$ & $1,23 \pm 0,10^{\mathrm{Aa}}$ \\
\hline & Ob & $1,31 \pm 0,14^{\mathrm{Ab}}$ & $1,26 \pm 0,12^{\mathrm{Ab}}$ & $1,25 \pm 0,08^{\mathrm{Aa}}$ \\
\hline \multirow{2}{*}{ VE (g) } & $\mathbf{C}$ & $0,84 \pm 0,09^{\mathrm{Aa}}$ & $0,83 \pm 0,07^{\mathrm{Aa}}$ & $0,89 \pm 0,07^{\mathrm{Aa}}$ \\
\hline & Ob & $0,92 \pm 0,11^{\mathrm{Ab}}$ & $0,88 \pm 0,09^{\mathrm{Aa}}$ & $0,89 \pm 0,06^{\mathrm{Aa}}$ \\
\hline \multirow{2}{*}{ VD (g) } & $\mathbf{C}$ & $0,25 \pm 0,03^{\mathrm{Aa}}$ & $0,25 \pm 0,03^{\mathrm{Aa}}$ & $0,25 \pm 0,03^{\mathrm{Aa}}$ \\
\hline & $\mathbf{O b}$ & $0,28 \pm 0,02^{\mathrm{Ab}}$ & $0,28 \pm 0,04^{\mathrm{Ab}}$ & $0,26 \pm 0,03^{\mathrm{Aa}}$ \\
\hline \multirow{2}{*}{$\mathrm{AT}(\mathrm{g})$} & $\mathbf{C}$ & $0,097 \pm 0,011^{\mathrm{Aa}}$ & $0,085 \pm 0,017^{\mathrm{Aa}}$ & $0,093 \pm 0,017^{\mathrm{Aa}}$ \\
\hline & Ob & $0,110 \pm 0,026^{\mathrm{Ab}}$ & $0,095 \pm 0,011^{\mathrm{Ba}}$ & $0,099 \pm 0,012^{\mathrm{ABa}}$ \\
\hline
\end{tabular}


Tabela 4. Estrutura macroscópica cardíaca post mortem "continua"

\begin{tabular}{|c|c|c|c|c|}
\hline \multirow{2}{*}{ Coração/Tíbia (g/cm) } & $\mathbf{C}$ & $0,27 \pm 0,03^{\mathrm{Aa}}$ & $0,26 \pm 0,02^{\mathrm{Aa}}$ & $0,27 \pm 0,02^{\mathrm{Aa}}$ \\
\hline & Ob & $0,30 \pm 0,03^{\mathrm{Ab}}$ & $0,28 \pm 0,03^{\mathrm{Ba}}$ & $0,27 \pm 0,02^{\mathrm{Ba}}$ \\
\hline \multirow{2}{*}{ VE/Tíbia (g/cm) } & $\mathbf{C}$ & $0,19 \pm 0,02^{\mathrm{Aa}}$ & $0,19 \pm 0,02^{\mathrm{Aa}}$ & $0,19 \pm 0,01^{\mathrm{Aa}}$ \\
\hline & Ob & $0,21 \pm 0,03^{\mathrm{Ab}}$ & $0,20 \pm 0,02^{\mathrm{Ba}}$ & $0,19 \pm 0,02^{\mathrm{Ba}}$ \\
\hline \multirow{2}{*}{ VD/Tíbia (g/cm) } & $\mathbf{C}$ & $0,057 \pm 0,006^{\mathrm{Aa}}$ & $0,057 \pm 0,006^{\mathrm{Ba}}$ & $0,055 \pm 0,006^{\mathrm{ABa}}$ \\
\hline & Ob & $0,065 \pm 0,005^{\mathrm{Ab}}$ & $0,062 \pm 0,008^{\mathrm{Ab}}$ & $0,056 \pm 0,007^{\mathrm{Ba}}$ \\
\hline \multirow{2}{*}{ AT/Tíbia (g/cm) } & $\mathbf{C}$ & $0,022 \pm 0,003^{\mathrm{Aa}}$ & $0,019 \pm 0,004^{\mathrm{Ba}}$ & $0,020 \pm 0,004^{\mathrm{ABa}}$ \\
\hline & Ob & $0,025 \pm 0,006^{\mathrm{Ab}}$ & $0,021 \pm 0,002^{\mathrm{Ba}}$ & $0,021 \pm 0,002^{\mathrm{Ba}}$ \\
\hline
\end{tabular}

Dados expressos em média \pm desvio-padrão. C: grupo controle submetido à dieta normocalórica por $15(\mathrm{n}=18), 30$ $(n=17)$ e $45(n=20)$ semanas de tratamento; Ob: grupo obeso submetido à dieta hipercalórica por $15(n=18), 30(n=$ 20) e 45 (n=15) semanas de tratamento; Letra maiúscula indica comparação entre os momentos fixado o grupo; letra minúscula indica comparação entre os grupos fixado o momento. Letras diferentes indicam diferença significativa $(\mathrm{p}<0,05)$. Análise de variância (ANOVA) para o esquema de dois fatores, complementada com o teste de comparações múltiplas de Bonferroni.

\subsubsection{2- Análise microscópica}

\subsubsection{1- Área seccional transversa do miócito}

As Figuras 7, 8, 9 e 10 mostram os resultados da área seccional transversa do miócito realizadas no ventrículo esquerdo e no músculo papilar dos ratos $\mathrm{C}_{15}, \mathrm{C}_{30}, \mathrm{C}_{45}, \mathrm{Ob}_{15}, \mathrm{Ob}_{30} \mathrm{e}$ $\mathrm{Ob}_{45}$. A comparação entre os três momentos, fixados os grupos, mostrou que a área seccional transversa do miócito no $\mathrm{VE}$ foi maior nos animais $\mathrm{C}_{15}$ em relação ao $\mathrm{C}_{45}$. $\mathrm{O}$ tempo de exposição à obesidade não influenciou a área seccional do miócito dos fragmentos do VE.

A comparação entre os dois grupos, fixados os momentos, mostrou que na $45^{\mathrm{a}}$ semana de tratamento, os animais obesos apresentaram elevação na área seccional do miócito do VE em relação ao $\mathrm{C}_{45}$. Entretanto, os animais $\mathrm{Ob}_{15}$ e $\mathrm{Ob}_{30}(\mathrm{p}=0,09)$ apresentaram áreas seccionais semelhantes em relação aos respectivos controles. 


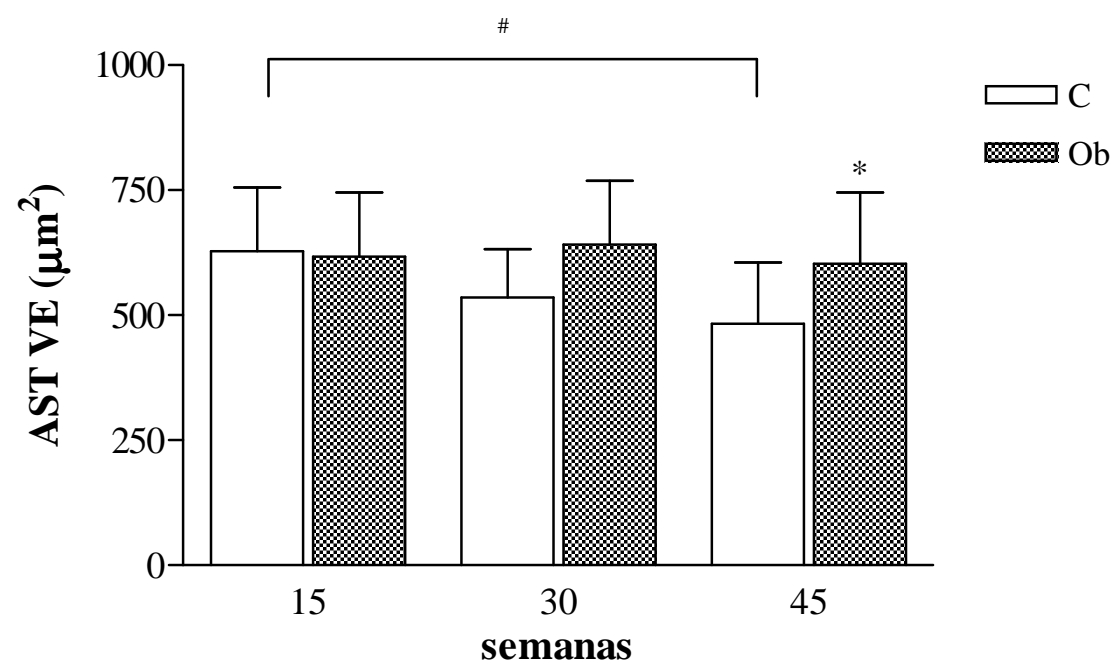

Figura 7. Área seccional transversa dos miócitos (AST) realizada em fragmentos do ventrículo esquerdo (VE) de animais controle $\left(\mathrm{C}_{15}=9 ; \mathrm{C}_{30}=8 ; \mathrm{C}_{45}=10\right)$ e obeso $\left(\mathrm{Ob}_{15}=8\right.$; $\mathrm{Ob}_{30}=8 ; \mathrm{Ob}_{45}=9$ ) submetidos a 15,30 e 45 semanas de tratamento. Dados expressos em média \pm desvio-padrão. Análise de variância (ANOVA) para o esquema de dois fatores e complementada com o teste post-hoc de Bonferroni. ${ }^{*} \mathrm{p}<0,05$ vs C. ${ }^{*} \mathrm{p}<0,05$ vs intra-grupo. 

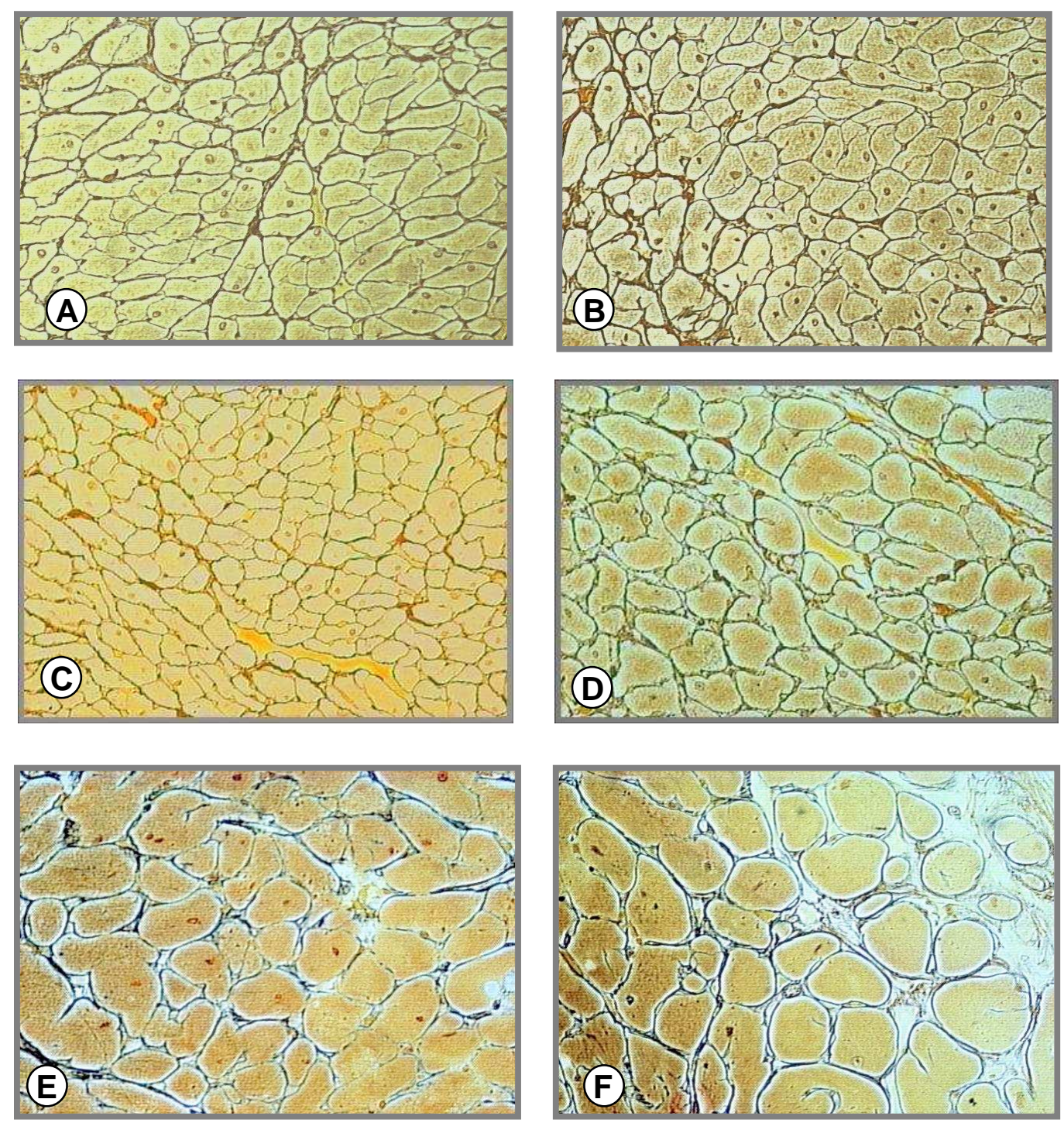

Figura 8. Secções transversas subendocárdicas do ventrículo esquerdo (VE); A: fragmento do VE do grupo $\mathrm{C}_{15}$; B: fragmento do $\mathrm{VE}$ do grupo $\mathrm{Ob}_{15}$; $\mathbf{C}$ : fragmento do $\mathrm{VE}$ do grupo $\mathrm{C}_{30}$; $\mathbf{D}$ : fragmento do VE do grupo $\mathrm{Ob}_{30} ; \mathbf{E}$ : fragmento do VE do grupo $\mathrm{C}_{45} ; \mathbf{F}$ : fragmento do VE do grupo $\mathrm{Ob}_{45}$; reticulina de Gomori 40X. 
As Figuras 9 e 10 mostram que não ocorreram alterações na área seccional do miócito no músculo papilar intra e entre grupos.

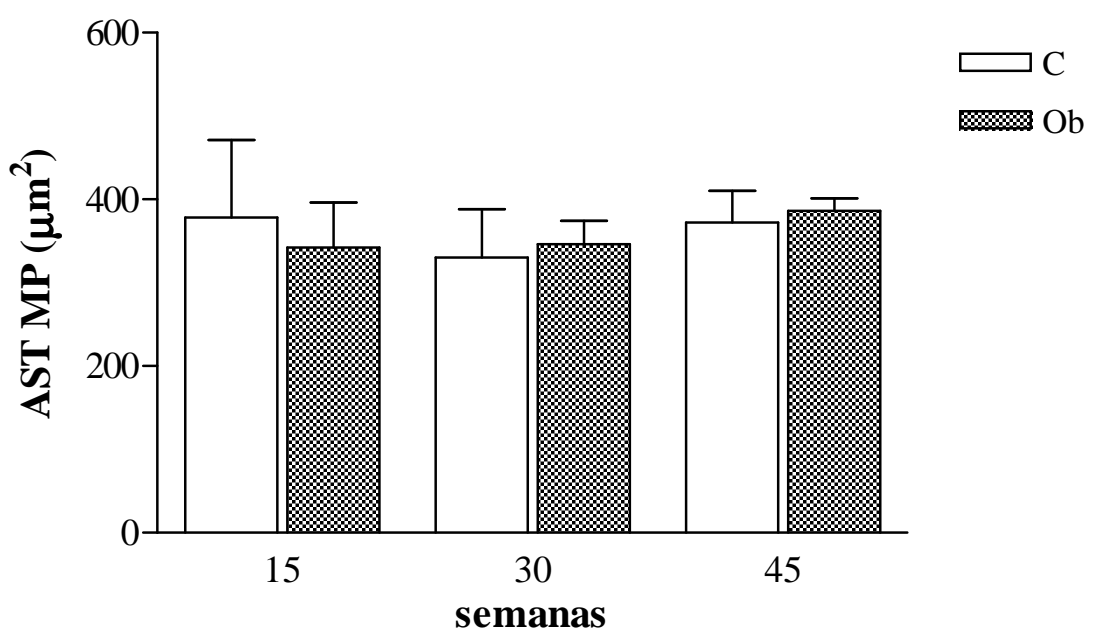

Figura 9. Área seccional transversa dos miócitos (AST) realizada em fragmentos do músculo papilar (MP) de animais controle $\left(\mathrm{C}_{15}=11 ; \mathrm{C}_{30}=8 ; \mathrm{C}_{45}=10\right)$ e obeso $\left(\mathrm{Ob}_{15}=9 ; \mathrm{Ob}_{30}=8\right.$; $\left.\mathrm{Ob}_{45}=9\right)$ submetidos a 15,30 e 45 semanas de tratamento. Dados expressos em média \pm desvio-padrão. Análise de variância (ANOVA) para o esquema de dois fatores. Não houve diferença estatística entre os grupos. 

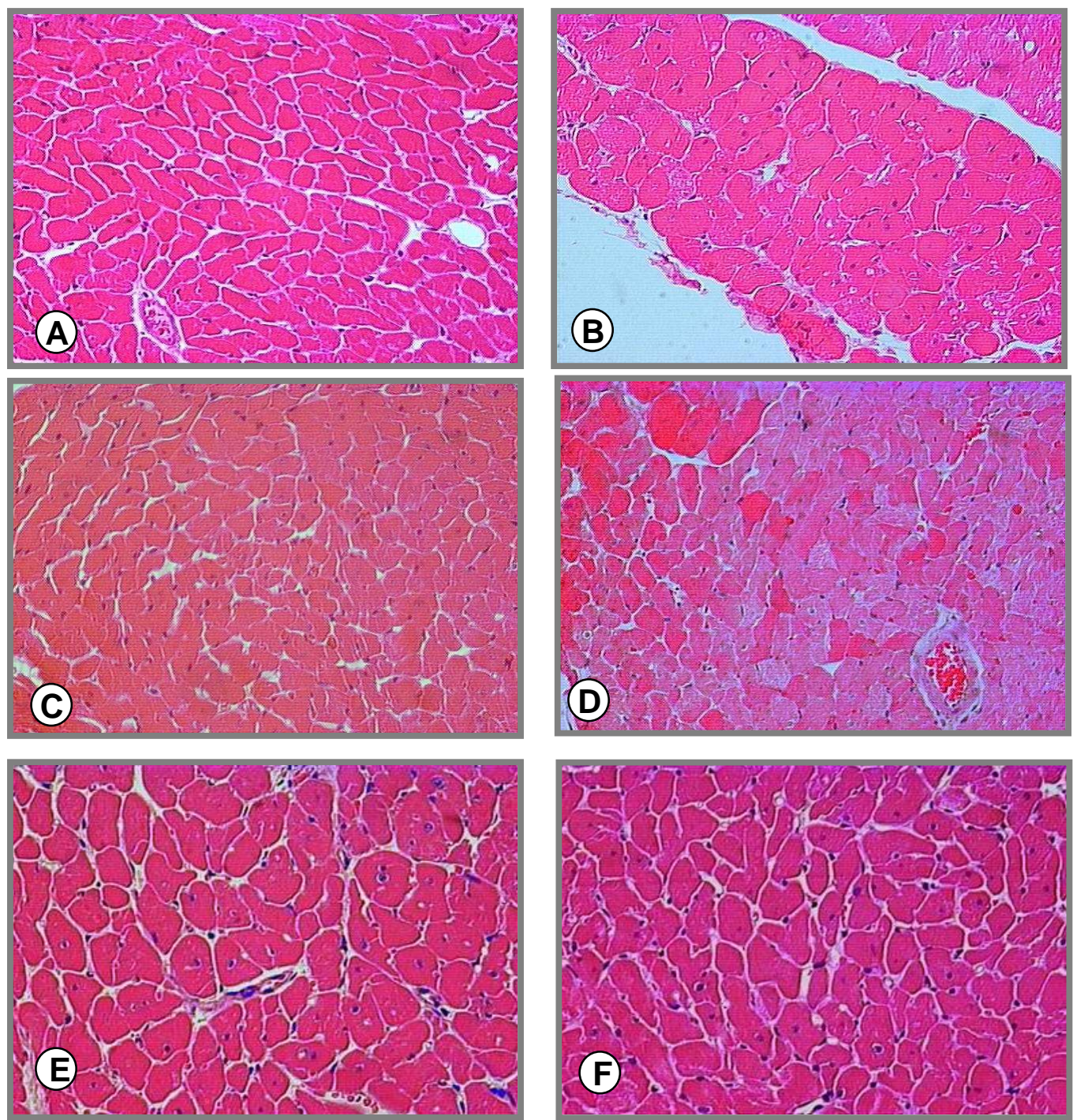

Figura 10. Secções transversas subendocárdicas do músculo papilar (MP); A: fragmento do MP do grupo $\mathrm{C}_{15}$; B: fragmento do MP do grupo $\mathrm{Ob}_{15}$; $\mathbf{C}$ : fragmento do $\mathrm{MP}$ do grupo $\mathrm{C}_{30}$; $\mathbf{D}$ : fragmento do MP do grupo $\mathrm{Ob}_{30} ; \mathbf{E}$ : fragmento do MP do grupo $\mathrm{C}_{45} ; \mathbf{F}$ : fragmento do MP do grupo $\mathrm{Ob}_{45}$; hematoxilina-eosina (HE) 40X. 


\subsubsection{2- Determinação da fração de colágeno miocárdico}

As Figuras 11, 12, 13 e 14 mostram a quantidade de colágeno intersticial nos fragmentos do VE e músculo papilar dos ratos $\mathrm{C}_{15}, \mathrm{C}_{30}, \mathrm{C}_{45}, \mathrm{Ob}_{15}, \mathrm{Ob}_{30}$ e $\mathrm{Ob}_{45}$. A comparação entre os três momentos, fixados os grupos, mostrou que a fração de colágeno intersticial no VE foi maior nos animais $\mathrm{C}_{45}$ em relação ao $\mathrm{C}_{15}$. $\mathrm{O}$ tempo de exposição à obesidade também influenciou o colágeno no $\mathrm{VE}$, desde que os animais $\mathrm{Ob}_{45}$ apresentaram aumento em relação ao $\mathrm{Ob}_{30}$ e $\mathrm{Ob}_{15}$; entretanto, não possível mostrar diferença estatística entres os grupos $\mathrm{Ob}_{15}$ e $\mathrm{Ob}_{30}(\mathrm{p}=0,08)$. A comparação entre os dois grupos, fixados os momentos, mostrou que a obesidade não promoveu alterações na fração de colágeno intersticial no VE (Figuras 11 e 12).

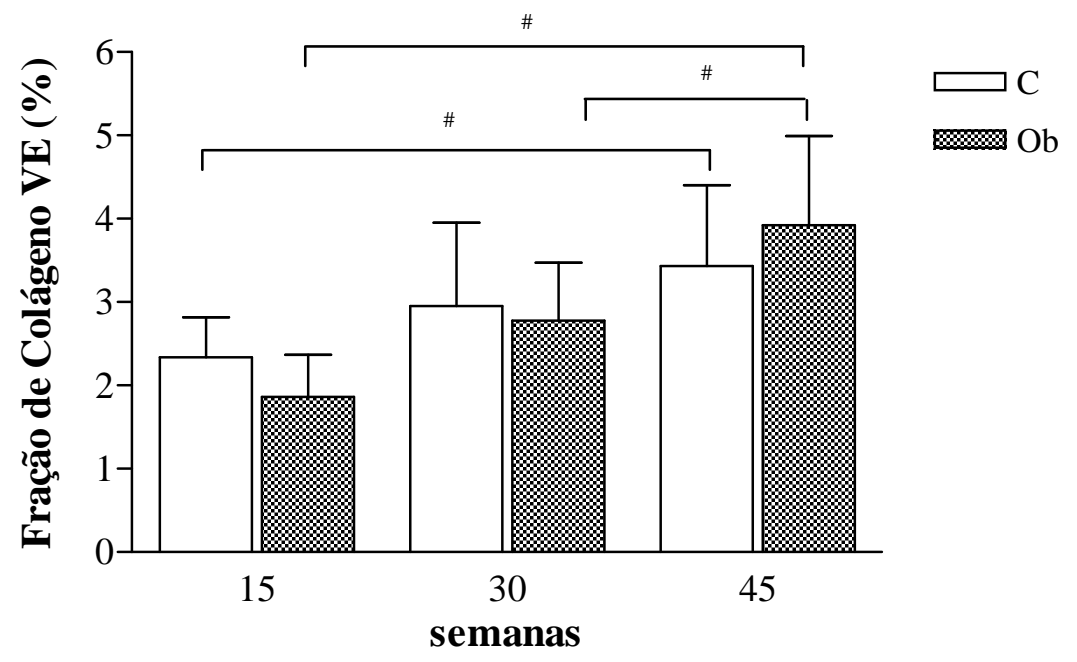

Figura 11. Fração de colágeno intersticial do ventrículo esquerdo (VE) de animais controle $\left(\mathrm{C}_{15}=11 ; \mathrm{C}_{30}=10\right.$; $\left.\mathrm{C}_{45}=10\right)$ e obeso $\left(\mathrm{Ob}_{15}=9 ; \mathrm{Ob}_{30}=8 ; \mathrm{Ob}_{45}=9\right)$ submetidos a 15,30 e 45 semanas de tratamento; Picrosirius Red (PSR) 40X. Dados expressos em média \pm desviopadrão. Análise de variância (ANOVA) para o esquema de dois fatores, complementada com o teste post-hoc de Bonferroni. Não houve diferença estatística entre os grupos controle e obeso. ${ }^{\#} \mathrm{p}<0,05$ vs intra-grupo. 

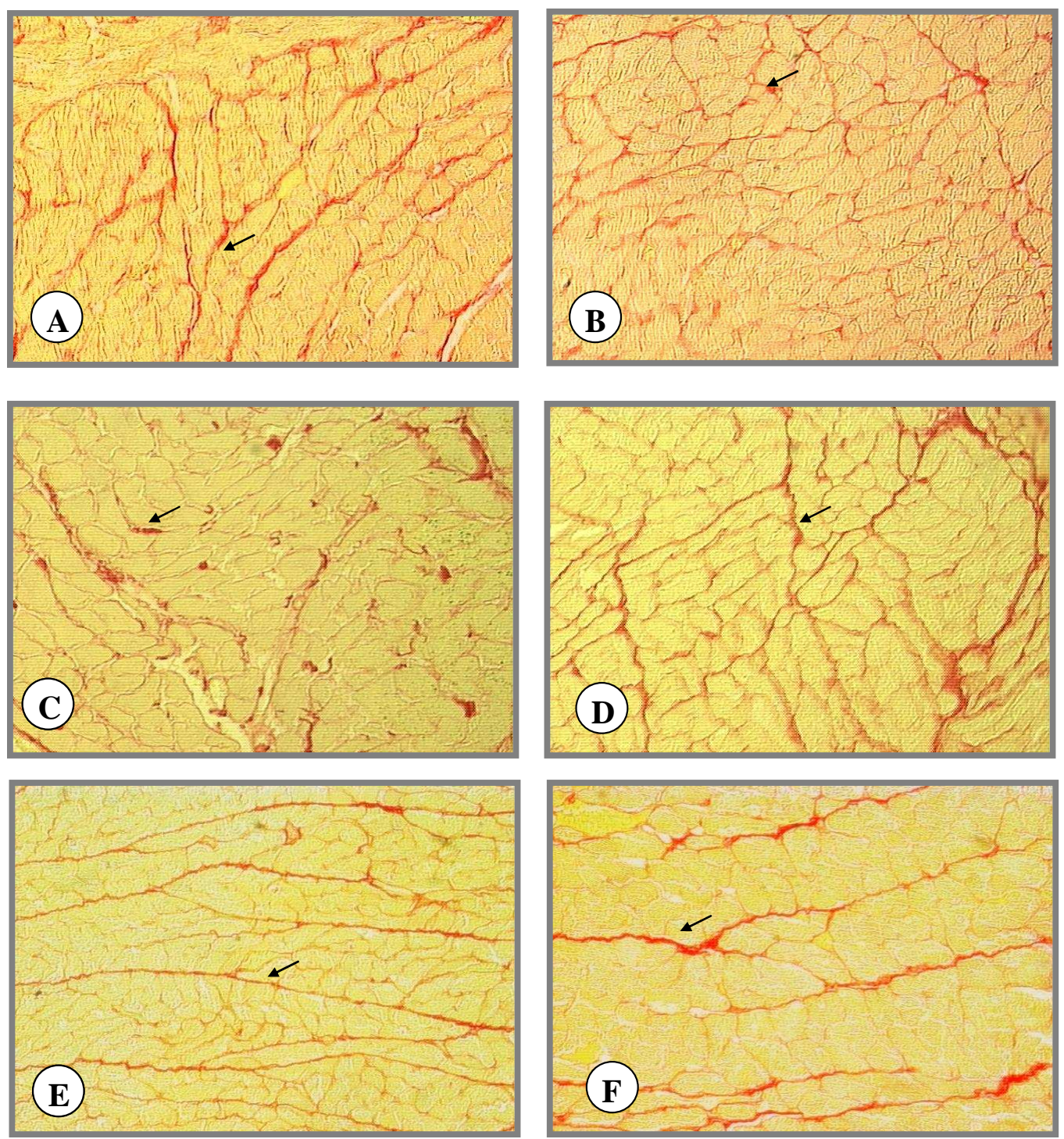

Figura 12. Secções transversas subendocárdicas do ventrículo esquerdo (VE); ( $)$ colágeno intersticial; A: fragmento do $\mathrm{VE}$ do grupo $\mathrm{C}_{15}$; B: fragmento do VE do grupo $\mathrm{Ob}_{15}$; C: fragmento do VE do grupo $\mathrm{C}_{30}$; D: fragmento do $\mathrm{VE}$ do grupo $\mathrm{Ob}_{30}$; $\mathbf{E}$ : fragmento do $\mathrm{VE}$ do grupo $\mathrm{C}_{45} ; \mathbf{F}$ : fragmento do $\mathrm{VE}$ do grupo $\mathrm{Ob}_{45}$; Picrosirius Red (PSR) $40 \mathrm{X}$. 
A Figura 13 mostra que a fração de colágeno intersticial no músculo papilar não alterou nos animais controle ao longo do tempo. Entretanto, o tempo de exposição à obesidade, após 45 semanas, promoveu elevação da fração de colágeno intersticial no músculo papilar em relação ao $\mathrm{Ob}_{30}$ e $\mathrm{Ob}_{15}$. A comparação entre os dois grupos, fixados os momentos, mostrou que a obesidade aumentou a fração de colágeno intersticial do músculo papilar nos animais $\mathrm{Ob}_{45}$ em relação ao respectivo controle (Figuras 13 e 14).

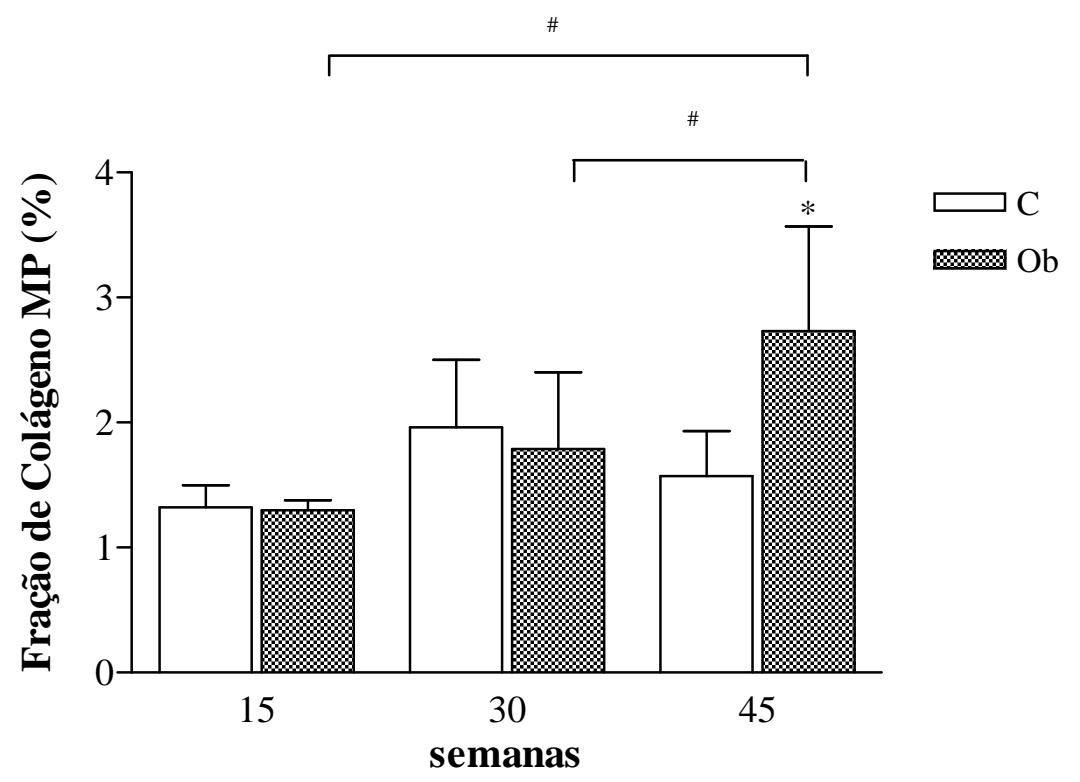

Figura 13. Fração de colágeno intersticial do músculo papilar (MP) de animais controle $\left(\mathrm{C}_{15}=7 ; \mathrm{C}_{30}=6 ; \mathrm{C}_{45}=5\right)$ e obeso $\left(\mathrm{Ob}_{15}=7 ; \mathrm{Ob}_{30}=6 ; \mathrm{Ob}_{45}=5\right)$ submetidos a 15,30 e 45 semanas de tratamento; Picrosirius Red (PSR) 40X. Dados expressos em média \pm desvio-padrão. Análise de variância (ANOVA) para o esquema de dois fatores, complementada com o teste post-hoc de Bonferroni. * $\mathrm{p}<0,05$ vs $\mathrm{C}$. ${ }^{\#} \mathrm{p}<0,05$ vs intragrupo. 

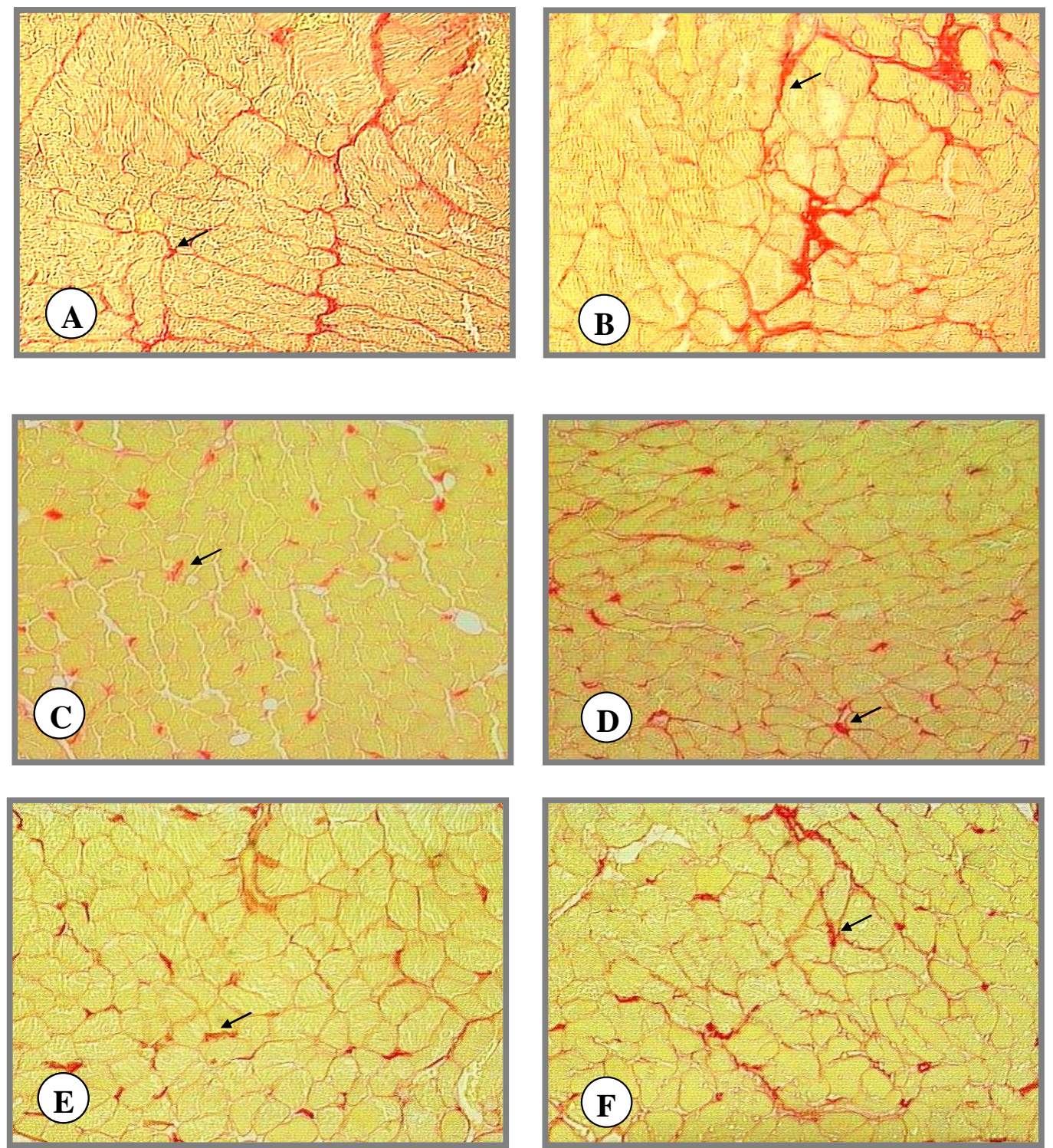

Figura 14. Secções transversas subendocárdicas do músculo papilar (MP); ( $\mathbf{\alpha}$ ) colágeno intersticial; A: fragmento do MP do grupo $\mathrm{C}_{15}$; B: fragmento do MP do grupo $\mathrm{Ob}_{15} ; \mathbf{C}$ : fragmento do MP do grupo $\mathrm{C}_{30}$; $\mathbf{D}$ : fragmento do MP do grupo $\mathrm{Ob}_{30} ; \mathbf{E}$ : fragmento do MP do grupo $\mathrm{C}_{45} ; \mathbf{F}$ : fragmento do MP do grupo $\mathrm{Ob}_{45}$; Picro-Sirius-red (PSR) 40X. 


\subsection{9- Avaliação da função cardíaca in vivo}

Os parâmetros funcionais cardíacos in vivo dos animais $\mathrm{C}_{15}, \mathrm{C}_{30}, \mathrm{C}_{45}, \mathrm{Ob}_{15}, \mathrm{Ob}_{30}$, e $\mathrm{Ob}_{45}$, analisados por meio do ecocardiograma, estão apresentados na Tabela 5. A comparação entre os três momentos, fixados os grupos, mostrou que a FC, o volume sistólico, o débito cardíaco, o índice cardíaco, $\Delta \mathrm{D}$ endo, $\Delta \mathrm{D}$ meso, a VEPP, as ondas $\mathrm{E}$ e $\mathrm{A}$, a razão $\mathrm{E} / \mathrm{A}$ e o TDE foram semelhantes entre os grupos controles ao longo do tempo. Entretanto, o tempo de exposição ao tratamento acarretou nos grupos controles alterações no estresse sistólico e no TRIV; enquanto no $\mathrm{C}_{15}$ houve diminuição do estresse sistólico em relação ao $\mathrm{C}_{30}$, o TRIV foi aumentado nos animais $\mathrm{C}_{30}$ versus $\mathrm{C}_{15}$. Nos animais obesos, o tempo de exposição ao tratamento não foi capaz de promover alterações na FC, no volume sistólico, no débito cardíaco, no índice cardíaco, na VEPP, nas ondas E e A, na razão E/A, no TDE e no TRIV. Entretanto, enquanto houve aumento da $\Delta \mathrm{D}$ endo e da $\Delta \mathrm{D}$ meso no grupo $\mathrm{Ob}_{30}$ em relação ao $\mathrm{Ob}_{15}$, o tempo de exposição à obesidade, após 15 semanas, promoveu maior estresse sistólico em relação ao $\mathrm{Ob}_{30}$. As $\Delta \mathrm{D}$ endo $(\mathrm{p}=0,11)$ e da $\Delta \mathrm{D}$ meso $(\mathrm{p}=0,09)$ dos animais $\mathrm{Ob}_{45}$ apresentaram tendência a diminuir em relação ao $\mathrm{Ob}_{30}$.

A comparação entre os dois grupos, fixados os momentos, mostrou que as $\Delta \mathrm{D}$ endo e da $\triangle \mathrm{D}$ meso, a VEPP e a onda $\mathrm{A}$ foram maiores no grupo $\mathrm{Ob}_{30}$ em relação ao $\mathrm{C}_{30}$. $\mathrm{A}$ VEPP também foi aumentada no $\mathrm{Ob}_{15}$ em relação ao $\mathrm{C}_{15}$. Entretanto, a obesidade, após 30 semanas, promoveu diminuição do índice cardíaco, do estresse sistólico, da razão E/A e do TRIV em relação ao respectivo controle. A obesidade em todos os momentos avaliados não acarretou alterações na FC, no volume sistólico, no débito cardíaco, na onda $\mathrm{E}$ e no TDE entre os grupos. 
Tabela 5. Função cardíaca in vivo após 15, 30 e 45 semanas

\section{Tratamento}

\begin{tabular}{|c|c|c|c|c|}
\hline Variáveis & Grupos & $15 \mathrm{sem}$ & 30 sem & 45 sem \\
\hline \multirow[b]{2}{*}{ FC (bpm) } & $\mathbf{C}$ & $285 \pm 31^{\mathrm{Aa}}$ & $290 \pm 28^{\mathrm{Aa}}$ & $303 \pm 47^{\mathrm{Aa}}$ \\
\hline & $\mathbf{O b}$ & $291 \pm 17^{\mathrm{Aa}}$ & $308 \pm 44^{\mathrm{Aa}}$ & $303 \pm 38^{\mathrm{Aa}}$ \\
\hline \multirow{2}{*}{ Volume sistólico (mL) } & $\mathbf{C}$ & $0,52 \pm 0,06^{\mathrm{Aa}}$ & $0,55 \pm 0,09^{\mathrm{Aa}}$ & $0,50 \pm 0,06^{\mathrm{Aa}}$ \\
\hline & $\mathbf{O b}$ & $0,60 \pm 0,05^{\mathrm{Aa}}$ & $0,55 \pm 0,08^{\mathrm{Aa}}$ & $0,53 \pm 0,06^{\mathrm{Aa}}$ \\
\hline \multirow{2}{*}{ Débito cardíaco (ml/min) } & $\mathbf{C}$ & $147 \pm 18^{\mathrm{Aa}}$ & $158 \pm 29^{\mathrm{Aa}}$ & $153 \pm 33^{\mathrm{Aa}}$ \\
\hline & $\mathbf{O b}$ & $175 \pm 25^{\mathrm{Aa}}$ & $168 \pm 24^{\mathrm{Aa}}$ & $159 \pm 8^{\mathrm{Aa}}$ \\
\hline \multirow{2}{*}{ Índice cardíaco $(\mathrm{mL} / \mathrm{min} / \mathrm{g} * \mathbf{1 0 0 0})$} & $\mathbf{C}$ & $324 \pm 34^{\mathrm{Aa}}$ & $332 \pm 61^{\mathrm{Aa}}$ & $299 \pm 67^{\mathrm{Aa}}$ \\
\hline & $\mathbf{O b}$ & $308 \pm 55^{\mathrm{Aa}}$ & $276 \pm 38^{\mathrm{Ab}}$ & $257 \pm 11^{\mathrm{Aa}}$ \\
\hline \multirow{2}{*}{$\Delta \mathrm{D}$ endo $(\%)$} & $\mathbf{C}$ & $46 \pm 3^{\mathrm{Aa}}$ & $45 \pm 3^{\mathrm{Aa}}$ & $50 \pm 6^{\mathrm{Aa}}$ \\
\hline & $\mathbf{O b}$ & $46 \pm 2^{\mathrm{Aa}}$ & $52 \pm 3^{\mathrm{Bb}}$ & $50 \pm 3^{\mathrm{ABa}}$ \\
\hline \multirow[b]{2}{*}{$\Delta \mathrm{D}$ meso $(\%)$} & $\mathbf{C}$ & $30 \pm 2^{\mathrm{Aa}}$ & $28 \pm 2^{\mathrm{Aa}}$ & $30 \pm 4^{\mathrm{Aa}}$ \\
\hline & $\mathbf{O b}$ & $28 \pm 2^{\mathrm{Aa}}$ & $32 \pm 2^{\mathrm{Bb}}$ & $31 \pm 3^{\mathrm{ABa}}$ \\
\hline \multirow{2}{*}{ VEPP $(\mathbf{m m} / \mathbf{s})$} & $\mathbf{C}$ & $36 \pm 2^{\mathrm{Aa}}$ & $35 \pm 3^{\mathrm{Aa}}$ & $38 \pm 4^{\mathrm{Aa}}$ \\
\hline & $\mathbf{O b}$ & $40 \pm 4^{\mathrm{Ab}}$ & $40 \pm 2^{\mathrm{Ab}}$ & $41 \pm 3^{\text {Aa }}$ \\
\hline \multirow{2}{*}{ Estresse sistólico (mmHg) } & $\mathbf{C}$ & $120 \pm 20^{\mathrm{Aa}}$ & $111 \pm 15^{\mathrm{Aa}}$ & $97 \pm 17^{\mathrm{Ba}}$ \\
\hline & $\mathbf{O b}$ & $115 \pm 14^{\mathrm{Aa}}$ & $89 \pm 16^{\mathrm{Bb}}$ & $99 \pm 10^{\mathrm{ABa}}$ \\
\hline \multirow{2}{*}{ Onda E (cm/s) } & $\mathbf{C}$ & $77 \pm 9^{\mathrm{Aa}}$ & $73 \pm 8^{\mathrm{Aa}}$ & $78 \pm 14^{\mathrm{Aa}}$ \\
\hline & $\mathbf{O b}$ & $80 \pm 8^{\mathrm{Aa}}$ & $77 \pm 9^{\mathrm{Aa}}$ & $74 \pm 12^{\mathrm{Aa}}$ \\
\hline \multirow{2}{*}{ Onda A $(\mathbf{c m} / \mathbf{s})$} & $\mathbf{C}$ & $52 \pm 11^{\mathrm{Aa}}$ & $47 \pm 9^{\mathrm{Aa}}$ & $60 \pm 16^{\mathrm{Aa}}$ \\
\hline & $\mathbf{O b}$ & $56 \pm 7^{\mathrm{Aa}}$ & $67 \pm 14^{\mathrm{Ab}}$ & $70 \pm 20^{\mathrm{Aa}}$ \\
\hline \multirow{2}{*}{ E/A } & $\mathbf{C}$ & $1,56 \pm 0,36^{\mathrm{Aa}}$ & $1,59 \pm 0,34^{\mathrm{Aa}}$ & $1,37 \pm 0,30^{\mathrm{Aa}}$ \\
\hline & $\mathbf{O b}$ & $1,48 \pm 0,30^{\mathrm{Aa}}$ & $1,20 \pm 0,26^{\mathrm{Ab}}$ & $1,19 \pm 0,48^{\mathrm{Aa}}$ \\
\hline
\end{tabular}


Tabela 5. Função cardíaca in vivo após 15, 30 e 45 semanas "continua"

\begin{tabular}{ccccc} 
TDE $(\mathbf{m s})$ & $\mathbf{C}$ & $41 \pm 5^{\mathrm{Aa}}$ & $49 \pm 10^{\mathrm{Aa}}$ & $49 \pm 8^{\mathrm{Aa}}$ \\
& Ob & $53 \pm 5^{\mathrm{Aa}}$ & $50 \pm 8^{\mathrm{Aa}}$ & $49 \pm 10^{\mathrm{Aa}}$ \\
\hline TRIV (ms) & $\mathbf{C}$ & $27 \pm 2^{\mathrm{Aa}}$ & $31 \pm 3^{\mathrm{Ba}}$ & $29 \pm 5^{\mathrm{ABa}}$ \\
\hline$-\mathrm{Oa}$ & $24 \pm 4^{\mathrm{Aa}}$ & $26 \pm 3^{\mathrm{Ab}}$ & $29 \pm 2^{\mathrm{Aa}}$ \\
\hline
\end{tabular}

Dados expressos em média \pm desvio-padrão. C: grupo controle submetido à dieta normocalórica por $15(n=7), 30(n=7)$ e 45 $(n=10)$ semanas de tratamento; Ob: grupo obeso submetido à dieta hipercalórica por $15(n=7), 30(n=10)$ e $45(n=7)$ semanas de tratamento; FC: frequiência cardíaca; $\Delta \mathrm{D}$ endo: fração de encurtamento endocárdico; $\Delta \mathrm{D}$ meso: fração de encurtamento mesocárdico; VEPP: velocidade de encurtamento da parede posterior do VE; E/A: razão entre os picos de fluxo de enchimento inicial (onda E) e da contração atrial (onda A) do fluxo transmitral; TDE: tempo de desaceleração da onda E mitral; TRIV: tempo de relaxamento isovolumétrico do VE; Letra maiúscula indica comparação entre os momentos fixado o grupo; letra minúscula indica comparação entre os grupos fixado o momento. Letras diferentes indicam diferença significativa $(\mathrm{p}<0,05)$. Análise de variância (ANOVA) para o esquema de dois fatores, complementada com o teste de comparações múltiplas de Bonferroni.

\subsubsection{0- Avaliação da função cardíaca in vitro}

$A$ avaliação da função cardíaca in vitro dos animais, $\mathrm{C}_{15}, \mathrm{C}_{30}, \mathrm{C}_{45}, \mathrm{Ob}_{15}, \mathrm{Ob}_{30}, \mathrm{eb}_{45}$, por meio de músculo papilar isolado do VE, está apresentada nas Tabelas 6, 7, 8, 9, 10, 11 e nas Figuras 15, 16, 17, 18, 19 e 20.

\subsubsection{1- Condição basal}

A comparação entre os três momentos, fixados os grupos, mostrou que a área seccional do músculo papilar foi semelhante entre os grupos controles ao longo do tempo. Entretanto, o tempo de exposição ao tratamento acarretou nos grupos controles alterações na $\mathrm{TD}$, na TR, na $+\mathrm{dT} / \mathrm{dt}$ e $-\mathrm{dT} / \mathrm{dt}$, desde que houve aumento destas variáveis no grupo $\mathrm{C}_{15} \mathrm{em}$ relação aos $\mathrm{C}_{30}$ e $\mathrm{C}_{45}$. Nos animais obesos, o tempo de exposição ao tratamento não foi capaz de promover alterações na TD, TR, na $+\mathrm{dT} / \mathrm{dt}$ e na área seccional do músculo papilar. Entretanto, acarretou elevação da -dT/dt grupo $\mathrm{Ob}_{15}$ em relação aos $\mathrm{Ob}_{30} \mathrm{Ob}_{45}$.

A comparação entre os dois grupos, fixados os momentos, mostrou que a TR foi menor no grupo $\mathrm{Ob}_{15}$ em relação ao $\mathrm{C}_{15}$. Entretanto, a obesidade, após 45 semanas, promoveu aumento da $+d T / d t$ e uma tendência de elevação da TD $(p=0,057)$ em relação ao respectivo 
controle. A obesidade não acarretou alterações na -dT/dt e na área seccional do músculo papilar entre os grupos.

Tabela 6. Contração isométrica basal

\section{Tratamento}

\begin{tabular}{|c|c|c|c|c|}
\hline Variáveis & Grupos & 15 sem & 30 sem & 45 sem \\
\hline \multirow{2}{*}{$\mathrm{TD}\left(\mathrm{g} / \mathrm{mm}^{2}\right)$} & $\mathbf{C}$ & $7,5 \pm 1,3^{\mathrm{Aa}}$ & $5,9 \pm 1,0^{\mathrm{Ba}}$ & $5,9 \pm 1,2^{\mathrm{Ba}}$ \\
\hline & $\mathbf{O b}$ & $6,9 \pm 1,8^{\mathrm{Aa}}$ & $5,9 \pm 1,1^{\mathrm{Aa}}$ & $6,7 \pm 1,1^{\mathrm{Aa}}$ \\
\hline \multirow{2}{*}{$\mathrm{TR}\left(\mathrm{g} / \mathrm{mm}^{2}\right)$} & $\mathbf{C}$ & $1,59 \pm 0,40^{\mathrm{Aa}}$ & $1,05 \pm 0,27^{\mathrm{Ba}}$ & $1,01 \pm 0,15^{\mathrm{Ba}}$ \\
\hline & Ob & $1,18 \pm 0,34^{\mathrm{Ab}}$ & $1,06 \pm 0,31^{\mathrm{Aa}}$ & $0,99 \pm 0,22^{\mathrm{Aa}}$ \\
\hline \multirow{2}{*}{$+\mathrm{dT} / \mathrm{dt}\left(\mathrm{g} / \mathrm{mm}^{2} / \mathrm{s}\right)$} & $\mathbf{C}$ & $81 \pm 14^{\mathrm{Aa}}$ & $63 \pm 16^{\mathrm{Ba}}$ & $56 \pm 12^{\mathrm{Ba}}$ \\
\hline & Ob & $77 \pm 21^{\mathrm{Aa}}$ & $67 \pm 13^{\mathrm{Aa}}$ & $66 \pm 11^{\mathrm{Ab}}$ \\
\hline \multirow{2}{*}{$-\mathrm{dT} / \mathrm{dt}\left(\mathrm{g} / \mathrm{mm}^{2} / \mathrm{s}\right)$} & $\mathbf{C}$ & $27 \pm 5^{\mathrm{Aa}}$ & $21 \pm 5^{\mathrm{Ba}}$ & $18 \pm 4^{\mathrm{Ba}}$ \\
\hline & Ob & $27 \pm 8^{\mathrm{Aa}}$ & $21 \pm 5^{\mathrm{Ba}}$ & $19 \pm 3^{\mathrm{Ba}}$ \\
\hline \multirow{2}{*}{ Área seccional $\left(\mathbf{m m}^{2}\right)$} & $\mathbf{C}$ & $1,12 \pm 0,24^{\mathrm{Aa}}$ & $1,27 \pm 0,25^{\mathrm{Aa}}$ & $1,23 \pm 0,23^{\mathrm{Aa}}$ \\
\hline & $\mathbf{O b}$ & $1,08 \pm 0,29^{\mathrm{Aa}}$ & $1,24 \pm 0,26^{\mathrm{Aa}}$ & $1,06 \pm 0,30^{\mathrm{Aa}}$ \\
\hline
\end{tabular}

Dados expressos em média \pm desvio-padrão. C: grupo controle submetido à dieta normocalórica por $15(\mathrm{n}=18), 30(\mathrm{n}=17) \mathrm{e}$ $45(n=20)$ semanas de tratamento; Ob: grupo obeso submetido à dieta hipercalórica por $15(n=18), 30(n=20)$ e $45(n=14)$ semanas de tratamento; concentração de cálcio extracelular: $2.5 \mathrm{mM}$; TD: tensão máxima desenvolvida; TR: tensão de repouso; +dT/dt: velocidade máxima de variação da tensão desenvolvida; -dT/dt: velocidade máxima de variação de decréscimo da tensão desenvolvida. Letra maiúscula indica comparação entre os momentos fixado o grupo; letra minúscula indica comparação entre os grupos fixado o momento. Letras diferentes indicam diferença significativa $(\mathrm{p}<0,05)$. Análise de variância (ANOVA) para o esquema de dois fatores, complementada com o teste de comparações múltiplas de StudentNewman-Keuls.

\subsubsection{1- Curva de tensão-comprimento}

A influência da variação de comprimento muscular sobre a tensão de repouso dos animais $\mathrm{C}_{15}, \mathrm{Ob}_{15}, \mathrm{C}_{30}, \mathrm{Ob}_{30}, \mathrm{C}_{45}$ e $\mathrm{Ob}_{45}$ está apresentada na Figura 15. A obesidade promoveu alterações no comportamento da curva de tensão-comprimento da TR somente na $15^{\mathrm{a}}$ semana de tratamento. A curva de tensão-comprimento da TR mostra que os animais $\mathrm{Ob}_{15}$ 
apresentaram menor rigidez miocárdica que os $\mathrm{C}_{15}$. Não foram observadas alterações na curva de tensão-comprimento nos demais grupos obesos $\left(\mathrm{Ob}_{30}\right.$ e $\left.\mathrm{Ob}_{45}\right)$ em relação aos respectivos controles.
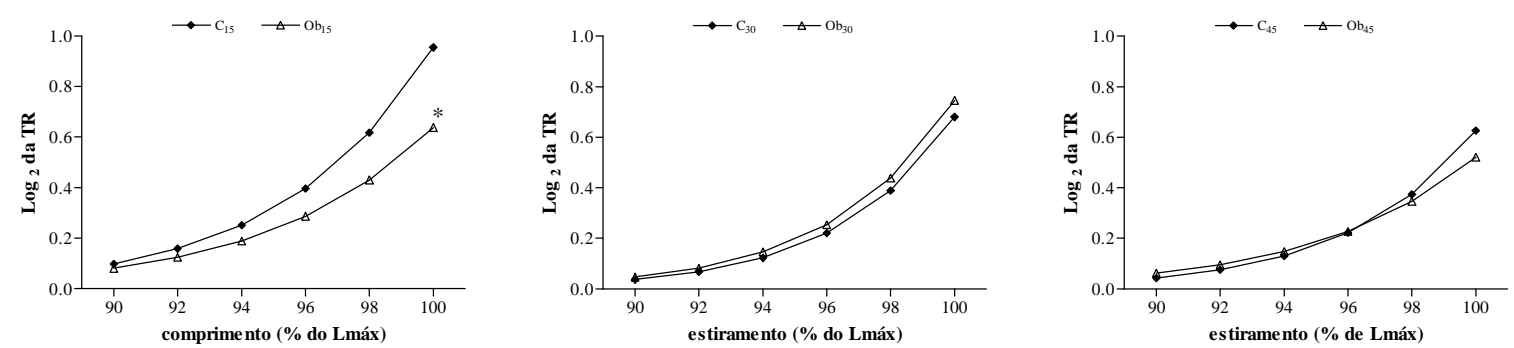

Figura 15. Comportamento da tensão de repouso em função da variação do comprimento do músculo em Lmáx (\%).

\subsubsection{2- Potenciação pós-pausa}

Os efeitos da potenciação pós-pausa na função do músculo papilar em valores absolutos $\left(\mathrm{g} / \mathrm{mm}^{2}\right)$ estão ilustrados na Tabela 7 e na Figura 16. Os resultados dos efeitos dos tempos das manobras, 10, 30 e 60 segundos, nos dois grupos, controle e obeso, não foram descritos.

A comparação entre os três períodos de tratamento, 15, 30 e 45 semanas, fixados os grupos obesos (Tabela 7 e Figura 16), mostrou que a TD, a $+d T / d t$ e a $-d T / d t$ sofreram alterações ao longo do tempo. Entretanto, estas variáveis também modificaram nos grupos controle (Tabela 7). A TD foi maior no grupo $\mathrm{Ob}_{15}$ em relação ao $\mathrm{Ob}_{30}$ e $\mathrm{Ob}_{45}$ após o estímulo ser cessado por 10, 30 e 60 segundos. Este mesmo comportamento foi visualizado nos animais $\mathrm{C}_{15}$. Além disso, a potenciação pós-pausa, nos momentos 30 e 60 segundos, promoveu diminuição das $+\mathrm{dT} / \mathrm{dt}$ nos grupos obesos ao longo do tempo $\left(\mathrm{Ob}_{15}>\mathrm{Ob}_{30}>\right.$ $\left.\mathrm{Ob}_{45}\right)$. Apesar de não ter sido possível mostrar diferença estatística entre os grupos $\mathrm{C}_{30}$ e $\mathrm{C}_{45}$ $(\mathrm{p}=0,08)$, o tempo de exposição ao tratamento no grupo controle, também reduziu progressivamente a $+\mathrm{dT} / \mathrm{dt}$. No momento 10 segundos, houve aumento $\mathrm{da}+\mathrm{dT} / \mathrm{dt}$ nos grupos 
$\mathrm{Ob}_{15}$ e $\mathrm{Ob}_{30}$ em relação $\mathrm{Ob}_{45}$. A -dT/dt também sofreu influência do tempo em ambos os grupos nos momentos 10, 30 e 60 segundos $\left(\mathrm{Ob}_{15}>\mathrm{Ob}_{30}>\mathrm{Ob}_{45}\right.$ e $\left.\mathrm{C}_{15}>\mathrm{C}_{30}>\mathrm{C}_{45}\right)$. Não foram observadas alterações no comportamento da TR entre os grupos obesos no momento basal e após a potenciação pós-pausa ao longo do tempo (Figura 16). Nos grupos controle houve aumento da TR no $\mathrm{C}_{15}$ em relação ao $\mathrm{C}_{30}$ e $\mathrm{C}_{45}$ no momento basal e após a realização da manobra.

A comparação entre os dois grupos, fixado o período de tratamento, indicou que a TR foi elevada nos animais $\mathrm{Ob}_{15}$ em relação ao $\mathrm{C}_{15}$ no momento basal. Os resultados da $\mathrm{TD}$, $+\mathrm{dT} / \mathrm{dt}$ e -dT/dt, no momento basal, mostraram que não houve diferença estatística entre os grupos controle e obeso. Entretanto, a manobra da potenciação pós-pausa, após 10, 30 e 60 segundos, acarretou menores valores da TD e da $+d T / d t$ somente no grupo $\mathrm{Ob}_{15}$ em relação ao respectivo controle. A potenciação pós-pausa também promoveu aumento dos valores da TR no $\mathrm{Ob}_{15}$ em relação ao $\mathrm{C}_{15}$ em todos os momentos. Esta manobra, no momento 10 segundos, acarretou aumento da $+\mathrm{dT} / \mathrm{dt}$ no grupo $\mathrm{Ob}_{30}$ versus $\mathrm{C}_{30}$. $\mathrm{O}$ comportamento da $-\mathrm{dT} / \mathrm{dt}$ foi semelhante entre os grupos após a manobra da potenciação pós-pausa. 


\begin{tabular}{|c|c|c|c|c|c|c|}
\hline & \multirow[b]{2}{*}{ Grupo } & \multirow[b]{2}{*}{ Tratamento } & \multicolumn{4}{|c|}{ Potenciação Pós-Pausa } \\
\hline & & & Basal & $10 ”$ & $30 ”$ & $60 "$ \\
\hline \multirow{6}{*}{$\begin{array}{c}\text { TD } \\
\left(\mathrm{g} / \mathrm{mm}^{2}\right)\end{array}$} & \multirow{3}{*}{$\mathbf{C}$} & 15 & $4,0 \pm 0,7^{\mathrm{Aa} \alpha}$ & $6,2 \pm 0,9^{\mathrm{Aa} \beta}$ & $7,6 \pm 1,2^{\text {Aa } \gamma}$ & $8,1 \pm 1,4^{\mathrm{Aa} \delta}$ \\
\hline & & 30 & $3,0 \pm 0,7^{\mathrm{Ba} \alpha}$ & $4,3 \pm 0,8^{\mathrm{Ba} \beta}$ & $5,6 \pm 1,0^{\mathrm{Ba} \gamma}$ & $6,0 \pm 1,1^{\mathrm{Ba} \delta}$ \\
\hline & & 45 & $2,5 \pm 0,7^{\mathrm{Ba} \alpha}$ & $4,1 \pm 0,8^{\mathrm{Ba} \beta}$ & $5,3 \pm 1,0^{\mathrm{Ba} \gamma}$ & $5,8 \pm 1,1^{\mathrm{Ba} \delta}$ \\
\hline & \multirow{3}{*}{$\mathbf{O b}$} & 15 & $3,6 \pm 1,1^{\mathrm{Aa} \alpha}$ & $5,4 \pm 1,2^{\mathrm{Ab} \beta}$ & $6,6 \pm 1,5^{\mathrm{Ab} \gamma}$ & $7,0 \pm 1,5^{\mathrm{Ab} \delta}$ \\
\hline & & 30 & $3,5 \pm 0,8^{\mathrm{Aa} \alpha}$ & $4,8 \pm 0,8^{\mathrm{Ba} \beta}$ & $5,7 \pm 1,0^{\mathrm{Ba} \gamma}$ & $6,1 \pm 1,1^{\mathrm{Ba} \delta}$ \\
\hline & & 45 & $2,5 \pm 0,7^{\mathrm{Ba} \alpha}$ & $4,1 \pm 0,9^{\mathrm{Ba} \beta}$ & $5,4 \pm 1,0^{\mathrm{Ba} \gamma}$ & $5,9 \pm 1,1^{\mathrm{Ba} \delta}$ \\
\hline \multirow{6}{*}{$\begin{array}{c}\text { TR } \\
\left(\mathrm{g} / \mathbf{m m}^{2}\right)\end{array}$} & \multirow{3}{*}{$\mathbf{C}$} & 15 & $1,4 \pm 0,3^{\mathrm{Aa \alpha}}$ & $1,4 \pm 0,3^{\mathrm{Aa} \alpha}$ & $1,3 \pm 0,3^{\mathrm{Aa} \beta}$ & $1,3 \pm 0,3^{\text {Aa } \gamma}$ \\
\hline & & 30 & $0,9 \pm 0,2^{\mathrm{Ba} \alpha}$ & $0,9 \pm 0,2^{\mathrm{Ba} \alpha}$ & $0,9 \pm 0,2^{\mathrm{Ba} \beta}$ & $0,8 \pm 0,2^{\text {Ba }}$ \\
\hline & & 45 & $0,8 \pm 0,2^{\mathrm{Ba \alpha}}$ & $0,9 \pm 0,2^{\mathrm{Ba} \beta}$ & $0,8 \pm 0,2^{\mathrm{Ba} \alpha}$ & $0,8 \pm 0,2^{\mathrm{Ba} \alpha}$ \\
\hline & \multirow{3}{*}{$\mathbf{O b}$} & 15 & $1,0 \pm 0,3^{\mathrm{Ab} \alpha}$ & $1,0 \pm 0,3^{\mathrm{Ab} \alpha}$ & $1,0 \pm 0,3^{\mathrm{Ab} \alpha}$ & $0,9 \pm 0,3^{\mathrm{Ab} \beta}$ \\
\hline & & 30 & $0,9 \pm 0,3^{\mathrm{Aa} \alpha}$ & $1,0 \pm 0,3^{\mathrm{Aa} \beta}$ & $0,9 \pm 0,3^{\mathrm{Aa} \alpha}$ & $0,9 \pm 0,2^{\mathrm{Aa} \alpha}$ \\
\hline & & 45 & $0,9 \pm 0,2^{\mathrm{Aa \alpha} \alpha}$ & $0,9 \pm 0,2^{\mathrm{Aa} \beta}$ & $0,9 \pm 0,2^{\text {Aa } \alpha}$ & $0,8 \pm 0,2^{\mathrm{Aa} \alpha}$ \\
\hline \multirow{6}{*}{$\begin{array}{c}+\mathrm{dT} / \mathrm{dt} \\
\left(\mathrm{g} / \mathrm{mm}^{2} / \mathrm{s}\right)\end{array}$} & \multirow{3}{*}{$\mathrm{C}$} & 15 & $41 \pm 12^{\mathrm{Aa} \alpha}$ & $63 \pm 12^{\mathrm{Aa \beta}}$ & $80 \pm 15^{\mathrm{Aa} \gamma}$ & $86 \pm 17^{\mathrm{Aa} \delta}$ \\
\hline & & 30 & $30 \pm 8^{\mathrm{Ba} \alpha}$ & $42 \pm 10^{\mathrm{Ba} \beta}$ & $56 \pm 12^{\mathrm{Ba \gamma}}$ & $62 \pm 13^{\mathrm{Ba} \delta}$ \\
\hline & & 45 & $22 \pm 7^{\mathrm{Ba} \alpha}$ & $36 \pm 9^{\mathrm{Ba} \beta}$ & $49 \pm 12^{\text {Bay }}$ & $54 \pm 14^{\mathrm{Ba} \delta}$ \\
\hline & \multirow{3}{*}{ Ob } & 15 & $37 \pm 11^{\mathrm{Aa} \alpha}$ & $56 \pm 13^{\mathrm{Ab} \beta}$ & $71 \pm 16^{\mathrm{Ab} \gamma}$ & $75 \pm 16^{\mathrm{Ab \gamma}}$ \\
\hline & & 30 & $37 \pm 9^{\operatorname{Aa} \alpha}$ & $50 \pm 11^{\mathrm{Ab} \beta}$ & $60 \pm 12^{\mathrm{Ba \gamma}}$ & $66 \pm 14^{\mathrm{Ba} \delta}$ \\
\hline & & 45 & $22 \pm 7^{\mathrm{Ba} \alpha}$ & $37 \pm 9^{\mathrm{Ba} \beta}$ & $51 \pm 11^{\mathrm{Ca \gamma}}$ & $56 \pm 12^{\mathrm{Ca} \delta}$ \\
\hline \multirow{6}{*}{$\begin{array}{c}-\mathrm{dT} / \mathrm{dt} \\
\left(\mathrm{g} / \mathrm{mm}^{2} / \mathrm{s}\right)\end{array}$} & \multirow{3}{*}{$\mathbf{C}$} & 15 & $17 \pm 4^{\mathrm{Aa} \alpha}$ & $23 \pm 4^{\mathrm{Aa} \beta}$ & $29 \pm 4^{\mathrm{Aa} \gamma}$ & $31 \pm 5^{\mathrm{Aa} \delta}$ \\
\hline & & 30 & $12 \pm 3^{B a \alpha}$ & $16 \pm 4^{\mathrm{Ba} \beta}$ & $21 \pm 5^{\text {Ba } \gamma}$ & $24 \pm 5^{\mathrm{Ba} \delta}$ \\
\hline & & 45 & $8 \pm 3^{\mathrm{Ca} \alpha}$ & $13 \pm 3^{\mathrm{Ca} \beta}$ & $18 \pm 3^{\mathrm{Ca \gamma}}$ & $20 \pm 4^{\mathrm{Ca} \delta}$ \\
\hline & \multirow{3}{*}{ Ob } & 15 & $15 \pm 4^{\mathrm{Aa} \alpha}$ & $22 \pm 5^{\mathrm{Aa} \beta}$ & $27 \pm 6^{\mathrm{Aa} \gamma}$ & $29 \pm 6^{\mathrm{Aa} \delta}$ \\
\hline & & 30 & $14 \pm 3^{\mathrm{Aa} \alpha}$ & $18 \pm 3^{\mathrm{Ba} \beta}$ & $22 \pm 3^{\text {Ba } \gamma}$ & $24 \pm 4^{\mathrm{Ba} \delta}$ \\
\hline & & 45 & $9 \pm 3^{\mathrm{Ba} \alpha}$ & $14 \pm 4^{\mathrm{Ca} \beta}$ & $18 \pm 4^{\mathrm{Ca \gamma}}$ & $21 \pm 5^{\mathrm{Ca} \delta}$ \\
\hline
\end{tabular}

Dados expressos em média \pm desvio-padrão. C: grupo controle submetido à dieta normocalórica por 15 ( $\mathrm{n}=18)$, 30 $(n=17)$ e $45(n=20)$ semanas de tratamento; Ob: grupo obeso submetido à dieta hipercalórica por $15(n=18), 30(n=20)$ e $45(n=14)$ semanas de tratamento; TD: tensão máxima desenvolvida; TR: tensão de repouso; +dT/dt: velocidade máxima de variação da tensão desenvolvida; -dT/dt: velocidade máxima de variação de decréscimo da tensão desenvolvida. Letras maiúsculas (vertical) indicam comparação entre os momentos fixado o grupo; letras minúsculas (vertical) indicam comparação entre os grupos fixado o momento. Letras gregas (horizontal) indicam comparação dos efeitos dos tempos da manobra; Letras diferentes indicam diferença significativa $(\mathrm{p}<0,05)$. Análise de variância (ANOVA) para o modelo de medidas repetidas para grupos independentes e complementada com teste de comparações múltiplas de Student-Newman-Keuls. 
A

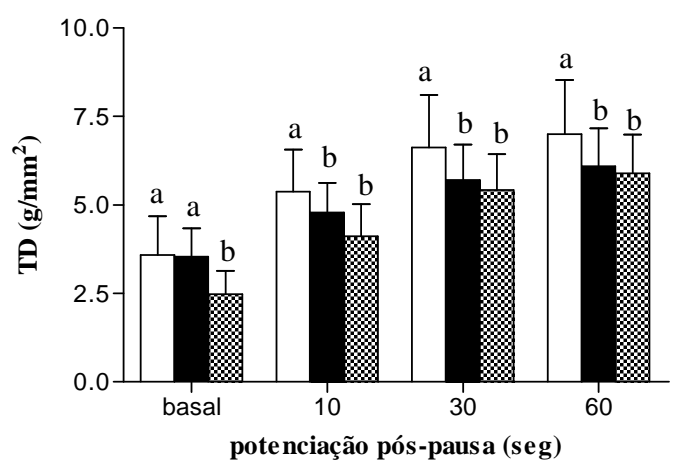

C

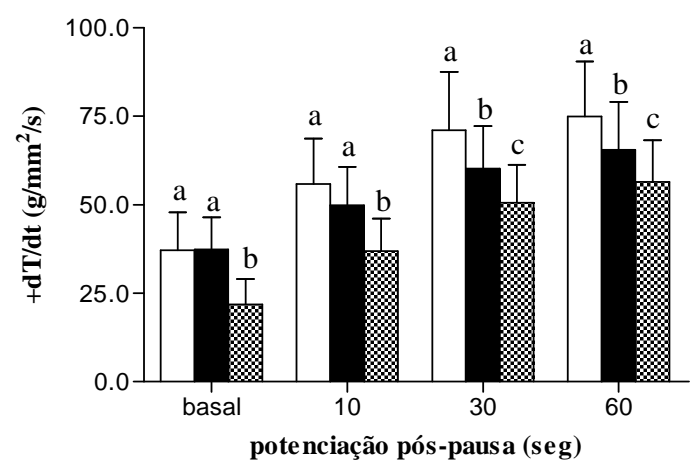

B

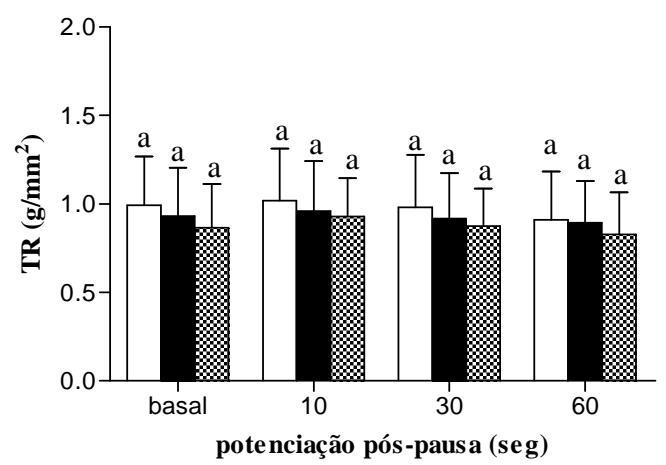

D

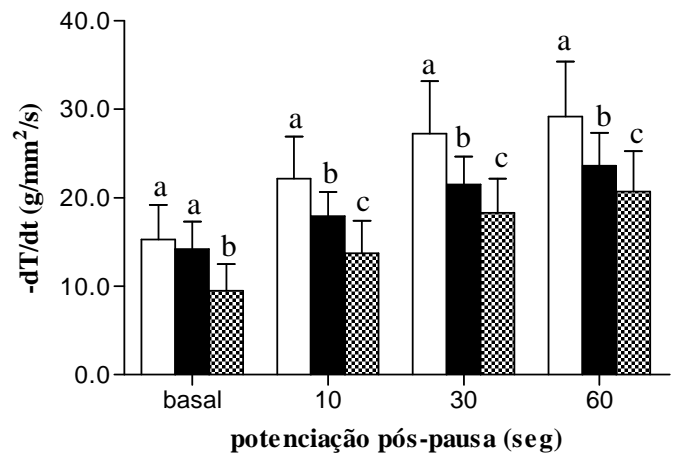

Figura 16. Potenciação pós-pausa no músculo papilar isolado de animais obesos $\left(\mathrm{Ob}_{15}, \mathrm{Ob}_{30} \mathrm{e}\right.$ $\left.\mathrm{Ob}_{45}\right)$. Ob: grupo obeso submetido à dieta hipercalórica por $15\left(\mathrm{Ob}_{15} ; \mathrm{n}=18\right), 30\left(\mathrm{Ob}_{30} ; \mathrm{n}=20\right) \mathrm{e}$ $45\left(\mathrm{Ob}_{45} ; \mathrm{n}=14\right)$ semanas de tratamento. Dados expressos em média \pm desvio-padrão. concentração de cálcio basal: $0,5 \mathrm{mM}$; TD: tensão máxima desenvolvida; TR: tensão de repouso; +dT/dt: velocidade máxima de variação da tensão desenvolvida; -dT/dt: velocidade máxima de variação de decréscimo da tensão desenvolvida. Letras diferentes indicam diferenças significativas entre os grupos obesos $(p<0,05)$. Análise de variância (ANOVA) para o modelo de medidas repetidas para grupos independentes e complementada com teste de comparações múltiplas de Student-Newman-Keuls.

\subsubsection{3- Elevação da concentração de cálcio extracelular}

Os efeitos da elevação da concentração de cálcio extracelular na função do músculo papilar em valores absolutos $\left(\mathrm{g} / \mathrm{mm}^{2}\right)$ estão mostrados na Tabela 8 e na Figura 17. Os resultados dos efeitos das concentrações de cálcio, 0,5, 10, 1,5, 2,0 e 2,5 mM, nos dois grupos controle e obeso, não foram descritos. 
A comparação entre os três períodos de tratamento, 15, 30 e 45 semanas, fixado os grupos obesos, mostrou que a TD e TR não sofreram alterações ao longo do tempo nas diferentes concentrações de cálcio (Tabela 8 e Figura 17). Entretanto, os animais controle $C_{15}$ apresentaram TD e TR maiores do que os demais grupos $\mathrm{C}_{30}$ e $\mathrm{C}_{45}$ em todas as concentrações de cálcio. Houve elevação da $+\mathrm{dT} / \mathrm{dt}$ nas $\left[\mathrm{Ca}^{+2}\right]$ de 0,5 até $2,5 \mathrm{mM}$ em ambos os grupos na $15^{\mathrm{a}}$ semana em relação ao $\mathrm{Ob}_{45}$ e $\mathrm{C}_{45}$, respectivamente. A elevação das concentrações de cálcio extracelular, 1,0, 1,5, 2,0 e 2,5 mM, promoveu diminuição da -dT/dt nos grupos $\mathrm{Ob}_{30} \mathrm{e}$ $\mathrm{Ob}_{45}$ em relação ao $\mathrm{Ob}_{15}$; entretanto, os animais controle apresentaram o mesmo comportamento (Tabela 8).

A comparação entre os dois grupos, fixada o período de tratamento, indicou que a TD foi menor no $\mathrm{Ob}_{15}$ em relação ao $\mathrm{C}_{15}$ nas concentrações de cálcio de 1,0, 1,5, 2,0 e 2,5 mM (Tabela 8); entretanto, não houve diferença entre os grupos na $\left[\mathrm{Ca}^{+2}\right]$ de $0,5 \mathrm{mM}$. Os valores da TR foram diminuídos nos animais $\mathrm{Ob}_{15}$ em relação ao $\mathrm{C}_{15}$ em todas as concentrações de cálcio. Os resultados da $+\mathrm{dT} / \mathrm{dt}$ mostraram que somente na $\left[\mathrm{Ca}^{+2}\right]$ de 1,0 $\mathrm{mM}$ houve diferença estatística entre os grupos $\left(\mathrm{Ob}_{30}>\mathrm{C}_{30}\right)$. A elevação das $\left[\mathrm{Ca}^{+2}\right]$ não promoveu alterações na $\mathrm{dT} / \mathrm{dt}$ entre os grupos controle e obeso em todos os momentos avaliados. 
Tabela 8. Elevação da concentração de cálcio extracelular

\begin{tabular}{|c|c|c|c|c|c|c|c|}
\hline & \multirow[b]{2}{*}{ Grupos } & \multirow[b]{2}{*}{ Tratamento } & \multicolumn{5}{|c|}{ Concentração de cálcio (mM) } \\
\hline & & & 0,5 & 1,0 & 1,5 & 2,0 & 2,5 \\
\hline \multirow{6}{*}{$\begin{array}{c}\text { TD } \\
\left(\mathrm{g} / \mathrm{mm}^{2}\right)\end{array}$} & \multirow{3}{*}{$\mathbf{C}$} & 15 & $3,9 \pm 0,8^{\mathrm{Aa} \alpha}$ & $5,5 \pm 0,9^{\mathrm{Aa} \beta}$ & $6,7 \pm 1,1^{\mathrm{Aa \gamma}}$ & $7,3 \pm 1,3^{\mathrm{Aa} \delta}$ & $7,6 \pm 1,4^{\mathrm{Aa} \delta}$ \\
\hline & & 30 & $2,9 \pm 0,5^{\mathrm{Ba} \alpha}$ & $4,1 \pm 0,7^{\mathrm{Ba} \beta}$ & $5,2 \pm 0,9^{\mathrm{Ba \gamma}}$ & $5,7 \pm 1,1^{\mathrm{Ba} \delta}$ & $5,9 \pm 1,1^{\mathrm{Ba} \delta}$ \\
\hline & & 45 & $2,7 \pm 0,6^{\mathrm{Ba} \alpha}$ & $4,0 \pm 0,7^{\mathrm{Ba} \beta}$ & $5,3 \pm 0,9^{\mathrm{Ba \gamma}}$ & $5,9 \pm 1,0^{\mathrm{Ba} \delta}$ & $6,2 \pm 1,1^{\mathrm{Ba} \delta}$ \\
\hline & \multirow{3}{*}{ Ob } & 15 & $3,4 \pm 0,9^{\mathrm{Aa} \alpha}$ & $4,8 \pm 1,1^{\mathrm{Ab} \beta}$ & $5,9 \pm 1,3^{\mathrm{Ab \gamma}}$ & $6,5 \pm 1,5^{\mathrm{Ab} \delta}$ & $6,7 \pm 1,6^{\mathrm{Ab} \delta}$ \\
\hline & & 30 & $3,4 \pm 0,7^{\mathrm{Aa} \alpha}$ & $4,6 \pm 0,8^{\mathrm{Aa} \beta}$ & $5,5 \pm 1,0^{\mathrm{Aa \gamma}}$ & $5,8 \pm 1,1^{\mathrm{Aa} \delta}$ & $5,9 \pm 1,1^{\mathrm{Aa} \delta}$ \\
\hline & & 45 & $2,6 \pm 0,7^{\mathrm{Aa} \alpha}$ & $4,3 \pm 0,8^{\mathrm{Aa} \beta}$ & $5,7 \pm 1,0^{\mathrm{Aa \gamma}}$ & $6,4 \pm 1,0^{\mathrm{Aa} \delta}$ & $6,6 \pm 1,1^{\mathrm{Aa} \delta}$ \\
\hline \multirow{6}{*}{$\begin{array}{c}\text { TR } \\
\left(\mathrm{g} / \mathrm{mm}^{2}\right)\end{array}$} & \multirow{3}{*}{$\mathbf{C}$} & 15 & $0,9 \pm 0,3^{\mathrm{Aa} \alpha}$ & $1,0 \pm 0,3^{\mathrm{Aa} \alpha}$ & $1,0 \pm 0,3^{\mathrm{Aa} \alpha}$ & $1,0 \pm 0,3^{\mathrm{Aa} \alpha}$ & $1,0 \pm 0,3^{\mathrm{Aa} \beta}$ \\
\hline & & 30 & $0,6 \pm 0,1^{\mathrm{Ba} \alpha}$ & $0,7 \pm 0,2^{\mathrm{Ba} \alpha}$ & $0,7 \pm 0,2^{\mathrm{Ba} \alpha}$ & $0,7 \pm 0,2^{\mathrm{Ba} \alpha}$ & $0,7 \pm 0,2^{\mathrm{Ba} \alpha}$ \\
\hline & & 45 & $0,6 \pm 0,2^{\text {Ba } \alpha}$ & $0,7 \pm 0,1^{\mathrm{Ba} \alpha}$ & $0,7 \pm 0,2^{\mathrm{Ba} \alpha}$ & $0,6 \pm 0,1^{\mathrm{Ba} \alpha}$ & $0,7 \pm 0,2^{\mathrm{Ba} \alpha}$ \\
\hline & \multirow{3}{*}{$\mathbf{O b}$} & 15 & $0,7 \pm 0,2^{\mathrm{Ab} \alpha}$ & $0,8 \pm 0,2^{\mathrm{Ab} \beta}$ & $0,8 \pm 0,2^{\mathrm{Ab} \beta}$ & $0,7 \pm 0,2^{\mathrm{Ab} \beta}$ & $0,7 \pm 0,2^{\mathrm{Ab} \beta}$ \\
\hline & & 30 & $0,7 \pm 0,2^{\mathrm{Aa} \alpha}$ & $0,7 \pm 0,2^{\mathrm{Aa} \alpha}$ & $0,7 \pm 0,2^{\mathrm{Aa} \alpha}$ & $0,7 \pm 0,2^{\mathrm{Aa} \alpha}$ & $0,7 \pm 0,2^{\mathrm{Aa \alpha}}$ \\
\hline & & 45 & $0,6 \pm 0,2^{\mathrm{Aa} \alpha}$ & $0,7 \pm 0,2^{\mathrm{Aa} \alpha}$ & $0,7 \pm 0,2^{\text {Aa } \alpha}$ & $0,7 \pm 0,2^{\mathrm{Aa} \alpha}$ & $0,7 \pm 0,2^{\text {Aa } \alpha}$ \\
\hline \multirow{6}{*}{$\begin{array}{c}+\mathrm{dT} / \mathrm{dt} \\
\left(\mathrm{g} / \mathrm{mm}^{2} / \mathrm{s}\right)\end{array}$} & \multirow{3}{*}{$\mathbf{C}$} & 15 & $43 \pm 9^{\operatorname{Aa} \alpha}$ & $59 \pm 11^{\text {Aaß }}$ & $74 \pm 14^{\mathrm{Aa \gamma}}$ & $82 \pm 16^{\mathrm{Aa \delta}}$ & $86 \pm 18^{\mathrm{Aa} \zeta}$ \\
\hline & & 30 & $32 \pm 7^{\mathrm{Ba} \alpha}$ & $43 \pm 10^{\mathrm{Ba} \beta}$ & $56 \pm 13^{\mathrm{Ba \gamma}}$ & $63 \pm 15^{\mathrm{Ba \delta}}$ & $66 \pm 15^{\mathrm{Ba} \delta}$ \\
\hline & & 45 & $27 \pm 7^{\mathrm{Ba} \alpha}$ & $39 \pm 8^{\mathrm{Ba} \beta}$ & $52 \pm 11^{\mathrm{Ba \gamma}}$ & $60 \pm 13^{\mathrm{Ba} \delta}$ & $64 \pm 14^{\mathrm{Ba \zeta}}$ \\
\hline & \multirow{3}{*}{ Ob } & 15 & $38 \pm 10^{\mathrm{Aa} \alpha}$ & $55 \pm 13^{\mathrm{Aa \beta}}$ & $69 \pm 16^{\mathrm{Aa \gamma}}$ & $76 \pm 19^{\mathrm{Aa} \delta}$ & $80 \pm 20^{\mathrm{Aa} \delta}$ \\
\hline & & 30 & $38 \pm 8^{\mathrm{Aa} \alpha}$ & $51 \pm 9^{\mathrm{ABb} \beta}$ & $62 \pm 11^{\mathrm{ABa} \gamma}$ & $67 \pm 13^{\mathrm{Ba} \delta}$ & $69 \pm 13^{\mathrm{Ba} \delta}$ \\
\hline & & 45 & $25 \pm 7^{\mathrm{Ba} \alpha}$ & $43 \pm 9^{\mathrm{Ba} \beta}$ & $58 \pm 11^{\mathrm{Ba} \gamma}$ & $67 \pm 12^{\mathrm{ABa} \delta}$ & $70 \pm 13^{\mathrm{Ba} \delta}$ \\
\hline \multirow{6}{*}{$\begin{array}{c}-d T / d t \\
\left(\mathrm{~g} / \mathrm{mm}^{2} / \mathrm{s}\right)\end{array}$} & \multirow{3}{*}{$\mathbf{C}$} & 15 & $18 \pm 4^{\mathrm{Aa} \alpha}$ & $25 \pm 4^{\mathrm{Aa} \beta}$ & $30 \pm 5^{\text {Aa } \gamma}$ & $32 \pm 6^{\mathrm{Aa} \delta}$ & $32 \pm 6^{\mathrm{Aa} \delta}$ \\
\hline & & 30 & $13 \pm 3^{\mathrm{Ba} \alpha}$ & $18 \pm 5^{\mathrm{Ba} \beta}$ & $22 \pm 5^{\mathrm{Ba} \gamma}$ & $24 \pm 5^{\mathrm{Ba} \delta}$ & $24 \pm 5^{\mathrm{Ba} \delta}$ \\
\hline & & 45 & $11 \pm 3^{\mathrm{Ba} \alpha}$ & $16 \pm 3^{\mathrm{Ba} \beta}$ & $20 \pm 3^{\mathrm{Ba} \gamma}$ & $21 \pm 3^{\mathrm{Ba} \delta}$ & $21 \pm 3^{\mathrm{Ba} \delta}$ \\
\hline & \multirow{3}{*}{ Ob } & 15 & $17 \pm 5^{\mathrm{Aa} \alpha}$ & $25 \pm 6^{\mathrm{Aa} \beta}$ & $29 \pm 7^{\text {Aa } \gamma}$ & $31 \pm 8^{\mathrm{Aa} \delta}$ & $31 \pm 8^{\mathrm{Aa} \delta}$ \\
\hline & & 30 & $15 \pm 3^{\mathrm{Aa} \alpha}$ & $20 \pm 3^{\mathrm{Ba} \beta}$ & $23 \pm 3^{\mathrm{Ba \gamma}}$ & $24 \pm 4^{\mathrm{Ba} \gamma}$ & $24 \pm 4^{\mathrm{Ba} \gamma}$ \\
\hline & & 45 & $10 \pm 3^{\mathrm{Ba} \alpha}$ & $18 \pm 4^{\mathrm{Ba} \beta}$ & $21 \pm 4^{\mathrm{Ba} \gamma}$ & $22 \pm 4^{\text {Ba } \gamma}$ & $22 \pm 4^{\mathrm{Ba} \gamma}$ \\
\hline
\end{tabular}

Dados expressos em média \pm desvio-padrão. C: grupo controle submetido à dieta normocalórica por $15(\mathrm{n}=18), 30(\mathrm{n}=17) \mathrm{e}$ $45(\mathrm{n}=20)$ semanas de tratamento; Ob: grupo obeso submetido à dieta hipercalórica por $15(\mathrm{n}=18), 30(\mathrm{n}=20)$ e $45(\mathrm{n}=14)$ semanas de tratamento; TD: tensão máxima desenvolvida; TR: tensão de repouso; +dT/dt: velocidade máxima de variação da tensão desenvolvida; -dT/dt: velocidade máxima de variação de decréscimo da tensão desenvolvida. Letras maiúsculas (vertical) indicam comparação entre os momentos fixado o grupo; letras minúsculas (vertical) indicam comparação entre os grupos fixado o momento. Letras gregas (horizontal) indicam comparação dos efeitos da manobra; Letras diferentes indicam diferença significativa $(\mathrm{p}<0,05)$. Análise de variância (ANOVA) para o modelo de medidas repetidas para grupos independentes e complementada com teste de comparações múltiplas de Student-Newman-Keuls. 


\section{$\square \mathrm{Ob}_{15} \square \mathrm{Ob}_{30} \quad \mathrm{Or} \mathrm{Ob}_{45}$}

A

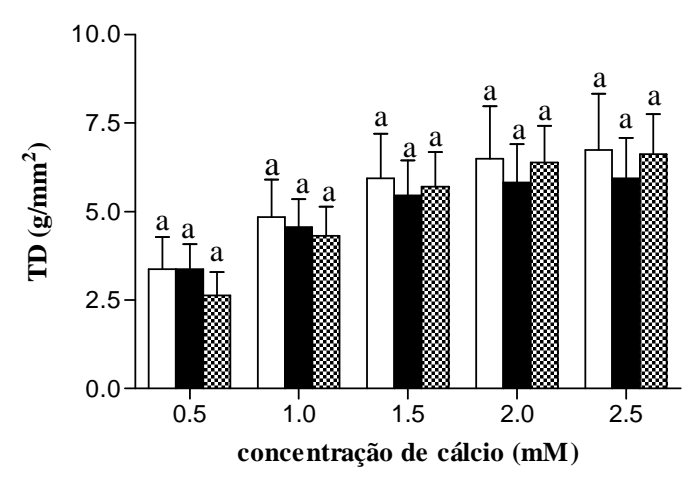

C

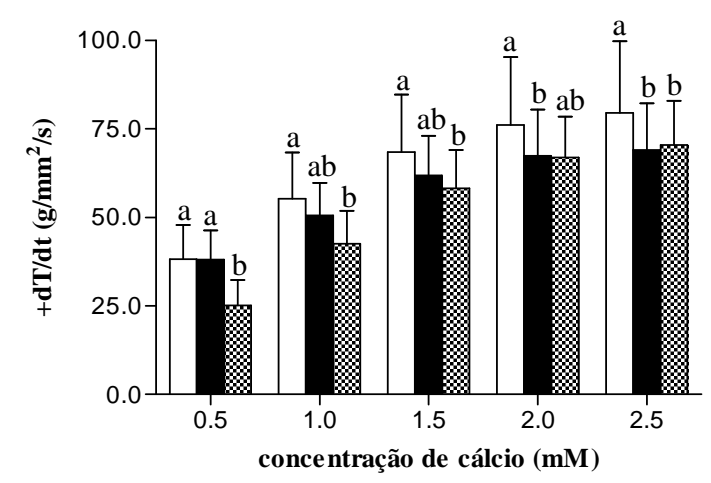

B

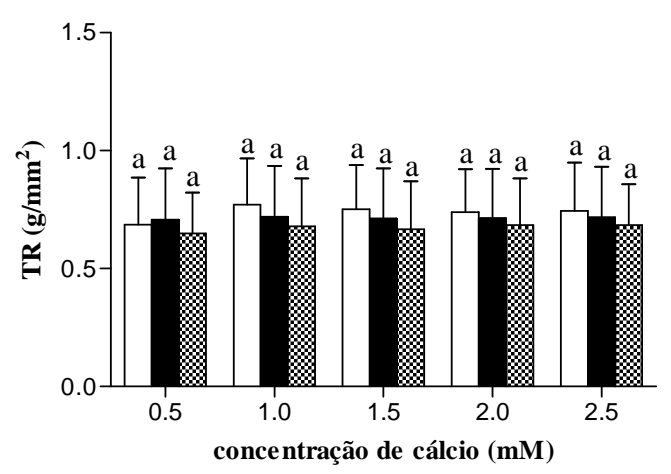

D

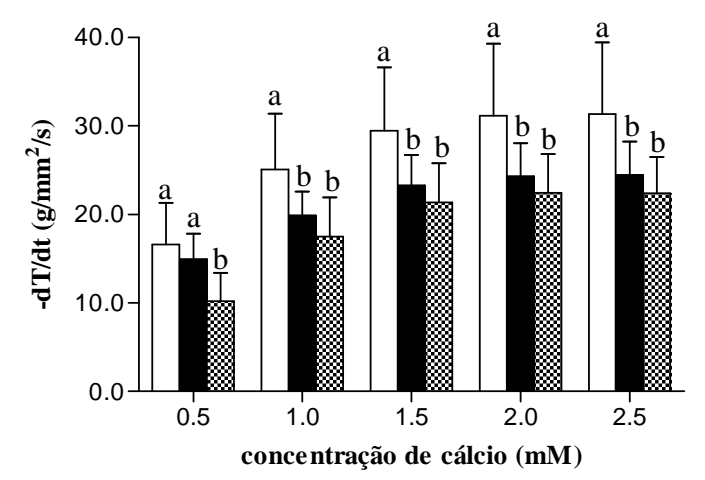

Figura 17. Efeitos da elevação da concentração de cálcio extracelular de 0,5 a $2,5 \mathrm{mM}$ no músculo papilar isolado de animais obesos $\left(\mathrm{Ob}_{15}, \mathrm{Ob}_{30}, \mathrm{Ob}_{45}\right)$. Ob: grupo obeso submetido à dieta hipercalórica por $15\left(\mathrm{Ob}_{15} ; \mathrm{n}=18\right), 30\left(\mathrm{Ob}_{30} ; \mathrm{n}=20\right)$ e $45\left(\mathrm{Ob}_{45} ; \mathrm{n}=14\right)$ semanas de tratamento. Dados expressos em média \pm desvio-padrão. TD: tensão máxima desenvolvida; TR: tensão de repouso; + dT/dt: velocidade máxima de variação da tensão desenvolvida; -dT/dt: velocidade máxima de variação de decréscimo da tensão desenvolvida. Letras minúsculas indicam comparação entre os momentos fixado o grupo obeso; Letras diferentes indicam diferenças significativas entre os grupos obesos $(\mathrm{p}<0,05)$. Análise de variância (ANOVA) para o modelo de medidas repetidas para grupos independentes e complementada com teste de comparações múltiplas de Student-Newman-Keuls.

\subsubsection{4- Elevação da freqüência cardíaca}

Os efeitos da elevação da freqüência do estímulo na função do músculo papilar em valores absolutos $\left(\mathrm{g} / \mathrm{mm}^{2}\right)$ estão na função do músculo papilar estão apresentados na Tabela 9 e na Figura 18. Os resultados dos efeitos da elevação do estímulo, 0,1, 0,2, 0,5, 0,7, 1,0 e 2,0

$\mathrm{Hz}$ nos dois grupos, controle e obeso, não foram descritos.

A comparação entre os três períodos de tratamento, 15, 30 e 45 semanas, fixado os grupos obesos (Tabela 9 e Figura 18), mostrou que a TD, +dT/dt e -dTdt sofreram alterações 
ao longo do tempo; entretanto, o tempo não modificou o comportamento da TR entre os grupos obesos. A TD foi elevada no grupo $\mathrm{Ob}_{15}$ em relação ao $\mathrm{Ob}_{30}$ e $\mathrm{Ob}_{45}$ com frequiência de estímulo de 0,1 e 0,2 Hz; entretanto, não houve diferença entre os grupos após elevação do estímulo de 0,5 a 2,0 Hz. No grupo controle ocorreu o mesmo comportamento até a freqüência de estímulo de $0,2 \mathrm{~Hz}$, uma vez que, com $0,5 \mathrm{~Hz}$, a TD ainda foi maior no $\mathrm{C}_{15} \mathrm{em}$ relação ao $\mathrm{C}_{30}$ e $\mathrm{C}_{45}$. A TR foi maior no grupo $\mathrm{C}_{15}$ do que nos $\mathrm{C}_{30}$ e $\mathrm{C}_{45}$ em todas as frequiências de estímulo. Além disso, a interação entre manobra e tempo de exposição aos tratamentos acarretou respostas diferentes na $+\mathrm{dT} / \mathrm{dt}$ e $-\mathrm{dT} / \mathrm{dt}$ nos grupos controles e obesos. (Tabela 9). Enquanto a duração da obesidade promoveu diminuição proporcional da $+\mathrm{dT} / \mathrm{dt}$ com freqüência de $0,2 \mathrm{~Hz}$, nos grupos controles este comportamento somente ocorreu com o estímulo de 0,1 Hz. Além disso, a partir da freqüência de estímulo de 0,5 Hz não foram mais observadas alterações na $+\mathrm{dT} / \mathrm{dt}$ entre os grupos obesos; este resultado não aconteceu de forma similar nos animais controles. A -dT/dt apresentou resultados semelhantes nos dois grupos somente com frequiências de estímulo de 1,0 e 2,0 Hz. $\left(\mathrm{Ob}_{15}>\mathrm{Ob}_{30}\right.$ e $\mathrm{Ob}_{45} ; \mathrm{C}_{15}>\mathrm{C}_{30}$ e $\mathrm{C}_{45}$ ). Enquanto, a freqüência de estímulo de $0,2 \mathrm{~Hz}$ acarretou redução progressiva nos animais obesos, o tempo de exposição à obesidade, com estímulos de 0,5 e 0,7Hz, também diminuiu a -dT/dt, entretanto, somente entre os animais $\mathrm{Ob}_{45}$ e $\mathrm{Ob}_{15}$. Nos grupos controle, o $\mathrm{C}_{15}$ apresentou maior -dT/dt do que o $\mathrm{C}_{30}$ e o $\mathrm{C}_{45}$ com estímulos de $0,2,0,5,0,7,1,0$ e 2,0 Hz.

A comparação entre os dois grupos, fixada os períodos de tratamento, indicou que a TD foi menor no $\mathrm{Ob}_{15}$ em relação ao $\mathrm{C}_{15}$ com frequiências de estímulos de $0,1,0,2$ e $0,5 \mathrm{~Hz}$ (Tabela 9). Os valores da TR foram diminuídos nos animais $\mathrm{Ob}_{15}$ em relação ao $\mathrm{C}_{15}$ em todas as freqüências de estímulos. Os resultados da $+\mathrm{dT} / \mathrm{dt}$ mostraram que somente na freqüência de estímulo de $0,1 \mathrm{~Hz}$ houve diferença estatística entre os grupos $\left(\mathrm{Ob}_{15}<\mathrm{C}_{15}\right)$. A manobra de elevação da freqüência cardíaca promoveu alterações na -dT/dt entre os grupos controle e obeso com estímulos de 0,1 e $0,2 \mathrm{~Hz}\left(\mathrm{Ob}_{30}>\mathrm{C}_{30}\right)$. 
Tabela 9. Elevação da frequiência cardíaca

\begin{tabular}{|c|c|c|c|c|c|c|c|c|}
\hline & \multirow[b]{2}{*}{ Grupo } & \multirow[b]{2}{*}{ Tratamento } & \multicolumn{6}{|c|}{ Freqüência de estímulo $(\mathrm{Hz})$} \\
\hline & & & 0,1 & 0,2 & 0,5 & 0,7 & 1,0 & 2,0 \\
\hline \multirow{6}{*}{$\begin{array}{c}\text { TD } \\
\left(\mathrm{g} / \mathrm{mm}^{2}\right)\end{array}$} & \multirow{3}{*}{$\mathbf{C}$} & 15 & $7,6 \pm 1,3^{\mathrm{Aa} a}$ & $6,0 \pm 0,9^{\mathrm{Aa \beta}}$ & $3,3 \pm 0,8^{\mathrm{Aa \gamma}}$ & $2,9 \pm 0,7^{\mathrm{Aa} \delta}$ & $2,4 \pm 0,7^{\mathrm{Aa} \lambda}$ & $2,1 \pm 0,6^{\mathrm{Aa \zeta}}$ \\
\hline & & 30 & $5,7 \pm 1,0^{\mathrm{Ba} \alpha}$ & $4,4 \pm 0,7^{\mathrm{Ba \beta}}$ & $2,5 \pm 0,5^{\mathrm{Ba \gamma}}$ & $2,1 \pm 0,4^{\mathrm{Ba} \delta}$ & $1,8 \pm 0,4^{\mathrm{Aa} \lambda}$ & $1,6 \pm 0,4^{\mathrm{ABa} \lambda}$ \\
\hline & & 45 & $5,7 \pm 1,0^{\mathrm{Ba} \alpha}$ & $4,3 \pm 0,9^{\mathrm{Ba \beta}}$ & $2,6 \pm 0,8^{\mathrm{Ba \gamma}}$ & $2,2 \pm 0,7^{\mathrm{AB} a \delta}$ & $1,9 \pm 0,7^{\mathrm{Aa} \lambda}$ & $1,5 \pm 0,7^{\mathrm{Ba} \zeta}$ \\
\hline & \multirow{3}{*}{ Ob } & 15 & $6,7 \pm 1,5^{\mathrm{Ab} \alpha}$ & $5,4 \pm 1,1^{\mathrm{Ab} \beta}$ & $2,8 \pm 0,8^{\mathrm{Ab \gamma}}$ & $2,4 \pm 0,7^{\text {Aa } \delta}$ & $2,1 \pm 0,6^{\mathrm{Aa} \lambda}$ & $1,8 \pm 0,6^{\mathrm{Aa} \lambda}$ \\
\hline & & 30 & $5,8 \pm 0,9^{\mathrm{Ba} \alpha}$ & $4,8 \pm 0,7^{\mathrm{Ba} \beta}$ & $2,7 \pm 0,5^{\mathrm{Aa \gamma}}$ & $2,4 \pm 0,4^{\mathrm{Aa} \delta}$ & $1,9 \pm 0,4^{\mathrm{Aa} \lambda}$ & $1,6 \pm 0,4^{\text {Aaל }}$ \\
\hline & & 45 & $6,1 \pm 1,0^{\mathrm{Ba} \alpha}$ & $4,6 \pm 0,8^{\mathrm{Ba} \beta}$ & $2,7 \pm 0,7^{\mathrm{Aa \gamma}}$ & $2,4 \pm 0,6^{\mathrm{Aa} \delta}$ & $1,9 \pm 0,5^{\mathrm{Aa} \lambda}$ & $1,4 \pm 0,4^{\mathrm{Aa} \zeta}$ \\
\hline \multirow{6}{*}{$\begin{array}{c}\text { TR } \\
\left(\mathrm{g} / \mathrm{mm}^{2}\right)\end{array}$} & \multirow{3}{*}{$\mathbf{C}$} & 15 & $1,2 \pm 0,3^{\text {Aaa } \delta}$ & 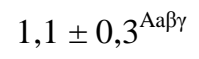 & $1,1 \pm 0,3^{\mathrm{Aa} \beta \gamma}$ & $1,1 \pm 0,3^{\mathrm{Aa \beta \gamma}}$ & $1,2 \pm 0,3^{\operatorname{Aa\gamma } \alpha}$ & $1,2 \pm 0,4^{\mathrm{A} a \delta}$ \\
\hline & & 30 & $0,8 \pm 0,2^{\mathrm{Ba} \alpha}$ & $0,7 \pm 0,2^{\mathrm{Ba \alpha}}$ & $0,7 \pm 0,2^{\mathrm{Ba} \alpha}$ & $0,7 \pm 0,2^{\mathrm{Ba} \alpha}$ & $0,7 \pm 0,2^{\mathrm{Ba} \alpha}$ & $0,8 \pm 0,2^{\mathrm{Ba} \alpha}$ \\
\hline & & 45 & $0,7 \pm 0,1^{\mathrm{Ba} a}$ & $0,7 \pm 0,1^{\mathrm{Ba} \alpha}$ & $0,7 \pm 0,1^{\mathrm{Ba} a}$ & $0,7 \pm 0,1^{\mathrm{Ba} \alpha}$ & $0,7 \pm 0,2^{\mathrm{Ba} a}$ & $0,8 \pm 0,2^{\mathrm{Ba} \beta}$ \\
\hline & \multirow{3}{*}{ Ob } & 15 & $0,9 \pm 0,3^{\mathrm{Ab} \alpha \beta}$ & $0,8 \pm 0,2^{\mathrm{Ab} \alpha}$ & $0,8 \pm 0,2^{\mathrm{Ab} \alpha}$ & $0,8 \pm 0,2^{\mathrm{Ab} \alpha}$ & $0,8 \pm 0,3^{\mathrm{Ab} \alpha \beta}$ & $0,9 \pm 0,3^{\mathrm{Ab \beta}}$ \\
\hline & & 30 & $0,8 \pm 0,2^{\mathrm{Aa} \alpha}$ & $0,8 \pm 0,2^{\mathrm{Aa} \alpha}$ & $0,8 \pm 0,2^{\mathrm{Aa} \alpha}$ & $0,8 \pm 0,2^{\mathrm{Aa} \alpha}$ & $0,8 \pm 0,2^{\mathrm{Aa} \alpha}$ & $0,9 \pm 0,3^{\mathrm{Aa} \beta}$ \\
\hline & & 45 & $0,8 \pm 0,2^{\text {Aaa } \delta}$ & $0,7 \pm 0,2^{\text {Aaa } \gamma}$ & $0,7 \pm 0,2^{\mathrm{Aa} \beta}$ & $0,7 \pm 0,2^{\mathrm{Aa} \beta \gamma}$ & $0,7 \pm 0,2^{\mathrm{Aa} \beta \gamma}$ & $0,8 \pm 0,2^{\mathrm{Aa} \delta}$ \\
\hline \multirow{6}{*}{$\begin{array}{c}+\mathrm{dT} / \mathrm{dt} \\
\left(\mathrm{g} / \mathrm{mm}^{2} / \mathrm{s}\right)\end{array}$} & \multirow{3}{*}{$\mathbf{C}$} & 15 & $82 \pm 15^{\mathrm{Aa} \alpha}$ & $63 \pm 11^{\mathrm{Aa \beta}}$ & $39 \pm 9^{\text {Aay }}$ & $36 \pm 9^{\mathrm{Aa \gamma \delta}}$ & $33 \pm 9^{\mathrm{Aa} \delta}$ & $32 \pm 9^{\mathrm{Aa} \delta}$ \\
\hline & & 30 & $61 \pm 13^{\mathrm{Ba \alpha}}$ & $47 \pm 9^{\mathrm{Ba} \beta}$ & $30 \pm 7^{\mathrm{Ba \gamma}}$ & $28 \pm 8^{\mathrm{B} a \gamma \delta}$ & $25 \pm 8^{\mathrm{Ba} \delta}$ & $25 \pm 9^{\mathrm{Ba} \delta}$ \\
\hline & & 45 & $54 \pm 13^{\mathrm{Ca} \alpha}$ & $41 \pm 11^{\mathrm{Ba} \beta}$ & $27 \pm 9^{\mathrm{Ba \gamma}}$ & $25 \pm 9^{\text {Baү } \delta}$ & $23 \pm 9^{\mathrm{Ba} \delta}$ & $20 \pm 9^{\mathrm{Ba} \lambda}$ \\
\hline & \multirow{3}{*}{ Ob } & 15 & $75 \pm 18^{\mathrm{Ab} a}$ & $59 \pm 13^{\mathrm{Aa \beta}}$ & $34 \pm 9^{\text {Aay }}$ & $31 \pm 8^{\mathrm{Aa} \delta}$ & $29 \pm 8^{\mathrm{Aa} \delta}$ & $28 \pm 9^{\mathrm{Aa} \delta}$ \\
\hline & & 30 & $63 \pm 8^{\mathrm{Ba} \alpha}$ & $52 \pm 6^{\mathrm{Ba \beta}}$ & $32 \pm 5^{\mathrm{Aa \gamma}}$ & $29 \pm 5^{\text {Aa } \gamma}$ & $26 \pm 5^{\mathrm{Aa} \delta}$ & $23 \pm 5^{\mathrm{Aa} \delta}$ \\
\hline & & 45 & $60 \pm 11^{\mathrm{Ba} a}$ & $44 \pm 9^{\mathrm{Ca \beta}}$ & $29 \pm 7^{\text {Aay }}$ & $27 \pm 6^{\text {Aar } \delta}$ & $23 \pm 5^{\mathrm{Aa} \delta}$ & $20 \pm 6^{\mathrm{Aa} \lambda}$ \\
\hline \multirow{6}{*}{$\begin{array}{c}-d T / d t \\
\left(\mathrm{~g} / \mathrm{mm}^{2} / \mathrm{s}\right)\end{array}$} & \multirow{3}{*}{$\mathbf{C}$} & 15 & $31 \pm 5^{\mathrm{Aa} \alpha}$ & $27 \pm 5^{\mathrm{Aa} \beta}$ & $18 \pm 4^{\mathrm{Aa} \gamma}$ & $17 \pm 4^{\mathrm{Aa} \delta}$ & $16 \pm 4^{\mathrm{Aa} \delta}$ & $16 \pm 5^{\mathrm{Aa} \delta}$ \\
\hline & & 30 & $22 \pm 3^{\mathrm{Ba} \alpha}$ & $18 \pm 3^{\mathrm{Ba} \beta}$ & $13 \pm 3^{\mathrm{Ba} \gamma}$ & $12 \pm 3^{\mathrm{B} a \gamma \delta}$ & $11 \pm 3^{\mathrm{Ba} \delta}$ & $11 \pm 3^{\mathrm{Ba} \delta}$ \\
\hline & & 45 & $20 \pm 3^{\mathrm{Ba} \alpha}$ & $16 \pm 3^{\mathrm{Ba \beta}}$ & $11 \pm 3^{\mathrm{Ba} \gamma}$ & $10 \pm 3^{\mathrm{Ba \gamma \delta}}$ & $10 \pm 3^{\mathrm{Ba} \delta \lambda}$ & $9 \pm 3^{\mathrm{Ba} \lambda}$ \\
\hline & \multirow{3}{*}{ Ob } & 15 & $30 \pm 6^{\mathrm{Aa} \alpha}$ & $25 \pm 5^{\mathrm{Aa} \beta}$ & $16 \pm 4^{\mathrm{Aa} \gamma}$ & $15 \pm 4^{\text {Aar } \delta}$ & $14 \pm 4^{\mathrm{Aa} \delta}$ & $15 \pm 5^{\text {Aar } \delta}$ \\
\hline & & 30 & $24 \pm 3^{\mathrm{Bb} \alpha}$ & $21 \pm 3^{\mathrm{Bb} \beta}$ & $14 \pm 2^{\mathrm{ABa} \gamma}$ & $13 \pm 2^{\mathrm{ABa \delta}}$ & $12 \pm 2^{\mathrm{Ba} \lambda}$ & $11 \pm 3^{\mathrm{Ba} \lambda}$ \\
\hline & & 45 & $22 \pm 4^{\mathrm{Ba} \alpha}$ & $18 \pm 4^{\mathrm{Ca} \beta}$ & $13 \pm 3^{\mathrm{Ba \gamma}}$ & $12 \pm 2^{\mathrm{Ba \gamma}}$ & $11 \pm 2^{\mathrm{Ba} \delta}$ & $9 \pm 3^{\mathrm{Ba} \delta}$ \\
\hline
\end{tabular}

Dados expressos em média \pm desvio-padrão. C: grupo controle submetido à dieta normocalórica por $15(\mathrm{n}=18), 30(\mathrm{n}=17)$ e 45 $(n=20)$ semanas de tratamento; Ob: grupo obeso submetido à dieta hipercalórica por $15(n=18), 30(n=20)$ e $45(n=14)$ semanas de tratamento; TD: tensão máxima desenvolvida; TR: tensão de repouso; +dT/dt: velocidade máxima de variação da tensão desenvolvida; -dT/dt: velocidade máxima de variação de decréscimo da tensão desenvolvida. Letras maiúsculas (vertical) indicam comparação entre os momentos fixado o grupo; letras minúsculas (vertical) indicam comparação entre os grupos fixado o momento. Letras gregas (horizontal) indicam comparação dos efeitos da manobra; Letras diferentes indicam diferença significativa ( $\mathrm{p}<0,05$ ). Análise de variância (ANOVA) para o modelo de medidas repetidas para grupos independentes e complementada com teste de comparações múltiplas de Student-Newman-Keuls. 
A

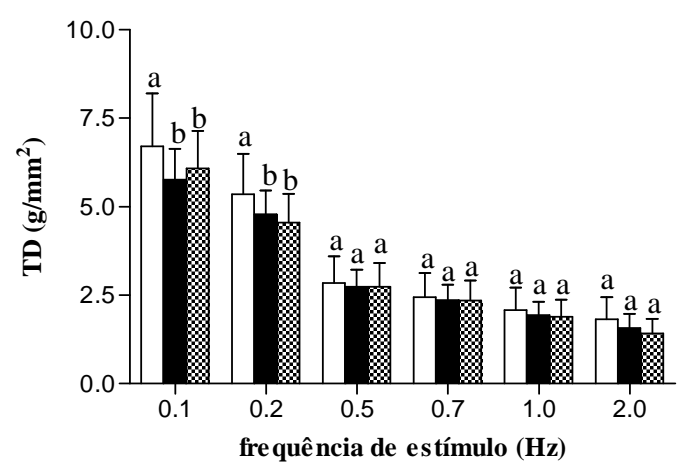

C

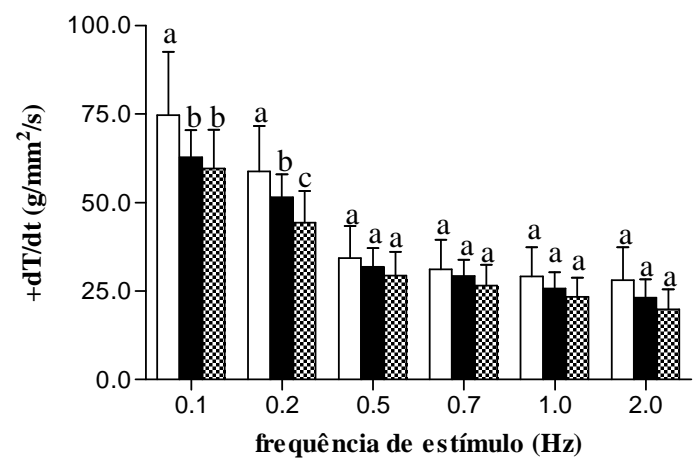

B

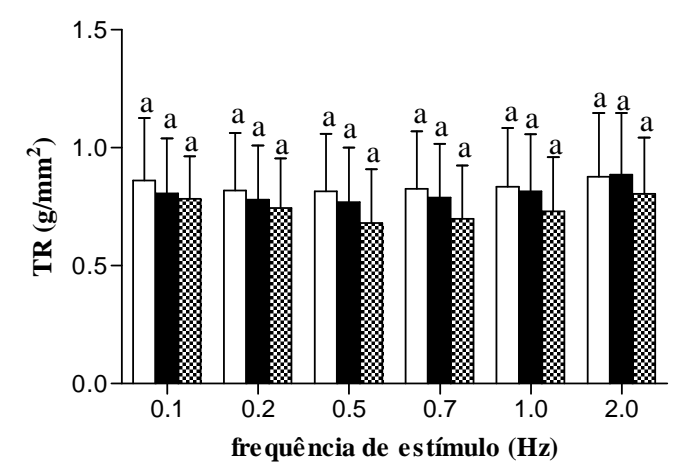

D

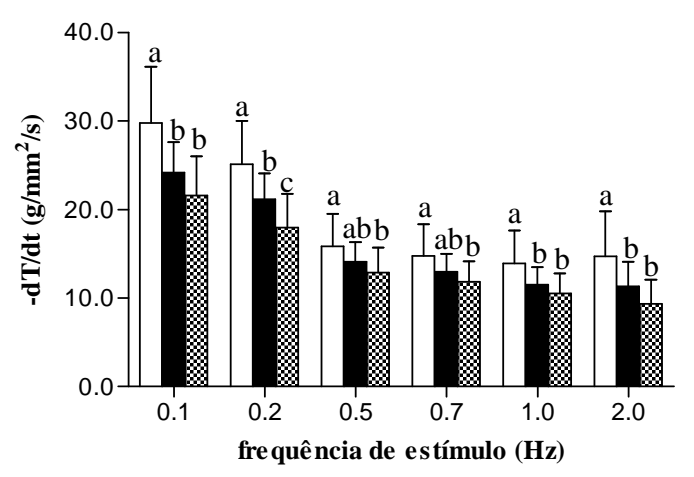

Figura 18. Efeitos da elevação da freqüência de estímulo de 0,1 a $2,0 \mathrm{~Hz}$ no músculo papilar isolado de animais obesos $\left(\mathrm{Ob}_{15}, \mathrm{Ob}_{30}\right.$ e $\left.\mathrm{Ob}_{45}\right)$. Ob: grupo obeso submetido à dieta hipercalórica por 15 $\left(\mathrm{Ob}_{15} ; \mathrm{n}=18\right), 30\left(\mathrm{Ob}_{30} ; \mathrm{n}=20\right)$ e $45\left(\mathrm{Ob}_{45} ; \mathrm{n}=14\right)$ semanas de tratamento. Dados expressos em média \pm desvio-padrão. A: TD (tensão máxima desenvolvida); B: TR (tensão de repouso); C: $+\mathrm{dT} / \mathrm{dt}$ (velocidade máxima de variação da tensão desenvolvida); D: -dT/dt (velocidade máxima de variação de decréscimo da tensão desenvolvida). Letras minúsculas indicam comparação entre os momentos fixado o grupo obeso; Letras diferentes indicam diferenças significativas entre os grupos obesos $(\mathrm{p}<0,05)$. Análise de variância (ANOVA) para o modelo de medidas repetidas para grupos independentes e complementada com teste de comparações múltiplas de Student-Newman-Keuls.

\subsubsection{5- Experimento diltiazem}

Os efeitos do bloqueio do músculo papilar com diltiazem em porcentagem estão apresentados na Tabela 10 e na Figura 19. Os resultados indicam que o tempo de exposição à obesidade não acarretou alterações na resposta funcional entre os grupos obesos em todas as variáveis $(\mathrm{TD},+\mathrm{dT} / \mathrm{dt}$ e $-\mathrm{dT} / \mathrm{dt})$ após bloqueio específico do canal $\mathrm{L}$ com diltiazem. Os resultados da comparação entre os grupos controles nos diferentes períodos de tratamento, 
$\mathrm{C}_{15}, \mathrm{C}_{30}$ e $\mathrm{C}_{45}$, e os efeitos do bloqueio do diltiazem nas diferentes concentrações de cálcio, 0,5, 1,0, 1,5, 2,0 e 2,5 mM nos dois grupos, controle e obeso, não foram descritos.

A comparação entre os dois grupos, fixada os períodos de tratamento, indicou que somente na $\left[\mathrm{Ca}^{+2}\right]$ de 2,0 mM, o diltiazem promoveu maior bloqueio da $-\mathrm{dT} / \mathrm{dt}$ no grupo $\mathrm{Ob}_{15}$ em relação ao respectivo controle (Tabela 10). O bloqueio do diltiazem não acarretou alterações no comportamento da TD e da $+\mathrm{dT} / \mathrm{dt}$ entre os grupos controles e obesos ao longo dos períodos de tratamento. 
Tabela 10. Experimento diltiazem

\begin{tabular}{|c|c|c|c|c|c|c|c|}
\hline & \multirow[b]{2}{*}{ Grupos } & \multirow[b]{2}{*}{ Tratamento } & \multicolumn{5}{|c|}{ Concentração de cálcio (mM) } \\
\hline & & & 0,5 & 1,0 & 1,5 & 2,0 & 2,5 \\
\hline \multirow{6}{*}{ TD $(\%)$} & \multirow{3}{*}{$\mathbf{C}$} & 15 & $85 \pm 10^{\mathrm{Aa} \alpha}$ & $77 \pm 9^{\mathrm{Aa} \beta}$ & $64 \pm 8^{\operatorname{Aa} \gamma}$ & $51 \pm 8^{\text {Aa } \delta}$ & $39 \pm 7^{\operatorname{Aa\lambda }}$ \\
\hline & & 30 & $84 \pm 5^{\text {Аa } \alpha}$ & $77 \pm 9^{\text {Aaß }}$ & $66 \pm 12^{\mathrm{Aa \gamma}}$ & $54 \pm 13^{\text {Aa } \delta}$ & $43 \pm 13^{\mathrm{Aa \lambda}}$ \\
\hline & & 45 & $89 \pm 6^{\mathrm{Aa} \alpha}$ & $85 \pm 8^{\mathrm{Aa} \beta}$ & $71 \pm 10^{\mathrm{Aa \gamma}}$ & $55 \pm 10^{\text {Aa } \delta}$ & $39 \pm 12^{\mathrm{Aa} \lambda}$ \\
\hline & \multirow{3}{*}{$\mathbf{O b}$} & 15 & $89 \pm 8^{\mathrm{Aa} \alpha}$ & $83 \pm 8^{\mathrm{Aa \beta}}$ & $73 \pm 10^{\mathrm{Aa \gamma}}$ & $61 \pm 11^{\mathrm{Aa} \delta}$ & $49 \pm 11^{\mathrm{Aa} \lambda}$ \\
\hline & & 30 & $88 \pm 3^{\mathrm{Aa} \alpha}$ & $79 \pm 5^{\mathrm{Aa} \beta}$ & $66 \pm 7^{\mathrm{Aa} \gamma}$ & $53 \pm 8^{\mathrm{Aa} \delta}$ & $41 \pm 8^{\mathrm{Aa \lambda}}$ \\
\hline & & 45 & $89 \pm 4^{\mathrm{Aa} \alpha}$ & $86 \pm 6^{\mathrm{Aa} \alpha}$ & $68 \pm 9^{\mathrm{Aa} \beta}$ & $53 \pm 12^{\text {Aa } \gamma}$ & $40 \pm 13^{\mathrm{Aa} \delta}$ \\
\hline \multirow{6}{*}{$+\mathrm{dT} / \mathrm{dt}(\%)$} & \multirow{3}{*}{$\mathbf{C}$} & 15 & $83 \pm 11^{\text {Aa } \alpha}$ & $74 \pm 10^{\mathrm{Aa} \beta}$ & $61 \pm 9^{\mathrm{Aa} \gamma}$ & $50 \pm 8^{\mathrm{Aa} \delta}$ & $40 \pm 6^{\mathrm{Aa} \lambda}$ \\
\hline & & 30 & $85 \pm 7^{\mathrm{Aa} \alpha}$ & $76 \pm 9^{\mathrm{Aa} \beta}$ & $64 \pm 13^{\text {Aa } \gamma}$ & $53 \pm 13^{\mathrm{Aa} \delta}$ & $44 \pm 12^{\mathrm{Aa} \lambda}$ \\
\hline & & 45 & $90 \pm 6^{\mathrm{Aa} \alpha}$ & $84 \pm 10^{\text {Aa } \beta}$ & $71 \pm 12^{\text {Aa }}$ & $56 \pm 14^{\mathrm{Aa} \delta}$ & $43 \pm 16^{\mathrm{Aa} \lambda}$ \\
\hline & \multirow{3}{*}{$\mathbf{O b}$} & 15 & $89 \pm 8^{\mathrm{Aa} \alpha}$ & $79 \pm 10^{\mathrm{Aa \beta}}$ & $68 \pm 14^{\mathrm{Aa \gamma}}$ & $57 \pm 14^{\mathrm{Aa} \delta}$ & $46 \pm 16^{\mathrm{Aa} \lambda}$ \\
\hline & & 30 & $86 \pm 10^{\mathrm{Aa} \alpha}$ & $75 \pm 12^{\mathrm{Aa \beta}}$ & $63 \pm 11^{\mathrm{Aa \gamma}}$ & $51 \pm 11^{\mathrm{Aa} \delta}$ & $41 \pm 10^{\mathrm{Aa} \lambda}$ \\
\hline & & 45 & $86 \pm 5^{\mathrm{Aa} \alpha}$ & $85 \pm 6^{\mathrm{Aa} \alpha}$ & $69 \pm 9^{\mathrm{Aa} \beta}$ & $55 \pm 11^{\mathrm{Aa} \gamma}$ & $44 \pm 11^{\mathrm{Aa} \delta}$ \\
\hline \multirow{6}{*}{$-d T / d t(\%)$} & \multirow{3}{*}{$\mathbf{C}$} & 15 & $82 \pm 10^{\mathrm{Aa} \alpha}$ & $71 \pm 11^{\mathrm{Aa} \beta}$ & $55 \pm 9^{\mathrm{Aa} \gamma}$ & $38 \pm 9^{\mathrm{Aa} \delta}$ & $27 \pm 7^{\mathrm{Aa} \lambda}$ \\
\hline & & 30 & $82 \pm 8^{\mathrm{Aa} \alpha}$ & $72 \pm 10^{\mathrm{Aa} \beta}$ & $58 \pm 12^{\text {Aa } \gamma}$ & $45 \pm 12^{\text {Аа } \delta}$ & $34 \pm 11^{\mathrm{Aa} \lambda}$ \\
\hline & & 45 & $86 \pm 7^{\mathrm{Aa} \alpha}$ & $79 \pm 10^{\text {Aaß }}$ & $62 \pm 13^{\text {Aa } \gamma}$ & $44 \pm 10^{\mathrm{Aa} \delta}$ & $29 \pm 8^{\mathrm{Aa \lambda}}$ \\
\hline & \multirow{3}{*}{$\mathbf{O b}$} & 15 & $86 \pm 9^{\mathrm{Aa} \alpha}$ & $78 \pm 10^{\mathrm{Aa} \beta}$ & $66 \pm 12^{\text {Aay }}$ & $52 \pm 12^{\mathrm{Ab \delta}}$ & $38 \pm 10^{\mathrm{Aa} \lambda}$ \\
\hline & & 30 & $81 \pm 11^{\mathrm{Aa} \alpha}$ & $69 \pm 15^{\mathrm{Aa} \beta}$ & $53 \pm 15^{\text {Aa } \gamma}$ & $38 \pm 13^{\mathrm{Aa} \delta}$ & $27 \pm 10^{\mathrm{Aa} \lambda}$ \\
\hline & & 45 & $80 \pm 9^{\operatorname{Aa} \alpha}$ & $80 \pm 8^{\mathrm{Aa} \alpha}$ & $58 \pm 12^{\mathrm{Aa} \beta}$ & $44 \pm 10^{\mathrm{Aa \gamma}}$ & $31 \pm 8^{\mathrm{Aa} \delta}$ \\
\hline
\end{tabular}

Dados expressos em percentual médio de bloqueio $(\%) \pm$ desvio padrão. C: grupo controle submetido à dieta normocalórica por $15(\mathrm{n}=10), 30(\mathrm{n}=10)$ e $45(\mathrm{n}=12)$ semanas de tratamento; Ob: grupo obeso submetido à dieta hipercalórica por $15(\mathrm{n}=8)$, 30 $(n=9)$ e $45(n=7)$ semanas de tratamento; concentração de diltiazem: $10^{-4} \mathrm{M}$; TD: tensão máxima desenvolvida; +dT/dt: velocidade máxima de variação da tensão desenvolvida; -dT/dt: velocidade máxima de variação de decréscimo da tensão desenvolvida. Análise de variância (ANOVA) para o modelo de medidas repetidas para grupos independentes e complementada com o teste de comparações múltiplas de Student-Newman-Keuls. Letras maiúsculas (vertical) indicam comparação entre os momentos fixado o grupo; letras minúsculas (vertical) indicam comparação entre os grupos fixado o momento. Letras gregas (horizontal) indicam comparação dos efeitos do bloqueio do diltiazem nas diferentes concentrações de cálcio; Letras diferentes indicam diferença significativa $(\mathrm{p}<0,05)$. 

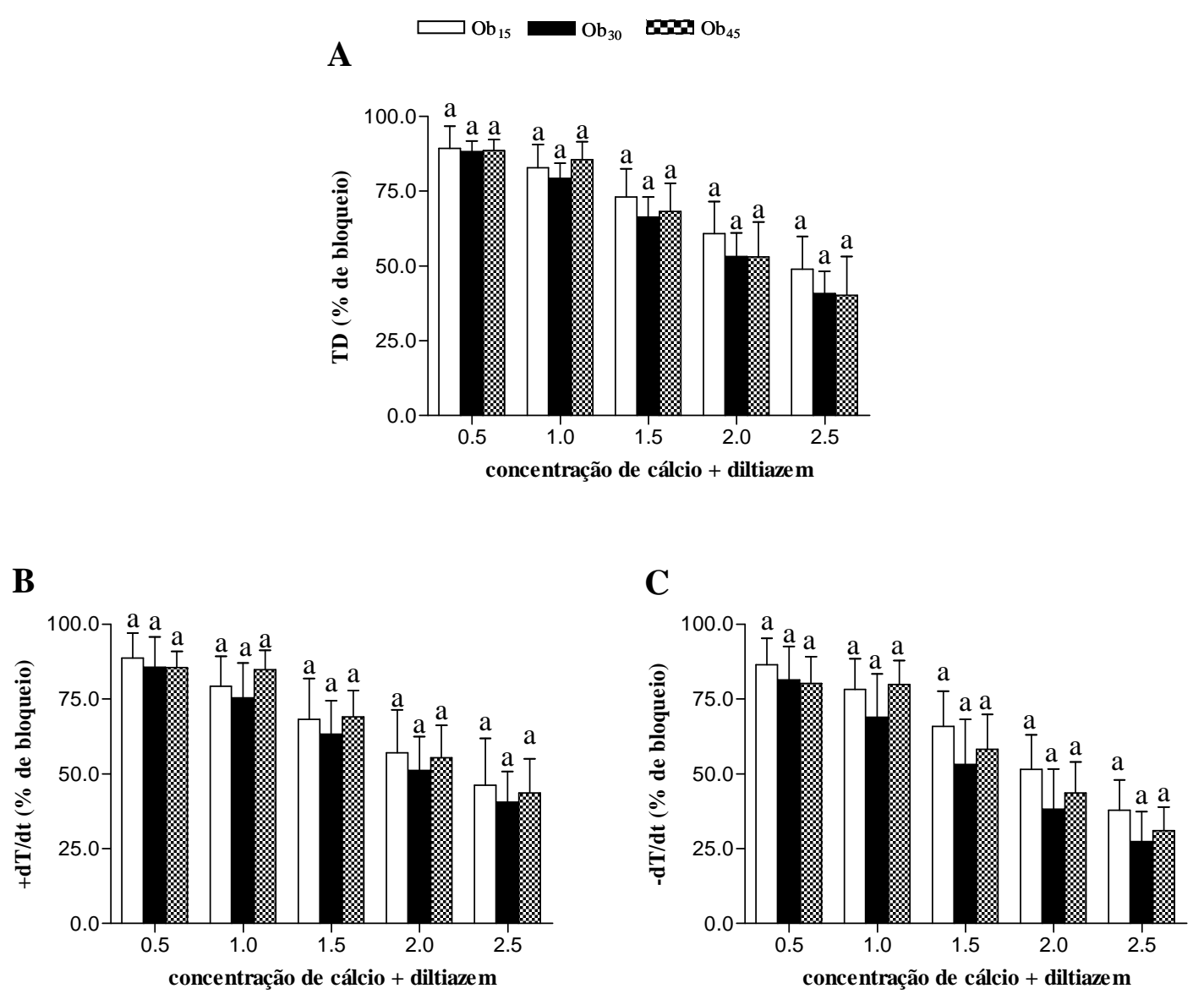

Figura 19. Efeitos do bloqueio dos canais L de cálcio com diltiazem $\left(10^{-4} \mathrm{M}\right)$ sobre o músculo papilar isolado dos grupos obesos; Ob: grupo obeso submetido à dieta hipercalórica por 15 $(n=8), 30(n=9)$ e $45(n=7)$ semanas de tratamento. A: TD (tensão máxima desenvolvida); B: +dT/dt (velocidade máxima de variação da tensão desenvolvida); C: -dT/dt (velocidade máxima de variação de decréscimo da tensão desenvolvida). Dados expressos em percentual médio de bloqueio $(\%) \pm$ desvio padrão. Letras minúsculas indicam comparação entre os momentos fixado o grupo obeso; Não houve diferenças significativas entre os grupos obesos. Análise de variância (ANOVA) para o modelo de medidas repetidas para grupos independentes e complementada com o teste de comparações múltiplas de Student-Newman-Keuls.

\subsubsection{6- Experimento ácido ciclopiazônico}

Os efeitos do bloqueio do músculo papilar com ácido ciclopiazônico em porcentagem estão apresentados na Tabela 11 e na Figura 20. Os resultados indicam que o tempo de exposição à obesidade não acarretou alterações na resposta funcional entre os grupos obesos na -dT/dt após bloqueio com ácido ciclopiazônico. Entretanto, o tempo de exposição à obesidade influenciou a TD e $+\mathrm{dT} / \mathrm{dt}$ em algumas $\left[\mathrm{Ca}^{+2}\right]$ após bloqueio. A droga promoveu maior bloqueio da TD no grupo $\mathrm{Ob}_{45}$ em relação ao $\mathrm{Ob}_{30}$ com $\left[\mathrm{Ca}^{+2}\right]$ de $0,5 \mathrm{mM}$; entretanto, o grupo $\mathrm{Ob}_{45}$ apresentou maior bloqueio desta variável versus o $\mathrm{Ob}_{15}$ nas $\left[\mathrm{Ca}^{+2}\right]$ de 2,0 e 2,5 
mM. O bloqueio da $+\mathrm{dT} / \mathrm{dt}$ foi maior nos animais $\mathrm{Ob}_{45}$ versus $\mathrm{Ob}_{30}$ e $\mathrm{Ob}_{15} \operatorname{com}\left[\mathrm{Ca}^{+2}\right]$ de 2,5 $\mathrm{mM}$; na $\left[\mathrm{Ca}^{+2}\right]$ de $0,5 \mathrm{mM}, \mathrm{a}+\mathrm{dT} / \mathrm{dt}$ apresentou menor bloqueio do grupo $\mathrm{Ob}_{30}$ em relação ao $\mathrm{Ob}_{15}$ e $\mathrm{Ob}_{45} ; \mathrm{a}+\mathrm{dT} / \mathrm{dt}$ foi menor na $\left[\mathrm{Ca}^{+2}\right]$ de $1,5 \mathrm{mM}$ no grupo $\mathrm{Ob}_{30}$ em relação ao $\mathrm{Ob}_{45}$. Os resultados da comparação entre os grupos controles nos diferentes períodos de tratamento, $\mathrm{C}_{15}, \mathrm{C}_{30}$ e $\mathrm{C}_{45}$, e os efeitos do bloqueio do diltiazem nas diferentes concentrações de cálcio, 0,5, 1,0, 1,5, 2,0 e 2,5 mM nos dois grupos, controle e obeso, não foram descritos.

A comparação entre os dois grupos, fixada os períodos de tratamento, indicou que somente na $\left[\mathrm{Ca}^{+2}\right]$ de 0,5 mM, o ácido ciclopiazônico promoveu menor bloqueio da TD e da $+\mathrm{dT} / \mathrm{dt}$ nos grupos $\mathrm{Ob}_{30}$ e $\mathrm{Ob}_{45}$ em relação aos respectivos controles (Tabela 11). Os resultados da -dT/dt mostram que a droga acarretou menor bloqueio desta variável no grupo $\mathrm{Ob}_{45}$ em relação ao $\mathrm{C}_{45} \mathrm{com}\left[\mathrm{Ca}^{+2}\right]$ de $0,5 \mathrm{mM}$. 
Tabela 11. Experimento ácido ciclopiazônico

\section{Concentração de cálcio (mM)}

\begin{tabular}{|c|c|c|c|c|c|c|c|}
\hline & Grupos & Tratamento & 0,5 & 1,0 & 1,5 & 2,0 & 2,5 \\
\hline \multirow{6}{*}{ TD (\%) } & \multirow{3}{*}{$\mathbf{C}$} & 15 & $33 \pm 14^{\text {Aa } \alpha}$ & $25 \pm 9^{\mathrm{Aa} \beta}$ & $21 \pm 8^{\mathrm{Aa} \beta}$ & $16 \pm 8^{\mathrm{Aa} \gamma}$ & $12 \pm 9^{\mathrm{Aa} \delta}$ \\
\hline & & 30 & $42 \pm 7^{\mathrm{Aa} \alpha}$ & $32 \pm 7^{\mathrm{ABa} \beta}$ & $30 \pm 6^{\mathrm{ABa} \beta}$ & $24 \pm 7^{\text {Aa } \gamma}$ & $19 \pm 7^{\mathrm{Aa} \delta}$ \\
\hline & & 45 & $54 \pm 13^{\text {Вa } a}$ & $39 \pm 12^{\mathrm{Ba \beta}}$ & $35 \pm 10^{\mathrm{Ba \gamma}}$ & $28 \pm 6^{\mathrm{Aa} \delta}$ & $23 \pm 6^{\mathrm{Aa} \lambda}$ \\
\hline & \multirow{3}{*}{ Ob } & 15 & $35 \pm 15^{\mathrm{ABa} \alpha}$ & $26 \pm 16^{\mathrm{Aa} \beta}$ & $18 \pm 17^{\mathrm{Aa} \gamma}$ & $12 \pm 17^{\mathrm{Aa} \delta}$ & $8 \pm 17^{\mathrm{Aa} \lambda}$ \\
\hline & & 30 & $25 \pm 10^{\mathrm{Ab} \alpha}$ & $21 \pm 7^{\mathrm{Aa} \beta}$ & $20 \pm 7^{\mathrm{Aa \gamma} \gamma}$ & $17 \pm 7^{\mathrm{ABa} \delta \gamma \beta}$ & $14 \pm 7^{\mathrm{ABa} \lambda \delta}$ \\
\hline & & 45 & $38 \pm 10^{\mathrm{Bb} \alpha}$ & $30 \pm 8^{\mathrm{Aa} \beta \alpha}$ & $30 \pm 6^{\operatorname{Aa} \gamma \beta}$ & $27 \pm 7^{\mathrm{Ba} \delta \beta \gamma}$ & $24 \pm 9^{\mathrm{Ba} \delta}$ \\
\hline \multirow{6}{*}{$+\mathrm{dT} / \mathrm{dt}(\%)$} & \multirow{3}{*}{$\mathbf{C}$} & 15 & $38 \pm 11^{\mathrm{Aa} \alpha}$ & $30 \pm 8^{\mathrm{Aa} \beta}$ & $31 \pm 5^{\mathrm{Aa} \beta}$ & $27 \pm 5^{\mathrm{Aa} \beta}$ & $24 \pm 6^{\mathrm{Aa} \beta}$ \\
\hline & & 30 & $40 \pm 8^{\mathrm{Aa} \alpha}$ & $31 \pm 9^{\mathrm{Aa} \beta}$ & $33 \pm 6^{\mathrm{Aa} \beta}$ & $29 \pm 6^{\mathrm{Aa} \beta}$ & $27 \pm 8^{\mathrm{Aa} \beta}$ \\
\hline & & 45 & $52 \pm 11^{\mathrm{Ba} \alpha}$ & $40 \pm 12^{\mathrm{Aa} \beta}$ & $37 \pm 9^{\operatorname{Aa} \gamma \beta}$ & $34 \pm 7^{\text {Aa } \beta \gamma \gamma}$ & $32 \pm 5^{\mathrm{Aa} \gamma \gamma \delta}$ \\
\hline & \multirow{3}{*}{ Ob } & 15 & $38 \pm 12^{\mathrm{Ba} \alpha}$ & $33 \pm 11^{\mathrm{Aa} \beta}$ & $29 \pm 10^{\mathrm{ABa} \gamma \beta}$ & $25 \pm 10^{\mathrm{Aa} \sigma \gamma}$ & $22 \pm 96^{\mathrm{Aa} \lambda \delta}$ \\
\hline & & 30 & $29 \pm 8^{\mathrm{Ab} \alpha}$ & $24 \pm 6^{\mathrm{Aa} \alpha \beta}$ & $25 \pm 6^{\mathrm{Aa} \alpha \beta}$ & $25 \pm 5^{\operatorname{Aa} \alpha \beta}$ & $21 \pm 6^{\mathrm{Aa} \beta}$ \\
\hline & & 45 & $42 \pm 17^{\mathrm{Bb} \alpha}$ & $34 \pm 16^{\text {Aaa }}$ & $37 \pm 7^{\text {Ba } \alpha}$ & $35 \pm 8^{\mathrm{Aa} \alpha}$ & $34 \pm 9^{\mathrm{Ba} \alpha}$ \\
\hline \multirow{6}{*}{$-\mathrm{dT} / \mathrm{dt}(\%)$} & \multirow{3}{*}{$\mathbf{C}$} & 15 & $30 \pm 14^{\mathrm{Aa} \alpha}$ & $30 \pm 7^{\mathrm{Aa} \alpha}$ & $32 \pm 3^{\mathrm{Aa \alpha} \alpha}$ & $32 \pm 3^{\mathrm{Aa} \alpha}$ & $34 \pm 3^{\mathrm{Aa} \alpha}$ \\
\hline & & 30 & $31 \pm 14^{\mathrm{Aa} \alpha}$ & $30 \pm 8^{\mathrm{Aa \alpha}}$ & $35 \pm 6^{\mathrm{Aa} \alpha}$ & $35 \pm 4^{\mathrm{Aa \alpha} \alpha}$ & $36 \pm 3^{\mathrm{Aa \alpha}}$ \\
\hline & & 45 & $45 \pm 12^{\mathrm{Ba} \alpha}$ & $35 \pm 11^{\mathrm{Aa} \beta}$ & $36 \pm 8^{\mathrm{Aa} \beta}$ & $34 \pm 7^{\mathrm{Aa} \beta}$ & $36 \pm 6^{\mathrm{Aa} \beta}$ \\
\hline & \multirow{3}{*}{ Ob } & 15 & $26 \pm 18^{\mathrm{Aa} \alpha}$ & $28 \pm 13^{\text {Aa } \alpha}$ & $30 \pm 12^{\mathrm{Aa} \alpha}$ & $31 \pm 12^{\mathrm{Aba}}$ & $31 \pm 11^{\mathrm{Aa} \alpha}$ \\
\hline & & 30 & $21 \pm 11^{\mathrm{Aa} \alpha}$ & $24 \pm 5^{\mathrm{Aa} \alpha}$ & $31 \pm 2^{\mathrm{Aa} \beta}$ & $32 \pm 3^{\mathrm{Aa} \beta}$ & $33 \pm 2^{\mathrm{Aa} \beta}$ \\
\hline & & 45 & $28 \pm 6^{\mathrm{Ab} \alpha}$ & $30 \pm 5^{\mathrm{Aa \alpha}}$ & $37 \pm 5^{\mathrm{Aa \beta}}$ & $39 \pm 5^{\mathrm{Aa} \beta}$ & $39 \pm 5^{\mathrm{Aa \beta}}$ \\
\hline
\end{tabular}

Dados expressos em percentual médio de bloqueio $(\%) \pm$ desvio padrão. C: grupo controle submetido à dieta normocalórica por 15 $(n=8), 30(n=7)$ e $45(n=8)$ semanas de tratamento; Ob: grupo obeso submetido à dieta hipercalórica por $15(n=10), 30(n=11)$ e 45 (n=6) semanas de tratamento; concentração de ácido ciclopiazônico: $30 \mu \mathrm{M}$; TD: tensão máxima desenvolvida; +dT/dt: velocidade máxima de variação da tensão desenvolvida; -dT/dt: velocidade máxima de variação de decréscimo da tensão desenvolvida. Análise de variância (ANOVA) para o modelo de medidas repetidas para grupos independentes e complementada com o teste de comparações múltiplas de Student-Newman-Keuls. Letras maiúsculas (vertical) indicam comparação entre os momentos fixado o grupo; letras minúsculas (vertical) indicam comparação entre os grupos fixado o momento. Letras gregas (horizontal) indicam comparação dos efeitos do bloqueio do ácido ciclopiazônico nas diferentes concentrações de cálcio; Letras diferentes indicam diferença significativa $(p<0,05)$. 


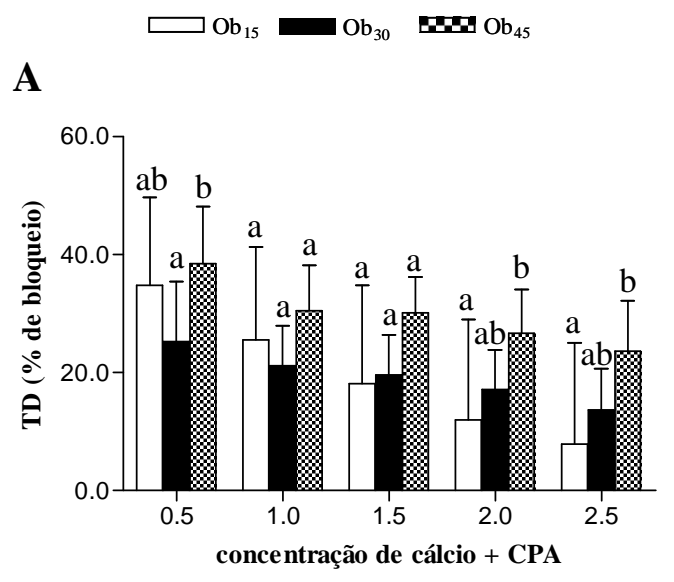

B

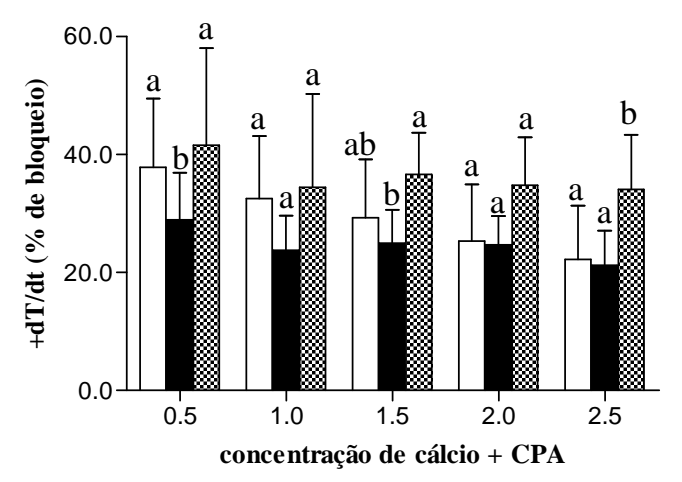

C

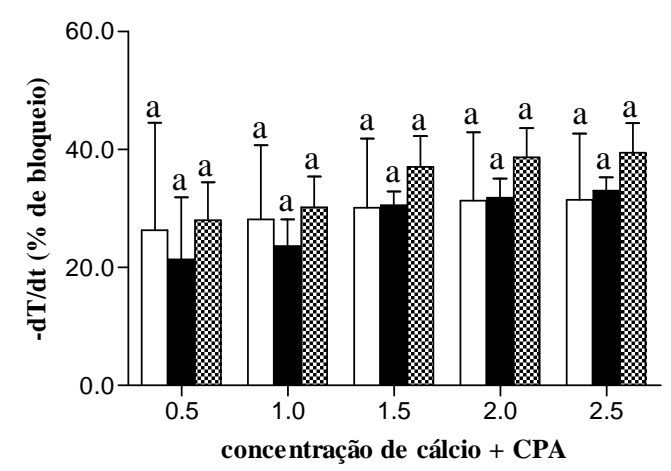

Figura 20. Efeitos do bloqueio $(\%)$ da $\mathrm{Ca}^{+2}$ ATPase do retículo sarcoplasmático com ácido ciclopiazônico $(30 \mu \mathrm{M})$ sobre o músculo papilar de ratos obesos. Ob: grupo obeso submetido à dieta hipercalórica por $15(n=10), 30(n=11)$ e $45(n=6)$ semanas de tratamento; A: TD (tensão máxima desenvolvida); B: +dT/dt (velocidade máxima de variação da tensão desenvolvida); C: -dT/dt (velocidade máxima de variação de decréscimo da tensão desenvolvida). Dados expressos em percentual médio de bloqueio $(\%) \pm$ desvio padrão. Letras minúsculas indicam comparação entre os momentos fixado o grupo obeso; Letras diferentes indicam diferenças significativas entre os grupos obesos $(\mathrm{p}<0,05)$. Análise de variância (ANOVA) para o modelo de medidas repetidas para grupos independentes e complementada com o teste de comparações múltiplas de Student-Newman-Keuls.

\subsubsection{1- Determinação do teor de água nos tecidos cardíaco, pulmonar e hepático}

A Tabela 12 mostra teor de água nos tecidos cardíaco, pulmonar e hepático dos ratos $\mathrm{C}_{15}, \mathrm{C}_{30}, \mathrm{C}_{45}, \mathrm{Ob}_{15}, \mathrm{Ob}_{30}$, e $\mathrm{Ob}_{45}$. A comparação entre os três momentos, fixados os grupos, mostra que o tempo de exposição aos tratamentos não modificou a teor de água nos tecidos cardíaco, pulmonar e hepático em ambos os grupos.

A comparação entre os dois grupos, fixados os momentos, mostra que a quantidade de água no fígado foi menor no grupo $\mathrm{Ob}_{15}$ em relação ao $\mathrm{C}_{15}$. A obesidade não acarretou 
alterações no teor de água no VE, VD, AT e pulmão entre os grupos em todos os momentos avaliados.

$\underline{\text { Tabela 12. Teor de água nos tecidos cardíaco, pulmonar e hepático }}$

\begin{tabular}{|c|c|c|c|c|}
\hline \multirow[b]{2}{*}{ Variáveis } & \multirow[b]{2}{*}{ Grupos } & \multicolumn{3}{|c|}{ Tratamento } \\
\hline & & 15 sem & 30 sem & 45 sem \\
\hline \multirow{2}{*}{ VE $(\%)$} & $\mathbf{C}$ & $75 \pm 1^{\mathrm{Aa}}$ & $75 \pm 3^{\mathrm{Aa}}$ & $74 \pm 2^{\mathrm{Aa}}$ \\
\hline & $\mathbf{O b}$ & $75 \pm 1^{\mathrm{Aa}}$ & $75 \pm 1^{\mathrm{Aa}}$ & $75 \pm 3^{\mathrm{Aa}}$ \\
\hline \multirow{2}{*}{ VD $(\%)$} & $\mathbf{C}$ & $76 \pm 1^{\mathrm{Aa}}$ & $76 \pm 3^{\mathrm{Aa}}$ & $75 \pm 2^{\mathrm{Aa}}$ \\
\hline & Ob & $76 \pm 1^{\mathrm{Aa}}$ & $75 \pm 1^{\mathrm{Aa}}$ & $75 \pm 3^{\text {Aa }}$ \\
\hline \multirow{2}{*}{ AT (\%) } & $\mathbf{C}$ & $78 \pm 1^{\mathrm{Aa}}$ & $76 \pm 2^{\mathrm{Aa}}$ & $76 \pm 4^{\mathrm{Aa}}$ \\
\hline & Ob & $77 \pm 2^{\mathrm{Aa}}$ & $77 \pm 2^{\mathrm{Aa}}$ & $77 \pm 2^{\mathrm{Aa}}$ \\
\hline \multirow{2}{*}{ Pulmão (\%) } & $\mathbf{C}$ & $78 \pm 1^{\mathrm{Aa}}$ & $78 \pm 2^{\mathrm{Aa}}$ & $78 \pm 1^{\mathrm{Aa}}$ \\
\hline & $\mathbf{O b}$ & $78 \pm 1^{\mathrm{Aa}}$ & $78 \pm 1^{\mathrm{Aa}}$ & $78 \pm 1^{\mathrm{Aa}}$ \\
\hline \multirow{2}{*}{ Fígado (\%) } & $\mathbf{C}$ & $68 \pm 1^{\mathrm{Aa}}$ & $68 \pm 2^{\mathrm{Aa}}$ & $68 \pm 1^{\mathrm{Aa}}$ \\
\hline & Ob & $66 \pm 1^{\mathrm{Ab}}$ & $67 \pm 1^{\mathrm{Aa}}$ & $67 \pm 1^{\mathrm{Aa}}$ \\
\hline $\begin{array}{l}\text { Dados expressos em média } \pm \\
30(\mathrm{n}=17) \text { e } 45(\mathrm{n}=20) \text { seman } \\
30(\mathrm{n}=20) \text { e } 45(\mathrm{n}=15) \text { sem } \\
\text { fixado o grupo; letras minús } \\
\text { indicam diferença significati } \\
\text { complementada com o teste d }\end{array}$ & $\begin{array}{l}\text { ão. C: grupc } \\
\text { ento; Ob: gi } \\
\text { amento; Le } \\
\text { m comparas } \\
\text { Análise d } \\
\text { ges múltinla }\end{array}$ & $\begin{array}{l}\text { ontrole subm } \\
\text { oo obeso subn } \\
\text { s maiúsculas } \\
\text { entre os gru }\end{array}$ & $\begin{array}{l}\text { dieta normoc } \\
\text { dieta hiperc } \\
\text { n comparaçã } \\
\text { ado o mome } \\
\text { para o esqu }\end{array}$ & $\begin{array}{l}\text { a por } 15(\mathrm{n}= \\
\text { ca por } 15(\mathrm{n}= \\
\text { tre os mome } \\
\text { Letras difere } \\
\text { de dois fat }\end{array}$ \\
\hline
\end{tabular}




\section{DISCUSSÃO}

\section{1- Modelo experimental de obesidade}

Os resultados obtidos mostraram que a dieta hiperlipídica promoveu obesidade a partir da $3^{\text {a }}$ semana de tratamento; o peso e a gordura corporal total e o índice de adiposidade foram maiores nos animais $\mathrm{Ob}_{0}$ em relação ao $\mathrm{C}_{0}$. A determinação do momento inicial da obesidade permitiu avaliarmos com precisão a influência do tempo de exposição à obesidade. Poucos estudos que induzem obesidade por dieta hiperlipídica verificam o início da obesidade. ${ }^{(148)}$ Levin et $\mathrm{al}^{(148)}$ definiram o momento inicial da obesidade, em ratos Sprague-Dawley, após constatarem que os animais alimentados com dieta rica em carboidratos tornavam-se obesos na $4^{\mathrm{a}}$ semana de tratamento.

Um aspecto importante que deve ser ressaltado neste trabalho foi o uso de um critério de classificação que, a partir do índice de adiposidade, permitiu utilizar animais verdadeiramente obesos e controles. Na experimentação biológica, em especial estudos experimentais, mesmo quando mantidas as condições laboratoriais semelhantes, não está assegurada uma homogeneidade de resposta. Por exemplo, animais submetidos às dietas normocalórica e hipercalórica poderiam apresentar, em maior ou menor escala, características comuns, como, o índice de adiposidade. Este fato poderia levar a resultados discrepantes porque não ocorreria heterogeneidade dos dados entre os grupos. Neste sentido, com a finalidade de diferenciar os grupos foi utilizado o critério de separação descrito na seção de material e métodos. As perdas por não adesão ao procedimento utilizado para a composição dos grupos foram, respectivamente, nos grupos controles $\left(\mathrm{C}_{15}=36,7 \% ; \mathrm{C}_{30}=33,3 \% ; \mathrm{C}_{45}=\right.$ $26,6 \%)$ e obesos $\left(\mathrm{Ob}_{15}=40 \% ; \mathrm{Ob}_{30}=30 \% ; \mathrm{Ob}_{45}=33,3 \%\right)$. Nascimento et al ${ }^{(105)}$ utilizando critério semelhante, a partir da mensuração da gordura na carcaça para a constituição dos grupos controle e obeso, verificaram resultados divergentes dos encontrados em nosso estudo, desde que, ocorreram perdas menores de animais em ambos os grupos. Alguns estudos 
separam os animais obesos baseados na freqüência de distribuição do ganho de peso; assim os animais que apresentam maiores e menores ganhos de peso são classificados como obesos e resistentes à obesidade, respectivamente. ${ }^{(107,148)}$

Embora tenha ocorrido descarte de animais neste estudo, é fundamental ressaltar que a literatura não realiza este tipo de separação e assume que todos os animais apresentam características distintas quando alimentados com dietas diferentes. Este fato poderia levar a erros de classificação, desde que, provavelmente, a ausência de um procedimento como o usado neste estudo, possibilita que sejam utilizados animais do grupo controle com características de ratos obesos e vice-versa. O modelo de dieta hiperlipídica utilizado no presente estudo, mesmo com as perdas observadas, foi de intensidade e duração suficiente para promover obesidade em ratos ao longo dos três períodos experimentais; o tempo de exposição aos tratamentos, após 15, 30 e 45 semanas, promoveu aumento do índice de adiposidade em relação aos respectivos controles. Outro aspecto importante é que, se usarmos qualquer variável relacionada com taxa de gordura corporal, seria também detectado obesidade nos animais tratados com dieta hiperlipídica em relação aos controles.

Embora a dieta hiperlipídica tenha ocasionado obesidade nos três momentos, o tempo de exposição à dieta não acarretou aumento proporcional no índice de adiposidade. O resultado mais consistente foi encontrado entre os grupos de 30 e 45 semanas. Entretanto, se utilizarmos os outros parâmetros analisados no trabalho, que também são usados na literatura como medidas de obesidade, ${ }^{(51,53,105,110,111,148)}$ pode se verificar diferenças de comportamento entre o índice de adiposidade e as outras variáveis, o que poderia levar a interpretações e conclusões divergentes. Por exemplo, o tempo de exposição à dieta hiperlipídica promoveu maior elevação da gordura corporal após 45 semanas de tratamento entre os grupos obesos; entretanto, este resultado não foi acompanhado pelo índice de adiposidade. Este fato pode ter ocorrido devido à maior elevação do depósito de gordura visceral no grupo de 45 semanas em 
relação aos demais grupos, o que conseqüentemente resultou em aumento da gordura coporal neste grupo. Diversos trabalhos experimentais que utilizaram dieta hiperlipídica para promover obesidade em ratos, por curtos e longos períodos, observaram aumento do índice de adiposidade. ${ }^{(51,53,105,106,111,148-150)}$

O desenvolvimento de obesidade em relação aos controles nos três períodos de tratamento ocorreu mesmo com os animais ingerindo menor quantidade de dieta hiperlipídica. Segundo Pereira et $a l,{ }^{(47)}$ as mudanças na composição dos nutrientes ou no tipo da dieta podem alterar a eficiência alimentar e, conseqüentemente, aumentar os estoques de gordura por caloria consumida. A elevação da ingestão calórica, visualizada nos animais obesos e ocasionada pelo aumento da densidade energética da dieta hiperlipídica, foi o fator responsável pelo excesso de adiposidade nesses animais, desde que, a eficiência alimentar foi maior somente após 15 semanas. A literatura mostra que o maior consumo de gordura pode não ser acompanhado de elevação na sua oxidação, o que favorece o maior acúmulo de tecido adiposo em animais alimentados com dietas hiperlipídicas. ${ }^{(151,152)}$

Outro aspecto importante que deve ser ressaltado foi que a obesidade não aumentou proporcionalmente com os períodos de tratamento. A variação no ganho de peso corporal é dependente da razão entre o consumo e gasto energético. O envelhecimento promove diminuição da taxa metabólica basal ${ }^{(153)}$ e como conseqüência pode acarretar elevação da gordura corporal, desde que mantida o aporte energético. Neste sentido, o aumento da gordura corporal nos animais obesos entre 30 e 45 semanas foi decorrente da acentuação do processo de envelhecimento. Embora o envelhecimento tenha acarretado diminuição da eficiência alimentar em ambos os grupos, o maior aporte energético constante nos animais obesos durante os períodos de tratamento, resultou na elevação da gordura corporal, mesmo com redução da capacidade de transformar calorias consumidas em ganho de peso. 
Trabalhos têm utilizado dietas altamentes ricas em gordura para acarretar obesidade em roedores; ${ }^{(51,54,109-112)}$ entretanto, é importante evitar a redução da relação proteína/energia a fim de não causar danos no desenvolvimento e no crescimento dos animais. ${ }^{(47)}$ Neste sentido, esta relação não foi prejudicada em nossos ratos, uma vez que, a quantidade de proteína ao longo dos três períodos de tratamento foram normais e elevadas em relação aos respectivos controles.

A obesidade tem sido freqüentemente associada com diversas comorbidades, como intolerância à glicose, resistência à insulina, hipertensão arterial, hiperinsulinemia, hiperleptinemia e dislipidemias. ${ }^{(51,52,103,106-112)}$ Neste estudo, a obesidade acarretou comorbidades de acordo com o momento analisado; por exemplo, a hipercolesterolemia em 15 semanas e a hiperglicemia e a hipertrigliceridemia após 30 semanas. Por outro lado, a intolerância à glicose, hiperinsulinemia, hiperleptinemia e resistência à insulina ocorreram em todos os momentos de avaliação. A obesidade não foi capaz de elevar a pressão arterial após 15, 30 e 45 semanas. Além disso, o tempo de exposição à obesidade não alterou o comportamento da PAS. Os mecanismos responsáveis pela alteração da pressão arterial, incluem a hiperatividade do sistema nervoso simpático, ${ }^{(154)}$ aumento da atividade do sistema renina-angiotensina-aldosterona $(\text { SRAA })^{(53,58,107-108)}$ e estresse oxidativo, ${ }^{(154)}$ os quais acarretam vasoconstrição periférica e aumento da reabsorção de sódio renal. A ausência de alteração na pressão arterial, provavelmente, reflete que a obesidade não alterou os fatores envolvidos no controle da pressão arterial. Os resultados deste estudo estão em concordância com alguns autores que não observaram alteração da PAS em animais obesos; ${ }^{(51,52)}$ entretanto, diverge de pesquisas em animais obesos que mostraram elevação dos níveis da PAS. ${ }^{(53,106-108)}$

Embora o aparecimento de comorbidades esteja relacionado com o tempo de obesidade ${ }^{(23,34,39,44)}$ este estudo mostrou que o aumento da duração não alterou, elevou ou diminuiu a intensidade das comorbidades. Assim, enquanto a intolerância à glicose, presente 
nos três períodos, permaneceu inalterada, a hipersinsulinemia constatada nos animais $\mathrm{Ob}_{30} \mathrm{e}$ $\mathrm{Ob}_{45}$, foi mais intensa nos $\mathrm{Ob}_{45}$.

Os resultados séricos da glicose mostraram, como referido acima, hiperglicemia basal somente no período de 30 semanas, entretanto, o tempo de exposição à obesidade não influenciou esta variável entre os animais obesos. O aumento da concentração de glicose pode ter sido causado pela elevação dos níveis de triglicérides séricos que promove elevação da produção hepática de glicose. ${ }^{(155)}$ Apesar deste aumento da glicemia de jejum no grupo $\mathrm{Ob}_{30}$, a sobrecarga de glicose nos grupos obesos acarretou intolerância à glicose ao longo dos três períodos de tratamento, uma vez que, estes ratos apresentaram perfis e áreas glicêmicas maiores em relação aos seus respectivos grupos controles. Outro aspecto importante, é que o tempo de exposição à obesidade não influenciou o perfil glicêmico entre os animais obesos, pois a intolerância à glicose inicialmente visualizada na $15^{\mathrm{a}}$ semana permaneceu até a $45^{\mathrm{a}}$ semana do protocolo experimental. A intolerância à glicose, estágio intermediário entre a homestase normal da glicose e o diabetes mellitus tipo $2,{ }^{(47)}$ deve estar relacionado com o desenvolvimento de resistência à insulina nos animais obesos. Portanto, hiperglicemia poderia estar relacionada com aumento da produção de glicose e resistência à ação da insulina.

Em favor desta suposição, nossos dados mostram que a obesidade acarretou hiperinsulinemia após 30 e 45 semanas, que se intensificou na $45^{\mathrm{a}}$ semana de tratamento. No grupo 15 semanas houve uma tendência $(p=0,051)$ de se observar hiperinsulinemia. As ações biológicas da insulina são essenciais para a regulação e a manutenção da homeostase da glicose ${ }^{(156)}$ A resistência à insulina, tipicamente definida pela diminuição da sensibilidade ou da resposta à ação metabólica da insulina, exerce um papel importante na fisiopatologia da obesidade. ${ }^{(157)}$ A resistência à ação da insulina ocorre quando os níveis circulantes normais deste hormônio são insuficientes para regular este processo. ${ }^{(158)}$ Nesta situação, as células $\beta$ do pâncreas secretam maiores quantidades de insulina, condição denominada 
hiperinsulinemia, acarretando aumento da captação de glicose, na tentativa de manter os níveis séricos glicêmicos normais. ${ }^{(159)}$ Nossos dados permitem sugerir que a obesidade, em todos os momentos avaliados, acarretou resistência à insulina, embora este resultado não tenha sido visualizado pelo teste de tolerância à insulina. A resistência à ação da insulina pode ser ocasionada por alterações nos números de receptores, na afinidade da insulina e na sinalização insulínica. ${ }^{(160,161)}$ Diversos pesquisadores têm observado que a resistência à insulina em modelos experimentais de obesidade pode estar associada às anormalidades no transportador da glicose 4 (GLUT4). ${ }^{(162,163)}$ Dentro deste contexto, podemos inferir que a resistência à insulina, visualizada pelo índice HOMA, pode ter ocorrido em nível de transporte de glicose (GLUT4), indicando que a sinalização insulínica estaria preservada.

Outro aspecto importante que deve ser ressaltado é a relação entre os tipos de ácidos graxos na dieta hiperlipídica e a sensibilidade à ação da insulina. A dieta hiperlipídica utilizada foi constituída por uma mistura de ácidos graxos mono (ômega-9) e polinsaturados (ômega-6), representando $78 \%$ da gordura fornecida ao animais obesos. Na literatura, há evidências consideráveis em experimentação animal, que a gordura saturada prejudica, enquanto que os ácidos graxos polinsaturados (ômega-3) melhoram à ação da insulina. ${ }^{(164)}$ As gorduras mono (ômega-9) e polinsaturadas (omêga 6) também acarretam resistência à insulina, embora em menor proporção do que a saturada. ${ }^{(164)}$ Storlien et al ${ }^{(164)}$ observaram que dietas ricas em ácidos graxos saturados, monoinsaturados (ômega-9) ou polinsaturados (ômega-6) levam à resistência à insulina que pode ser prevenida pela substituição destes ácidos pelos de cadeia longa (ômega-3) dos óleos de peixe.

Os resultados deste estudo estão de acordo com autores que observaram que a obesidade induzida por dieta hiperlipídica insaturada promove intolerância à glicose, hiperinsulinemia e resistência à insulina em períodos $\operatorname{curtos}^{(52,104,109,111,165-167)}$ e prolongados. ${ }^{(112)}$ 
Neste trabalho foi constatado que a obesidade aumentou as concentrações séricas de leptina após 15, 30 e 45 semanas em relação aos respectivos controles. O tempo de exposição à obesidade influenciou no nível deste hormônio; entretanto, não houve aumento proporcional das concentrações de leptina ao longo do tempo, permanecendo constante entre os animais $\mathrm{Ob}_{30}$ e $\mathrm{Ob}_{45}(\mathrm{p}=0,10)$. Esse dado contrasta com o índice de adiposidade que aumentou significantemente entre 30 e 45 semanas. A leptina é produzida pelo tecido adiposo e age no sistema nervoso aumentando a saciedade. ${ }^{(154,168)}$ O níveis de leptina se correlacionam com a quantidade de gordura corporal, diminuindo a lipogênese e aumentando a lipólise. ${ }^{(169)}$ Atualmente tem sido relatado que as dietas hiperlipídicas inibem a ação da leptina, e como conseqüência elevam a ingestão alimentar devido a falha no mecanismo da saciedade e acarretam aumento da adiposidade. ${ }^{(169,170)}$ Entretanto, no presente estudo, a diminuição da ingestão alimentar nos animais obesos em relação aos respectivos controles sugere que a hiperleptinemia foi efetiva no controle do balanço energético, regulando em todos os momentos, o consumo alimentar. Nossos resultados estão em concordância com autores que verificaram que a obesidade induzida por dietas ricas em gordura eleva as concentrações de leptina; no entanto, a maioria destes estudos encontram resistência à ação deste hormônio, acarretando hiperfagia. ${ }^{(59,111)}$

Dietas ricas em gorduras têm sido extensivamente usadas em roedores para fornecer modelos experimentais de síndrome metabólica que, associam, entre outros, obesidade e dislipidemias. ${ }^{(171)}$ Neste estudo, a obesidade não modificou de maneira consistente o perfil lipídico ao longo dos três períodos de tratamento. Na literatura é bem descrito que a displipidemia em animais e humanos obesos é caracterizada por elevação dos níveis de TG, LDL e ácidos graxos não-esterificados (NEFA) e diminuição dos níveis séricos de HDL. ${ }^{(172,173)}$ Segundo Sinitskaya et al, ${ }^{(171)}$ a caracterização da dislipidemia é difícil em ratos, mesmo após modificações na razão carboidratos/gordura. Embora nosso modelo experimental 
de obesidade tenha falhado em promover alterações importantes nos níveis circulantes de lipídios, como aumento do LDL e diminuição do HDL, alguns resultados isolados foram observados, como por exemplo, hipercolesterolemia e elevação dos níveis de ácidos graxos não-esterificados após 15 semanas de obesidade e, aumento dos níveis de TG na 30ª semana e tendência a elevação $(\mathrm{p}=0,10)$ nos animais $\mathrm{Ob}_{15}$ em relação aos respectivos controles. Zammit et $\mathrm{al}^{(174)}$ relatam que a hipertrigliceridemia induzida pela dieta hiperlipídica pode ser resultado do aumento da absorção dos TG na forma de quilomícrons, da elevação da produção endógena das VLDL, e/ou diminuição da captura de TG pelos tecidos periféricos. A ausência de diferença nos animais $\mathrm{Ob}_{45}$ pode ser devido à maior capacidade de captação de TG pelo tecido adiposo visualizado ao se analisar o índice de adiposidade neste grupo, que se mostrou aumentado em relação ao $\mathrm{Ob}_{30}$. Embora a obesidade durante 15 semanas tenha promovido hipercolesterolemia, este resultado pode ser devido ao nível baixo de colesterol encontrado no grupo $\mathrm{C}_{15}$.

As concentrações de ácidos graxos não-esterificados (NEFA) são usadas para indicar a mobilização de gordura durante período insuficiente de consumo de energia. ${ }^{(175)}$ Neste trabalho, os resultados dos níveis de NEFA mostram alterações entre os grupos controle e obeso somente após 15 semanas de tratamento; houve influência do tempo de exposição à obesidade entre os grupos obesos 30 e 45 semanas para esta variável. A liberação de ácidos graxos dos adipócitos depende da taxa de lipólise de TG mediada pela lipase hormôniosensível. ${ }^{(176)}$ Esta enzima é regulada pelas catecolaminas, adrenalina e noradrenalina, que a ativam e pela insulina, que a inibe. Quando não está inibida, a lipase hormônio-sensível remove abundante quantidade de TG dos adipócitos, que são lançados na circulação na forma de ácidos graxos livres e captados pelos hepatócitos. Neste estudo, a ausência de alterações nos níveis circulantes de NEFA, entre os grupos controles e obesos, após 30 e 45 semanas, pode ter ocorrido pela hiperinsulinemia observada na $30^{\mathrm{a}}$ e $45^{\mathrm{a}}$ semana de obesidade. $\mathrm{O}$ 
aumento dos níveis de insulina pode ter bloqueado a atividade da lipase hormônio-sensível, diminuindo a liberação de ácidos graxos.

A obesidade não modificou as concentrações séricas de HDL ao longo do tempo em relação aos respectivos controles. O tempo também não influenciou os níveis de HDL entre os grupos obesos. Segundo Mahan et al, ${ }^{(177)}$ os efeitos dos ácidos graxos monoinsaturados sobre HDL-colesterol dependem do conteúdo total de gordura da dieta. À medida que se aumenta o nível de lipídios e ácidos graxos monoinsaturados da dieta, o HDL-colesterol aumenta levemente, comparando à dieta com menor nível lipídico. A ausência de alteração nos níveis de HDL entre os grupos pode ter ocorrido porque na composição da dieta hiperlipídica, há maior quantidade de ácidos graxos monoinsaturados, levando conseqüentemente, a estabilização ou aumento dos níveis de HDL. Um achado divergente do que geralmente é encontrado na literatura foi a diminuição do LDL nos animais obesos após 30 e 45 semanas em relação aos respectivos controles, uma vez que, a obesidade promove aumento dos níveis de LDL, conforme descrito anteriormente. ${ }^{(172,173)}$ Este comportamento pode ter ocorrido devido à composição da dieta utilizada neste estudo, predominantemente insaturada. Estudos mostram que a gordura insaturada na dieta reduz substancialmente os níveis de colesterol. ${ }^{(178,179)}$ Em contrapartida os ácidos graxos saturados, na sua maioria, aumentam os níveis séricos das lipoproteínas, principalmente as de baixa densidade (LDL), pois reduzem a síntese e atividade dos receptores LDL. ${ }^{(180,181)}$

\section{2- Obesidade e remodelação cardíaca}

Remodelação cardíaca pode ser definida como alterações moleculares, celulares e intersticiais que se manifestam clinicamente por modificações no tamanho, na forma e função do coração após uma agressão, sendo que, este processo pode ocorrer de forma fisiológica ou patológica. ${ }^{(182)} \mathrm{Na}$ obesidade existem diversas evidências, estruturais e funcionais, que o 
processo de remodelação ocorre tanto em humanos quanto em roedores. ${ }^{(55)}$ Entres as mudanças geralmente observadas podemos citar, hipertrofia do ventrículo esquerdo, dilatação do átrio esquerdo, elevação da massa do ventrículo esquerdo, modificações na cavidade do VE, prejuízo da função diastólica e sistólica e fibrose intersticial.

\subsection{1- Influência da obesidade sobre a estrutura cardíaca}

A obesidade, nos diversos momentos de avaliação, acarretou alterações morfológicas típicas de remodelamento cardíaco. Estas modificações, analisadas por quatro metodologias, pesagem do coração post mortem, ecocardiograma, área seccional transversa do miócito e fração de colágeno miocárdico, variaram de acordo com o tempo de exposição à obesidade, parâmetros analisados e metodologias utilizadas. Por exemplo, um dado que mostrou a divergência dos resultados em razão da metodologia foi o comportamento do peso do VE no grupo $\mathrm{Ob}_{45}$; enquanto no post mortem estes animais não apresentaram diferença em relação ao controle, os dados ecocardiográficos mostraram elevação da massa do VE no grupo $\mathrm{Ob}_{45}$.

O estudo macroscópico post mortem mostrou que a obesidade acarretou hipertrofia cardíaca no momento 15 semanas. Entretanto, o processo hipertrófico que ocorreu, consistentemente na $15^{\mathrm{a}}$ semana, não foi constatado após 45 semanas de obesidade. $\mathrm{Na} 30^{\mathrm{a}}$ semana de obesidade, a remodelação cardíaca também foi observada, embora não tenha sido possível mostrar diferença estatística nos pesos do VE $(p=0,07)$, do AT $(p=0,09)$ e na relação coração/Tíbia $(\mathrm{p}=0,052)$ entre os grupos. A influência do tempo de exposição à obesidade sobre o processo de remodelação cardíaca post mortem, presente ou ausente, dependeu da variável utilizada. Quando o parâmetro foi analisado isoladamente, houve somente alteração a nível atrial. Outro método utilizado é a normalização do coração e das câmaras cardíacas pelo comprimento da tíbia, ${ }^{(65,183,184)}$ analogia de correção para a altura que se utiliza em humanos. ${ }^{(185)}$ Esta metodologia foi aplicada, pois o comprimento da tíbia apresenta menos 
variação do que o peso corporal. A normalização destes parâmetros pelo comprimento da tíbia acarretou diminuição do processo de remodelação, provavelmente, devido ao maior crescimento da tíbia ao longo do tempo.

A remodelação cardíaca pode também ser analisada normalizando-se os pesos do coração e de seus componentes pelo peso corporal. ${ }^{(183)}$ No entanto, segundo Okoshi, ${ }^{(186)}$ a própria normalização pode induzir a erros de interpretação dos resultados, uma vez que, as modificações nas medidas cardíacas podem não ser proporcionais às variações do peso corporal. Neste trabalho, o aumento do coração nos animais obesos não foi proporcional à elevação dos pesos corporais, após 15, 30 e 45 semanas; assim, a utilização deste índice poderia subestimar o grau de hipertrofia.

A segunda metodologia utilizada para avaliar a estrutura cardíaca, o ecocardiograma, permitiu diferentemente do estudo post mortem, analisar o diâmetro e a espessura das cavidades cardíacas in vivo. Os dados medidos, durante a diástole e a sístole ventricular, mostraram que a obesidade, em todos os períodos analisados, promoveu alterações nos diversos índices que avaliam a remodelação cardíaca. A hipertrofia do ventrículo esquerdo foi visualizada nos grupos obesos de 15, 30 e 45 semanas, desde que, ocorreram aumentos da EDSIV, da EDPP, da massa e da espessura relativa do VE em relação aos respectivos controles. O tempo de exposição à obesidade promoveu aumento do processo de remodelação cardíaca observada pela elevação proporcional da EDPP, da EDSIV e da espessura relativa do VE. A análise comparativa entre o estudo ecocardiográfico e morfológico post mortem mostrou que o tempo de exposição à obesidade apresentou resultados divergentes em relação ao comportamento do VE; enquanto o ecocardiograma permite inferir que a obesidade intensificou a hipertrofia do VE, a análise anatômica não mostrou alterações desta câmara ao longo do tempo. 
Os dados deste experimento estão de acordo com diversas pesquisas que mostraram que a obesidade induzida por dieta hiperlipídica promoveu remodelação cardíaca avaliada por ecocardiograma ${ }^{(51)}$ e morfologia post mortem. ${ }^{(54,106)}$ Entretanto, Carrol et al ${ }^{(51)}$ divergiram dos nossos resultados, uma vez que, mostraram que ratos obesos, alimentados por 12 semanas, não apresentaram remodelação do coração. Não há referências na literatura a respeito da influência do tempo de exposição à obesidade sobre o processo de remodelação cardíaca estrutural.

A análise da hipertrofia cardíaca também foi analisada pela mensuração da área seccional transversa do miócito (AST), corados com hematoxilina-eosina (HE). ${ }^{(121)}$ Embora, a coloração com HE seja freqüentemente utilizada em diversos trabalhos experimentais, ${ }^{(51,53,60,121)}$ em nosso estudo as lâminas de VE não apresentaram qualidade suficiente para leitura. A técnica de reticulina de Gomori foi utilizada, pela primeira vez, como alternativa para a mensuração da AST dos fragmentos do VE, embora a literatura não utilize esta técnica para a medida da AST. Embora, a obesidade após 45 semanas promoveu elevação da AST do VE em relação ao respectivo controle, na $30^{\mathrm{a}}$ semana também houve tendência $(\mathrm{p}=0,09)$ de se observar hipertrofia do VE. O tempo de exposição à obesidade, a nível microscópico, não acarretou alteração na AST dos fragmentos da parede subendocárdica do VE e do músculo papilar. Outro aspecto importante, é que as alterações induzidas pela obesidade no VE não foram observadas no músculo papilar. Este comportamento pode ser atribuído à técnica utilizada para a mensuração do músculo papilar, desde que, as lâminas não apresentaram boa qualidade de leitura. Os dados encontrados na AST do VE divergem parcialmente dos dados anatômicos post mortem e ecocardiográficos referidos anteriormente. Os resultados obtidos na AST do VE estão em divergência com outros pesquisadores, ${ }^{(51,53)}$ que mostraram área seccional do miócito inalterada em ratos obesos alimentados por dieta 
hiperlipídica durante 12 e 17 semanas. Não foram encontrados trabalhos que avaliaram a área seccional do miócito ao longo do tempo de obesidade.

A remodelação cardíaca estrutural tem como finalidade adaptar o coração às sobrecargas de trabalho impostas, por exemplo, pela obesidade. A hipertrofia do miócito ocorre como resposta adaptativa às variações de cargas pressóricas e volume e/ou perturbações metabólicas. ${ }^{(187)}$ Segundo Fiedler et al, ${ }^{(188)}$ uma resposta adaptativa pode se tornar prejudicial e contribuir para a disfunção cardíaca. Neste trabalho, a partir dos resultados obtidos, podemos sugerir que a obesidade acarretou remodelação cardíaca de magnitude mais fisiológica do que patológica. Na obesidade, geralmente, tem sido observado hipertrofia cardíaca do tipo excêntrica, ${ }^{(34,35,44)}$ a qual ocorre em resposta à uma sobrecarga de volume, acarretando aumento dos sarcômeros em série; ${ }^{(120)}$ entretanto, também pode ocorrer remodelamento concêntrico, onde o padrão geométrico do VE se altera por adição de sarcômeros em paralelo, em virtude de sobrecarga pressórica. A literatura mostra que longos períodos de obesidade estão associados com hipertrofia excêntrica, e que poucos estudos reportam remodelação concêntrica do coração na ausência de comorbidades como a hipertensão arterial. $^{(23,44)}$ Neste estudo, embora a pressão arterial manteve-se inalterada, a obesidade, após 30 e 45 semanas, acarretou hipertrofia do tipo concêntrica, em razão do diâmetro normal do VE, do aumento da espessura relativa do VE e da elevação da área seccional do VE nos animais obesos. Entretanto, não há evidências consistentes que a obesidade, após 15 semanas, promoveu hipertrofia concêntrica, desde que, a espessura relativa do VE não alterou entre os grupos obesos e controle. O estímulo para a remodelação cardíaca ocorre por fatores mecânicos e bioquímicos, que agem nos receptores, canais iônicos e integrinas presentes na membrana sarcolemal, ativando sinalizadores bioquímicos citosólicos que desencadeiam alterações na expressão gênica e aumento da síntese de proteínas. ${ }^{(118,189)}$ Atualmente, sabe-se que o adipócito recebe influência de diversas 
substâncias, como insulina, cortisol, catecolaminas, glucagon, hormônios tireoidianos, e, em resposta secreta inúmeros peptídeos que podem atuar diretamente ou indiretamente na remodelação cardiovascular, como leptina, adiponectina, renina, angiotensinogênio, angiotensina I e II e receptores, enzima de conversão da angiotensina (ECA), resistina, fator de necrose tumoral $\alpha$ (TNF- $\alpha$ ), inibidor do ativador de plasminogênio (PAI-1) e interleucina 6 (IL-6). ${ }^{(190,191)} \mathrm{O}$ aumento da leptina e insulina pelo tecido adiposo está associado com ativação do sistema nervoso simpático. ${ }^{(154)}$ Desta forma, alguns sinalizadores oriundos do tecido adiposo podem ter acarretado hipertrofia cardíaca nos animais obesos. Neste trabalho, a hiperleptinemia pode ter influenciado o processo de remodelação, agindo diretamente ou indiretamente, ativando o sistema nervoso autônomo simpático. ${ }^{(154)}$ A insulina é um hormônio que estimula a síntese de proteínas, inibindo a quebra protéica no coração. ${ }^{(192-194)}$ Desde que, estudos clínicos têm observado uma relação positiva entre insulina e hipertrofia cardíaca do VE ${ }^{(195,196)}$ neste estudo, pode-se sugerir que a hipersinsulinemia ocasionada pela obesidade também participou deste processo de remodelação.

Nesta investigação, a obesidade não promoveu variações no colágeno intersticial do VE em relação aos respectivos controles, em todos os períodos de tratamento; entretanto, houve aumento de colágeno no músculo papilar de ratos obesos em relação ao controle após 45 semanas de tratamento. Outro aspecto importante é que o tempo de exposição à obesidade aumentou a quantidade de colágeno do VE, apesar de não existir diferença significativa entre os grupos $\mathrm{Ob}_{15}$ e $\mathrm{Ob}_{30}(\mathrm{p}=0,08)$; esta relação entre o tempo e os níveis de colágeno no músculo papilar ficou evidente entre 15 e 45 semanas de tratamento.

Os mecanismos relacionados com acúmulo de colágeno na obesidade experimental permanecem desconhecidos. ${ }^{(51,97,197-199)}$ Como referido anteriormente o tecido adiposo secreta inúmeros peptídeos que podem atuar diretamente ou indiretamente na remodelação do colágeno intersticial. ${ }^{(190,191)}$ Brands et al $^{(198)}$ sugerem que o maior conteúdo de colágeno está 
relacionado com aumento da insulina, que estimulam a expressão de colágeno por meio do fator beta de crescimento de transformação (TGF- $\beta) .{ }^{(199)}$ De acordo com inúmeros estudos, a angiotensina II também seria um dos agentes responsáveis pela fibrose intersticial secundária à obesidade, pois ativa o TGF- $\beta \cdot{ }^{(97,119,199,200)}$ No entanto, a ausência de alteração dos níveis de colágeno intersticial do VE em relação ao controle, sugere que os fatores envolvidos no controle da síntese e degradação de colágeno na obesidade não foram capazes de modificar a quantidade de colágeno e promover fibrose miocárdica. Os dados deste estudo a nível ventricular estão em concordância com outros estudos que não obervaram aumento de colágeno intersticial na obesidade. ${ }^{(51)}$ Não encontramos explicação para a elevação isolada de colágeno no músculo papilar após 45 semanas; como referido acima, este aumento pode estar relacionado com aumento da síntese e/ou diminuição da degradação. A elevação dos níveis de colágeno induzida pela duração da obesidade sugere que os fatores estimulantes ou inibidores envolvidos no metabolismo do colágeno sofreram alteração ao longo do tempo. Estudos futuros são necessários para esclarecer a relação entre colágeno e tempo de exposição à obesidade. Não foram encontrados na literatura, trabalhos que avaliaram o tempo de exposição à obesidade sobre o colágeno miocárdico.

\subsection{2- Influência da obesidade sobre a função cardíaca}

O principal objetivo deste estudo foi avaliar a influência do tempo de exposição à obesidade sobre a função cardíaca in vivo e in vitro. Dentro dexte contexto, foram utilizadas duas metodologias diferentes, o ecocardiograma e o estudo do músculo papilar isolado do VE.

O ecocardiograma é um método não invasivo, de baixo custo, que fornece informações importantes sobre a morfologia e a função do coração. Segundo Okoshi et al, ${ }^{(118)}$ outro aspecto importante, é que este método possibilita obter dados sobre o coração, in vivo, 
em condições muito próximas às fisiológicas, portanto, sujeito às variações de pré-carga, póscarga, contratilidade e freqüência cardíaca.

A avaliação da função sistólica e diastólica do VE mostrou que a remodelação cardíaca induzida pela obesidade promoveu alterações significantes nos animais após 30 semanas em relação ao controle. As principais constatações destas mudanças funcionais foram visualizadas pelas frações de encurtamento endocárdico e mesocárdico $(\Delta \mathrm{D}$ endo e $\Delta \mathrm{D}$ meso), VEPP, estresse sistólico, onda A, razão E/A e TRIV. Dentro deste contexto, embora não ocorreu aumento do volume sistólico no grupo $\mathrm{Ob}_{30}$, houve mehora da capacidade do ventrículo de ejetar, avaliadas pelas $\Delta \mathrm{D}$ endo e $\triangle \mathrm{D}$ meso e VEPP; estes dados corroboram com a diminuição do diâmetro do sistólico do VE. Estes parâmetros dependem da contratilidade, variações das cargas e da freqüência cardíaca, portanto, sofrem influência dos sistemas nervosos autônomo e hormonais. ${ }^{(118)} \mathrm{O}$ aumento do desempenho sistólico pode estar relacionado com diminuição da pós-carga e melhoria da contratilidade. Em favor desta suposição, os achados encontrados mostraram redução do estresse sistólico parietal e hipertrofia da parede do VE na obesidade após 30 semanas. Nossos dados divergem de estudos experimentais que encontraram função sistólica diminuída ou inalterada pelo ecocardiograma. ${ }^{(51,60,201)}$

O estudo da função diastólica do VE é muito importante, tendo em vista que as alterações no enchimento desta cavidade podem anteceder a disfunção sistólica. ${ }^{(202)}$ Neste estudo, a obesidade após 15 e 45 semanas não acarretou alterações nos índices que avaliam a diástole. Por outro lado, a obesidade no grupo 30 semanas, aumentou a onda A e diminuiu a razão E/A, indicando alteração do enchimento cardíaco. A análise conjunta dos dados sugere que a obesidade acarretou disfunção diastólica de intensidade leve; a favor desta afirmação, encontra-se a ausência de alterações na onda E e no TDE e diminuição do TRIV. Segundo alguns autores, ${ }^{(28,38,43)}$ o prolongamento do TRIV é a mais consistente anormalidade diastólica 
observada em indivíduos obesos. A elevação da onda A e a diminuição da onda E e razão E/A sugerem presença de disfunção diastólica. ${ }^{(28,32,35,37,38)} \mathrm{O}$ enchimento diastólico depende do relaxamento ativo e das propriedades passivas do músculo cardíaco; enquanto o primeiro está relacionado com o trânsito de $\mathrm{Ca}^{+2},{ }^{(75,172,195)}$ o segundo depende das propriedades viscoelásticas do miocárdio. ${ }^{(37,76,94,203)}$ As causas da disfunção diastólica na obesidade não estão esclarecidas, ${ }^{(37,204,205)}$ podendo estar relacionada com resistência à insulina, hperinsulinemia, hiperglicemia e/ou alterações hemodinâmicas. Não foram encontrados trabalhos que avaliaram a função diastólica em ratos obesos alimentados por dieta hiperlipídica.

O tempo de exposição à obesidade promoveu somente melhora da função sistólica após 30 semanas. Este resultado pode ser conseqüente a diminuição do estresse sistólico parietal do VE e hipetrofia cardíaca. Embora não ocorreu diferença significante entre os $\mathrm{Ob}_{15}$ e $\mathrm{Ob}_{45}$ na fração de ecurtamento mesocárdica $(\mathrm{p}=0,09)$, houve uma tendência de aumento deste parâmetro no grupo $\mathrm{Ob}_{45}$. Não foram encontrados na literatura trabalhos que avaliaram a duração da obesidade sobre a função cardíaca avaliada por meio de ecocardiograma.

A função cardíaca também foi avaliada in vitro pelo estudo do músculo papilar isolado do VE. Este tipo de preparação permite avaliar, conforme descrito anteriormente, a capacidade do músculo cardíaco de desenvolver força e encurtar independentemente de mudanças na carga, na freqüência e geometria cardíaca, as quais podem modificar a performance in vivo. ${ }^{(206)}$ Neste sentido, o ensaio usado controlou precisamente a pós-carga, a pré-carga e a freqüência cardíaca, o que é difícil de ser obtido no coração in vivo, permitindo avaliar a função miocárdica intrínseca e detectar alterações mecânicas precoces. Por outro lado, as informações obtidas neste tipo de preparação podem não refletir a função cardíaca in vivo, pois pode não sofrer influência de alterações metabólicas e hormonais existentes, por exemplo, na obesidade. 
Para esta análise funcional, a área seccional do músculo papilar foi utilizada como procedimento para a composição dos grupos. Este procedimento descartou áreas seccionais do músculo papilar acima de $1,7 \mathrm{~mm}^{2}$. O descarte pela área seccional do músculo papilar é freqüentemente usado na literatura, ${ }^{(207,208)}$ pois possibilita no estudo a comparação apenas de animais com áreas seccionais semelhantes. A utilização de músculos com área diferentes pode acarretar erros de interpretação, pois há uma relação inversa entre a área seccional e o desenvolvimento de força. ${ }^{(209)}$ Dentro deste contexto, as perdas por não adesão ao procedimento utilizado para a composição dos grupos foram, respectivamente, nos grupos controles $\left(\mathrm{C}_{15}=5,2 \% ; \mathrm{C}_{30}=15 \% ; \mathrm{C}_{45}=9,1 \%\right)$ e obesos $\left(\mathrm{Ob}_{15}=0 \% ; \mathrm{Ob}_{30}=4,8 \% ; \mathrm{Ob}_{45}=\right.$ 17,7\%). Neste trabalho, a obesidade e o tempo de exposição não acarretaram diferenças nas áreas seccionais do músculo papilar.

O uso do músculo papilar isolado permitiu analisar a função miocárdica em condições basais e após intervenções inotrópicas e lusitrópicas. Atualmente diversas pesquisas têm utilizado estas manobras com a finalidade de identificar alterações nas fases de contração e relaxamento que podem, eventualmente, não serem observadas em condições basais. ${ }^{(118)}$ Além disso, as mesmas auxiliam no entendimento dos possíveis mecanismos responsáveis pelas alterações no desempenho funcional do miocárdio. As manobras mais freqüentemente utilizadas são potenciação pós-pausa, variação da concentração de cálcio extracelular e alteração da frequiência de estímulo cardíaco, que permitem verificar a participação do trânsito de $\mathrm{Ca}^{+2}$ intracelular na patogênese da disfunção do miocárdio.

De acordo com os resultados obtidos, a obesidade, após 15, 30 e 45 semanas, não promoveu prejuízo funcional em situação basal com ativação máxima dos sarcômeros. Em favor desta afirmação são os valores encontrados nos grupos em todos os momentos, que mostraram diferenças apenas na TR em 15 semanas e na + dT/dt após 45 semanas. Além disso, a obesidade não acarretou rigidez miocárdica em todos os momentos de avaliação. 
Desta forma, a obesidade após 15, 30 e 45 semanas, apesar de acarretar hipertrofia cardíaca durante o processo de remodelação, não alterou a função miocárdia em situação basal. A análise do tempo de exposição à obesidade mostrou apenas diferença no comportamento da dT/dt, desde que ocorreu diminuição desta variável após 30 semanas; entretanto, o mesmo comportamento ocorreu no grupo controle.

Este estudo mostrou que algumas alterações mecânicas não visualizadas em situação basal entre o grupo controle e obeso, ocorreram após as manobras inotrópicas. Neste sentido, as modificações funcionais mais consistentes ocorreram após 15 semanas de obesidade. Neste grupo, a obesidade prejudicou a função miocárdica, visualizada pela diminuição da TD após a realização das manobras da potenciação pós-pausa, da elevação da concentração de cálcio extracelular e do aumento da freqüência de estímulo. Nos grupos obesos 30 e 45 semanas, as manobras não promoveram alterações que indiquem a presença de disfunção miocárdica. Desde que trabalhos mostram a existência de interação entre duração e intensidade da obesidade e alterações no sistema cardiovascular, ${ }^{(23,34,39,44)}$ a ausência de modificações funcionais miocárdicas nos grupos $\mathrm{Ob}_{30}$ e $\mathrm{Ob}_{45}$, mostra que o tempo de obesidade não modificou a função do miocárdio em relação ao controle.

A disfunção miocárdica induzida pela obesidade após 15 semanas pode ter sido decorrente de diversos fatores, como alterações no uso do substrato energético, na composição das proteínas contráteis, no trânsito de $\mathrm{Ca}^{+2}$ intracelular, na matriz extracelular, na modulação autonômica e diminuição no número de miócitos. ${ }^{(118,203,206)} \mathrm{Na}$ obesidade, os mecanismos responsáveis pela disfunção miocárdica não estão bem esclarecidos; alterações no trânsito de $\mathrm{Ca}^{+2}$ e no sistema $\beta$-adrenérgico têm sido sugeridas por vários autores. ${ }^{(50,52,210,211)}$ A partir dos experimentos realizados, pode-se sugerir que a disfunção miocárdica induzida pela obesidade após 15 semanas foi decorrente de alterações relacionadas com o trânsito de $\mathrm{Ca}^{+2}$ intracelular. Poucos trabalhos experimentais têm observado que a 
disfunção cardíaca oriunda da obesidade está envolvida com alterações no trânsito de $\mathrm{Ca}^{+2} \cdot{ }^{(52,61)}$ Relling et al, ${ }^{(52)}$ utilizando ratos submetidos à dieta hiperlipídica, por 12 semanas, mostraram que a obesidade promoveu disfunção dos cardiomiócitos, provavelmente, por diminuição da recaptura dos íons cálcio. Em pesquisa recente em nosso laboratório, Leopoldo et $\mathrm{al}^{(61)}$ observaram que a obesidade, induzida por um ciclo de dietas hiperlipídica em ratos Wistar durante 15 semanas, acrescida de solução de água com açúcar, acarretou disfunção cardíaca decorrente de prejuízo da recaptura de $\mathrm{Ca}^{+2}$ pela Serca2a.

Embora a obesidade deprimiu a função após 15 semanas e não alterou o desempenho mecânico nos $\mathrm{Ob}_{30}$ e $\mathrm{Ob}_{45}$, em relação aos respectivos controles, a análise conjunta das três manobras mostrou que o tempo de exposição, isto é, a comparação entre os $\mathrm{Ob}_{15}, \mathrm{Ob}_{30}$ e $\mathrm{Ob}_{45}$, acarretou diferença de comportamento entre os grupos obesos semelhante aos observados nos controle. Este resultado significa que não houve influência da duração da obesidade, mas do processo de envelhecimento. A ausência de alterações com o tempo de exposição pode estar relacionada com o tipo de dieta hiperlipídica utilizada, rica em ácidos graxos insaturados. $\mathrm{O}$ aumento do tempo de exposição à dieta hiperlipídica insaturada pode ter acarretado efeito protetor no coração, diferente do que ocorreu nos animais $\mathrm{Ob}_{15}$. A revisão de literatura, nos permite acreditar que este é o primeiro estudo que analisou a performance miocárdica em diferentes períodos de obesidade a partir de diversas manobras.

Além das manobras referidas que avaliaram a relação função cardíaca e trânsito de $\mathrm{Ca}^{+2}$, aumentando a oferta destes íons às proteínas contráteis, foram realizadas também intervenções farmacológicas que diminuíram a disponiblidade de $\mathrm{Ca}^{+2}$ citosólico. O fluxo de cálcio pelos canais L do sarcolema, o qual representa o evento inicial do acoplamento excitação-contração, foi avaliado por meio de bloqueador específico, o diltiazem. Diversos autores têm utilizado em pesquisas experimentais diferentes tipos de bloqueadores dos canais $\mathrm{L}$ de cálcio, entre eles, nifedipina, verapamil e diltiazem. ${ }^{(133,137,138)} \mathrm{O}$ diltiazem inibe o influxo 
de cálcio no músculo cardíaco por meio de bloqueio competitivo com o cálcio que entra pelos canais lentos voltagem-dependentes. Os resultados obtidos neste trabalho mostraram que a análise conjunta envolvendo os grupos, tempo de tratamentos e a manobra, não revelou diferenças significativas entre os grupos obeso e controle na atividade dos canais L do sarcolema. Esses achados estão de acordo com pesquisa recente realizada em nosso laboratório, dados não publicados, que mostra que a obesidade não alterou a expressão protéica do canal L sarcolemal.

Nos cardiomiócitos, os canais L são caracterizados pela abertura prolongada e condutância elevada durante o processo de despolarização da membrana sarcolemal. ${ }^{(212,213)}$ Portanto, o canal L desempenha papel importante nas características dos potenciais de ação bem como no início do ciclo de contração no miócito. ${ }^{(82)}$ Este canal pode ser modulado por agentes farmacológicos, incluindo bloqueadores e/ou agonistas, e por meio de mecanismos dependentes do AMPcíclico. ${ }^{(214-216)}$ Os receptores agonistas $\beta$-adrenérgicos e os inibidores da fosfodiesterase aumentam as correntes de canais L por meio de elevações nas concentrações intracelulares de AMPcíclico. Segundo diversos autores, ${ }^{(217-219)}$ o aumento de AMPcíclico, secundários à ativação do receptor $\beta$-adrenérgico e estimulação da adenil-ciclase pelas proteína G, levam a ativação da proteína quinase A dependente de AMPcíclico. Neste sentido, as subunidades catalíticas da proteína quinase A fosforilam as subunidades $\alpha 1$ e $\beta$ do canal L, acarretando prolongamento do tempo de abertura destes canais, o que resulta em aumento do influxo de $\mathrm{Ca}^{+2}{ }^{(220)}$ Além disso, as proteínas $\mathrm{G}$ também podem modular diretamente estes canais. O aumento do influxo de cálcio acarreta maior liberação desses íons do RS, acarretanto maior disponibilidade de $\mathrm{Ca}^{+2}$ para o ciclo contrátil. Outros moduladores intrínsecos podem influenciar a função dos canais $\mathrm{L}$, como a concentração de $\mathrm{Ca}^{+2}$ citosólico livre e o $\mathrm{pH} \cdot{ }^{(221,222)}$ A liberação elevada de $\mathrm{Ca}^{+2}$ do retículo sarcoplasmático pode reduzir a magnitude do influxo de $\mathrm{Ca}^{+2}$, bem como acelerar o tempo de curso de inativação da corrente. 
A redução do $\mathrm{pH}$ intracelular também pode acarretar diminuição da magnitude da corrente dos canais L proporcionando disfunção destes canais. Em razão do comportamento semelhante entre os grupos controle e obeso, pode se inferir que o número de canais L e os mecanismos envolvidos na regulação da atividade deste canal não sofreram influência da obesidade.

O papel da obesidade sobre o trânsito de $\mathrm{Ca}^{+2}$ miocárdico foi também avaliado verificando-se a função da Serca2a. O RS, maior sítio de acúmulo e liberação de cálcio durante o ciclo cardíaco, tem importante papel na regulação do ciclo de contração e relaxamento do coração. A atividade da Serca2a, responsável pela recaptura de $\mathrm{Ca}^{+2}$ do citosol pelo RS, é dependente da concentração de cálcio citoplasmático, da quantidade de cálcio no retículo sarcoplasmático e da fosfolambam. ${ }^{(140)}$ Neste trabalho, a recaptura de íons cálcio pela Serca2a foi mediada pela ação de um bloqueador específico, o ácido ciclopiazônico. Pesquisas experimentais têm utilizado diferentes drogas bloqueadoras da atividade da Serca2a no coração, entre elas, a tapsigargina e o ácido ciclopiazônico. ${ }^{(223-226)} \mathrm{O}$ ácido ciclopiazônico (CPA) produz respostas inotrópicas negativas, como diminuição da força contrátil e prolongamento do tempo e velocidade do relaxamento. No presente estudo, o bloqueio da Serca2a variou entre 25 a 50\%. Segundo Baudet et al, ${ }^{(225)}$ a inibição da recaptura do cálcio pelo CPA é incompleta, mesmo em altas concentrações e longos tempos de exposição. A inibição da Serca2a em altas concentrações pode acarretar mudanças no efluxo de cálcio em favor do trocador $\mathrm{Na}^{+} / \mathrm{Ca}^{+2}$. Os resultados deste experimento mostraram que a atividade da Serca2a na obesidade foi preservada em todos os momentos de avaliação. Outro aspecto importante é que o tempo de exposição à obesidade não influenciou a função da Serca2a. Esses resultados estão de acordo com trabalho realizado em nosso laboratório, dados não publicados, que não observou alterações na quantidade de proteínas da Serca2a. Diversos modelos experimentais têm mostrado que o prejuízo da atividade da Serca2a está relacionado 
com alterações funcionais. ${ }^{(87,89)}$ Entretanto, na obesidade, a relação Serca2a e função cardíaca é pouco estudada. ${ }^{(52,74,227)}$ Pesquisa com cães, ${ }^{(227)}$ alimentados por 9 semanas com dieta hiperlipídica, observou diminuição da expressão de RNAm da Serca2a no miocárdio. Relling et $\mathrm{al}^{(52)}$ utilizando ratos submetidos à dieta hiperlipídica, por 12 semanas, mostraram que a obesidade, não acompanhada de comorbidades, promoveu aumento da expressão protéica da

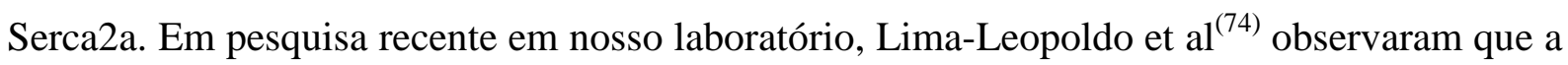
obesidade, induzida por um ciclo de dietas hiperlipídicas em ratos Wistar durante 15 semanas, acrescida de solução de água com açúcar, aumentou os níveis de RNAm da Serca2a. Entretanto, todos estes autores não avaliaram a função da Serca2a na obesidade. Portanto, a função da Serca2a foi avaliada pela primeira vez na obesidade experimental.

A atividade da Serca2a é o processo mais importante na recaptação do $\mathrm{Ca}^{+2}$ no músculo cardíaco. Esta proteína de ação enzimática pode ser modulada diretamente ou indiretamente por vários fatores. ${ }^{(86)} \mathrm{A}$ fosfolambam (PLB), também localizada na membrana do retículo sarcoplasmático (RS), inibe diretamente a afinidade entre a Serca2a e os íons cálcio, prejudicando a recaptura de $\mathrm{Ca}^{+2}$ para o RS. ${ }^{(228)}$ Entretanto, a PLB em seu estado fosforilado, na serina-16 e/ou treonina-17, altera a inibição da Serca2a. A fosforilação da PLB via sistema $\beta$-adrenérgico, na serina-16, altera o bloqueio exercido pela PLB em relação à Serca2a, permitindo a recaptura de cálcio para o RS. ${ }^{(86,229,230)}$ Além disso, a modulação direta da Serca2a é acarretada pela fosforilação da PLB via calmodulina quinase dependente de $\mathrm{Ca}^{+2}$, na treonina $17 .^{(76,231)}$ Outros agentes podem modular diretamente a atividade e expressão da Serca2a, entre eles, os hormônios tireoidianos, ${ }^{(232)}$ a insulina ${ }^{(233)}$ e nitrosilação. ${ }^{(234)}$ Dentro dexte contexto, neste estudo, a ausência de alterações na atividade da Serca2a na obesidade, após 15, 30 e 45 semanas, sugere que estes fatores descritos acima, não influenciaram os mecanismos de controle desta proteína. 


\section{CONCLUSÃO}

O tempo de exposição à obesidade não intensifica a disfunção cardíaca, a atividade do canal L e da Serca2a e promove aumento do colágeno miocárdico. A elevação dos níveis de colágeno não acarreta prejuízo da função cardíaca in vivo e in vitro. 


\section{REFERÊNCIAS}

1. Korner J, Aronne LJ. The emerging of body weight regulation and its impact on obesity treatment. J Clin Invest. 2003;111(5):565-70.

2. Mathew B, Patel SB, Reams GP, Freeman RH, Spear RM, Villarreal D. Obesityhypertension: emerging concepts in pathophysiology and treatment. Am J Med Sci. 2007;334(1):23-30.

3. Eckel RH, Barouch WW, Ershow AG. Report of the National Heart, Lung, and Blood Institute-National of Diabetes and Digestive and Kidney Diseases Working Group on the Pathophysiology of Obesity-Associated Cardiovascular Disease. Circulation. 2002;105(24):2923-8.

4. O' Brien PE, Dixon JB. The extent of the problem of obesity. Am J Surg. 2002;184(6B):4S-8S.

5. Wong CY, O' Moore-Sullivan T, Leano R, Byrne N, Beller E, Marwick TH. Alterations of left ventricular myocardial characteristics associated with obesity. Circulation. 2004;110(19):3081-7.

6. World Health Organization. Obesity and Overweight. Geneva:WHO. [access 2009 Aug 20]. Available from: http://www.who.int/en/

7. Kac G, Velasques-Melendez G. A transição nutricional e a epidemiologia da obesidade na América Latina. Cad Saúde Pública. 2003;19(1):S4-S5.

8. Monteiro CA, Mondini L, de Souza AL, Popkin BM. The nutrition transition in Brazil. Eur J Clin Nutr. 1995;49(2):105-13.

9. Francischi RP, Pereira LO, Freitas CS, Klopfer M, Santos RC, Vieira P, et al. Obesidade: atualização sobre sua etiologia, morbidade e tratamento. Rev Nutr. 2000;13(1):17-28. 
10. Francischi RP, Pereira LO, Lancha Jr AH. Exercício, comportamento alimentar e obesidade: revisão dos efeitos sobre a composição corporal e parâmetros metabólicos. Rev Paul Educ Fís. 2001;15(2):117-40.

11. BRASIL. Ministério do Planejamento, Orçamento e Gestão. Instituto Brasileiro de Geografia e Estatística - IBGE. Pesquisa de Orçamentos Familiares 2002-2003. Antropometria e análise do estado nutricional de crianças e adolescentes no Brasil. Rio de Janeiro: IBGE, 2006.

12. Rolls BJ, Shide DJ. The influence of dietary fat on food intake and body weight. Nutr Rev. 1992;50(10):283-90.

13. Stein CJ, Colditz GA. The epidemic of obesity. J Clin Endocrinol Metab. 2004;89(6):2522-5.

14. Malnick SD, Knobler H. The medical complications of obesity. QJM. 2006;99(9):56579.

15. Poirier P, Giles TD, Bray GA, Hong Y, Stern JS, Pi-Sunyer X, et al. Obesity and cardiovascular disease: pathophysiology, evaluation, and effect of weight loss. Arterioscler Thromb Vasc Biol. 2006;26(5):968-76.

16. Fontaine KR, Redden DT, Wang C, Westfall AO, Allison DB. Years of Life lost due to obesity. JAMA. 2003;289(2):187-93.

17. Hu FB, Willett WC, Li T, Stampfer MJ, Colditz GA, Manson JE. Adiposity as compared with physical activity in predicting mortality among women. N Engl J Med. 2004;351(26):2694-703.

18. Olshansky S, Passaro D, Hershow R, Layden J, Carnes B, Brody J, et al. A potential decline in life expectancy in the United States in the 21st century. N Engl J Med. 2005;352(11):1138-45. 
19. Pardo Silva MC, De Laet C, Nusselder WJ, Mamun A, Peeters A. Adult obesity and number of years lived with and without cardiovascular disease. Obesity. 2006;14(7):1264-73.

20. Wilson PW, D'Agostino RB, Sullivan L, Parise H, Kannel WB. Overweight and obesity as determinants of cardiovascular risk. Arch Intern Med. 2002;162(16):1867-72.

21. Seidell JC, Verschuren WM, van Leer EM, Kromhout D. Overweight, underweight, and mortality. A prospective study of 48,287 men and women. Arch Intern Med. 1996;156(9):958-63.

22. Sowers JR. Obesity and cardiovascular disease. Clin Chem. 1998;44(8 Pt 2):1821-5.

23. Alpert MA, Lambert CR, Panayiotou H, Terry BE, Cohen MV, Massey CV, et al. Relation of duration of morbid obesity to left ventricular mass, systolic function, and diastolic filling, and effect of weight loss. Am J Cardiol. 1995;76(16):1194-7.

24. Chen YT, Vaccarino V, Williams CS, Butler J, Berkman LF, Krumholz HM. Risk factors for heart failure in the elderly: a prospective community-based study. Am J Med. 1999;106(6):605-12.

25. Wilhelmsen L, Rosengren A, Eriksson H, Lappas G. Heart failure in the general population of men-morbidity, risk factors and prognosis. $\mathrm{J}$ Intern Med. 2001;249(3):253-61.

26. Di Stante B, Galandauer I, Aronow WS, McClung JA, Alas L, Salabay C, et al. Prevalence of left ventricular diastolic dysfunction in obese persons with and without Diabetes Mellitus. Am J Cardiol. 2005;95(12):1527-8.

27. Peterson LR, Waggoner AD, Schechtman KB, Meyer T, Gropler RJ, Barzilai B, et al. Alterations in left ventricular structure and functions in young healthy obese women. $\mathrm{J}$ Am Coll Cardiol. 2004;43(8):1399-404. 
28. Morricone L, Malavazos AE, Coman C, Donati C, Hassan T, Caviezel F. Echocardiographic abnormalities in normotensive obese patients: relationship with visceral fat. Obes Res. 2002;10(6):489-98.

29. Alaud-din A, Meterissian S, Lisbona R, MacLean LD, Forse RA. Assessment of cardiac function in patients who were morbidly obese. Surgery. 1990;108(4):809-18.

30. Garavaglia GE, Messerli FH, Nunez BD, Schmieder RE, Grossman E.Myocardial contractility and left ventricular function in obese patients with essential hypertension. Am J Cardiol. 1988;62(9):594-7.

31. Dorbala S, Crugnale S, Yang D, Di Carli MF. Effect of body mass index on left ventricular cavity size and ejection fraction. Am J Cardiol. 2006;97(5):725-9.

32. Iacobellis G, Ribaudo MC, Zappaterreno A, Iannucci CV, Di Mario U, Leonetti F. Adapted changes in left ventricular structure and function in severe uncomplicated obesity. Obes Res. 2004;12(10):1616-21.

33. Otto ME, Belohlavek M, Khandheria B, Gilman G, Svatikova A, Somers V. Comparison of right and left ventricular function in obese and nonobese men. Am J Cardiol. 2004;93(12):1569-72.

34. Pascual M, Pascual DA, Soria F, Vicente T, Hernández AM, Tébar FJ, et al. Effects of isolated obesity on systolic and diastolic left ventricular function. Heart. 2003;89(10):1152-6.

35. Iacobellis G, Ribaudo MC, Leto G, Zappaterreno A, Vecci E, Di Mario U, et al. Influence of excess fat on cardiac morphology and function: study in uncomplicated obesity. Obes Res. 2002;10(8):767-73.

36. Crisostomo LL, Araújo LMB, Câmara E, Carvalho C, Silva FA, Vieira M, et al. Comparison of left ventricular mass and function in obese versus nonobese women $<40$ years of age. Am J Cardiol. 1999;84(9):1127-9. 
37. Mureddu GF, de Simone G, Greco R, Rosato GF, Contaldo F. Left ventricular filling pattern in uncomplicated obesity. Am J Cardiol. 1996;77(7):509-14.

38. Berkalp B, Cesur V, Corapcioglu D, Erol C, Baskal N. Obesity and left ventricular diastolic dysfunction. Int J Cardiol. 1995;52(1):23-6.

39. Scaglione R, Dichiara A, Indovina A, Lipari R, Ganguzza A, Parrinello G, et al. Left ventricular diastolic and systolic function in normotensive obese subjects: influence of degree and duration of obesity. Eur Heart J. 1992;13(6):738-42.

40. de Divittiis O, Fazio S, Petitto M, Maddalena G, Contaldo F, Mancini M. Obesity and cardiac function. Circulation. 1981;64(3):477-82.

41. Avelar E, Cloward TV, Walker JM, Farney RJ, Strong M, Pendleton RC, et al. Left ventricular hypertrophy in severe obesity: interactions among blood pressure, nocturnal hypoxemia, and body mass. Hypertension. 2007;49(1):34-9.

42. Krishnan R, Becker RJ, Beighley LM, López-Candales A. Impact of body mass index on markers of left ventricular thickness and mass calculation: results of a pilot analysis. Echocardiography. 2005;22(3):203-10.

43. Wikstrand J, Pettersson P, Björntorp P. Body fat distribution and left ventricular morphology and function in obese females. J Hypertens. 1993;11(11):1259-66.

44. Alpert MA. Obesity cardiomyopathy: pathophysiology and evolution of the clinical syndrome. Am J Med Sci. 2001;321(4):225-36.

45. Alpert MA, Fraley MA, Birchem JA, Senkottaiyan N. Management of obesity cardiomyopathy. Expert Rev Cardiovasc Ther. 2005;3(2):225-30.

46. Licata G, Scaglione R, Paterna S, Parrinello G, Indovina A, Dichiara MA, et al. Left ventricular function response to exercise in normotensive obese subjects: influence of degree and duration of obesity. Int J Cardiol. 1992;37(2):223-30. 
47. Pereira LO, de Francischi RP, Lancha Jr AH. Obesidade: Hábitos Nutricionais, Sedentarismo e Resistência à Insulina. Arq Bras Endocrinol Metab 2003;47(2):111-27.

48. Christoffersen C, Bollano E, Lindegaard MLS, Bartels ED, Goetze JP, Andersen CB, et al. Cardiac lipid accumulation associated with diastolic dysfunction in obese mice. Endocrinology. 2003;144(8):3483-90.

49. Dong F, Zhang X, Yang X, Esberg LB, Yang H, Zhang Z, et al. Impaired cardiac contractile function in ventricular myocytes from leptin-deficient ob/ob obese mice. $\mathrm{J}$ Endocrinol. 2006;188(1):25-36.

50. Ren J, Walsh MF, Jefferson L, Natavio M, IIg KJ, Sowers JR, et al. Basal and ethanolinduced cardiac contractile response in lean and obese zucker rat hearts. J Biomed Sci. 2000;7(5):390-400.

51. Carroll JF, Zenebe WJ, Strange TB. Cardiovascular function in a rat model of dietinduced obesity. Hypertension. 2006;48(1):65-72.

52. Relling DP, Esberg LB, Frang CX, Johnson WT, Murphy EJ, Carlson EC, et al. High-fat diet-induced juvenile obesity leads to cardiomyocyte dysfunction and upregulation of Foxo3a transcription factor independent of lipotoxicity and apoptosis. J Hypertens. 2006;24(3):549-61.

53. Fitzgerald SM, Henegar JR, Brands MW, Henegar LK, Hall JE. Cardiovascular and renal responses to a high-fat diet in Osborne-Mendel rats. Am J Physiol Regul Integr Comp Physiol. 2001;281(2):R547-52.

54. Carroll JF, Dwyer TM, Grady AW, Reinhar GA, Montani J-P, Cockrell K, et al. Hypertension, cardiac hypertrophy, and neurohumoral activity in a new animal model of obesity. Am J Physiol. 1996;271(1 Pt 2):H373-8.

55. Abel ED, Litwin SE, Sweeney G. Cardiac remodeling in obesity. Physiol Rev. 2008;88(2):389-419. 
56. Lichtenstein AH, Kennedy E, Barrier P, Danford D, Ernst ND, Grundy SM, et al. Dietary fat consumption and health. Nutr Rev. 1998;56(5 Pt 2):S3-28.

57. Tucker LA, Kano MJ. Dietary fat and body fat: a multivariate study of 205 adult females. Am J Clin Nutr. 1992;56(4):616-22.

58. Boustany-Kari CM, Gong M, Akers WS, Guo Z, Cassis LA. Enhanced vascular contractility and diminished coronary artery flow in rats made hypertensive from dietinduced obesity. Int J Obes (Lond). 2007;31(11):1652-9.

59. Ren J, Zhu BH, Relling DP, Esberg LB, Ceylan-Isik AF. High-fat diet-induced obesity leads to resistance to leptin-induced cardiomyocyte contractile response. Obesity (Silver Spring). 2008;16(11):2417-23.

60. Leopoldo AS, Sugizaki MM, Lima-Leopoldo AP, Nascimento AF, Martinez PF, Luvizotto RAM, et al. Cardiac remodeling in rat model of diet-induced obesity. Can J Cardiol., in press.

61. Leopoldo AS, Lima-Leopoldo AP, Sugizaki MM, Nascimento AF, Campos DHS, Oliveira Júnior SA, et al. Myocardial dysfunction induced by obesity is related to abnormal calcium handling. Biol Res.

62. Hu FB, Willett WC. Optimal diets for prevention of coronary heart disease. JAMA. 2002;288(20):2569-78.

63. Roche HM. Fatty acids and the metabolic syndrome. Proc Nutr Soc. 2005;64(1):23-9.

64. Kuller LH. Nutrition, lipids, and cardiovascular disease. Nutr Rev. 2006;64(2 Pt 2):S1526.

65. Okere IC, Chandler MP, McElfresh TA, Rennison JH, Sharov V, Sabbah HN, et al. Differential effects of saturated and unsaturated fatty acid diets on cardiomyocyte apoptosis, adipose distribution, and serum leptin. Am J Physiol Heart Circ Physiol. 2006;291(1):H38-44. 
66. Chemla D, Javouhey-Donzel A, Suard I, Maupoil V, Lecarpentier Y, Pourny JC, et al. Influence of dietary polyunsaturated fatty acids on contractility, lusitropy and compliance of isolated rat myocardium. J Mol Cell Cardiol. 1995;27(8):1745-55.

67. Hoffmann P, Bartels T, Heinemann S, Beitz J, Taube C. Cardiovascular actions of dihydralazine as modified by dietary linoleic acid. Biomed Biochim Acta. 1986;45(8):1057-67.

68. Courtois M, Khatami S, Fantini E, Athias P, Mielle P, Grynberg A. Polyunsaturated fatty acids in cultured cardiomyocytes: effect on physiology and beta-adrenoceptor function. Am J Physiol. 1992;262(2 Pt 2):H451-6.

69. McLennan PL, Abeywardena MY, Charnock JS. A comparison of the long-term effects of n-3 and n-6 polyunsaturated fatty acid dietary supplements and the action of indomethacin upon the mechanical performance and susceptibility of the rat heart to dysrhythmia. Prostaglandins Leukot Med. 1987;27(2-3):183-95.

70. Ding YF, Brower GL, Zhong Q, Murray D, Holland M, Janicki JS, et al. Defective intracellular $\mathrm{Ca}^{2+}$ homeostasis contributes to myocyte dysfunction during ventricular remodelling induced by chronic volume overload in rats. Clin Exp Pharmacol Physiol. 2008;35(7):827-35.

71. Sugizaki MM, Leopoldo AS, Okoshi MP, Bruno A, Conde SJ, Lima-Leopoldo AP, et al. Severe food restriction induces myocardial dysfunction related to SERCA2 activity. Can J Physiol Pharmacol. 2009;87(9):666-73.

72. Tsutsui H, Ishibashi Y, Imanaka-Yoshida K, Yamamoto S, Yoshida T, Sugimachi M, et al. Alterations in sarcoplasmic reticulum calcium-storing proteins in pressure-overload cardiac hypertrophy. Am J Physiol. 1997;272(1 Pt 2):H168-75.

73. Suarez J, Scott B, Dillmann WH. Conditional increase in SERCA2a protein is able to reverse contractile dysfunction and abnormal calcium flux in established diabetic cardiomyopathy. Am J Physiol Regul Integr Comp Physiol. 2008;295(5):R1439-45. 
74. Lima-Leopoldo AP, Sugizaki MM, Leopoldo AS, Carvalho RF, Nogueira CR, Nascimento AF, et al. Obesity induces upregulation of genes involved in myocardial $\mathrm{Ca}^{2+}$ handling. Braz J Med Biol Res. 2008;41(7):615-20.

75. Opie LH. Myocardial contraction and relaxation. In: Opie LH. The Heart. Physiology from cell to circulation. $3^{\text {rd }}$ ed. Philadelphia: Lippincott-Raven; 1998. p.209-31.

76. Bers DM. Cardiac excitation-contraction coupling. Nature. 2002;415(6868):198-205.

77. Fabiatto A. Calcium-induced release of calcium from the cardiac sarcoplasmic reticulum. Am J Physiol. 1983;245(1):C1-14.

78. Bers DM. Ca influx via sarcolemmal Ca channels. In: Bers DM. Excitation-contraction coupling and cardiac contractile force. $2^{\text {nd }}$ ed. Dordrecht: Kluwer Academic publishers; 2001. p.203-244.

79. Wier WG. Intracellular calcium during excitation-contraction coupling in mammalian ventricle. Med Sci Sports Exerc. 1991;23(10):1149-56.

80. Balke CW, Shorofsky SR. Alterations in calcium handling in cardiac hypertrophy and heart failure. Cardiovasc Res. 1998;37(2):290-9.

81. Aggarwal R, Boyden PA. Diminished $\mathrm{Ca}^{2+}$ and $\mathrm{Ba}^{2+}$ currents in myocytes surviving in the epicardial border zone of the 5-day infarcted canine heart. Circ Res. 1995;77(6):1180-91.

82. Mukherjee R, Spinale FG. L-type calcium channel abundance and function with cardiac hypertrophy and failure: a review. J Mol Cell Cardiol. 1998;30(10):1899-916.

83. de Tomasi LC, Bruno A, Sugizaki MM, Lima-Leopoldo AP, Nascimento AF, Júnior SA, et al. Food restriction promotes downregulation of myocardial L-type $\mathrm{Ca}^{2+}$ channels. Can J Physiol Pharmacol. 2009;87(6):426-31. 
84. Rossner KL. Calcium current in congestive heart failure of hamster cardiomyopathy. Am J Physiol. 1991;260(4 Pt 2):H1179-86.

85. Bracken N, Howarth FC, Singh J. Effects of streptozotocin-induced diabetes on contraction and calcium transport in rat ventricular cardiomyocytes. Ann N Y Acad Sci. 2006;1084:208-22.

86. Frank KF, Bölck B, Erdmann E, Schwinger RH. Sarcoplasmic reticulum $\mathrm{Ca}^{2+}$-ATPase modulates cardiac contraction and relaxation. Cardiovasc Res. 2003;57(1):20-7.

87. Wold LE, Dutta K, Mason MM, Ren J, Cala SE, Schwanke ML, et al. Impaired SERCA function contributes to cardiomyocyte dysfunction in insulin resistant rats. J Mol Cell Cardiol. 2005;39(2):297-307.

88. Li SY, Yang X, Ceylan-Isik AF, Du M, Sreejayan N, Ren J. Cardiac contractile dysfunction in Lep/Lep obesity is accompanied by NADPH oxidase activation, oxidative modification of sarco(endo)plasmic reticulum $\mathrm{Ca}^{2+}$-ATPase and myosin heavy chain isozyme switch. Diabetologia. 2006;49(6):1434-46.

89. Netticadan T, Temsah RM, Kent A, Elimban V, Dhalla NS. Depressed levels of $\mathrm{Ca}^{2+-}$ cycling proteins may underlie sarcoplasmic reticulum dysfunction in the diabetic heart. Diabetes. 2001;50(9):2133-8.

90. Fukui S, Fukumoto Y, Suzuki J, Saji K, Nawata J, Shinozaki T, et al. Diabetes mellitus accelerates left ventricular diastolic dysfunction through activation of the reninangiotensin system in hypertensive rats. Hypertens Res. 2009;32(6):472-80.

91. Falcão-Pires I, Gonçalves N, Moura C, Lamego I, Eloy C, Lopes JM, et al. Effects of diabetes mellitus, pressure-overload and their association on myocardial structure and function. Am J Hypertens. 2009;22(11):1190-8.

92. Jobe LJ, Meléndez GC, Levick SP, Du Y, Brower GL, Janicki JS. TNF-alpha inhibition attenuates adverse myocardial remodeling in a rat model of volume overload. Am $\mathbf{J}$ Physiol Heart Circ Physiol. 2009;297(4):H1462-8. 
93. Bomfim AS, Mandarim de-Lacerda CA. Enalapril altera a formação da matriz colágena do miocárdio de ratos espontaneamente hipertensos. Arq Bras Cardiol. 2003;81(1):64-8.

94. Webber KT, Pick R, Jalil JE, Janicki JS, Carroll EP. Patterns of myocardial fibrosis. J Mol Cell Cardiol. 1989; 21(Suppl 5):121-31.

95. Mizushige K, Yao Li, Norna T, Kiyomoto H, Yu Y, Hosomi N, et al. Alteration in left ventricular diastolic filling and accumulation of myocardial collagen at insulin-resistant prediabetic stage of a type II diabetic rat model. Circulation. 2000;101(8):899-907.

96. Toblli JE, Cao G, DeRosa G, Forcada P. Reduced cardiac expression of plasminogen activator inhibitor 1 and transforming growth factor b1 in obese Zucker rats by perindopril. Heart. 2005;91(1):80-6.

97. Carroll JF, Tyagi SC. Extracellular matrix remodeling in the heart of the homocysteinemic obese rabbits. Am J Hypertens. 2005;18(5 Pt 1):692-8.

98. Silva DCT. Effects of short-term high-fat diet on cardiac function and remodeling of rats. In: IV Encontro de Pós-Graduação da Faculdade de Medicina de Botucatu, 2008, Botucatu. Anais do IV Encontro de Pós-Graduação da Faculdade de Medicina de Botucatu, 2008.

99. Committee on Care and Use of Laboratory Animals. Guide for the care and use of laboratory animals. Bethesda: National Institute of Health; 1985.

100. Nascimento AF, Sugizaki MM, Leopoldo AS, Lima-Leopoldo AP, Luvizotto RA, Nogueira CR, et al. A hypercaloric pellet-diet cycle induces obesity and co-morbidities in Wistar rats. Arq Bras Endocrinol Metabol. 2008;52(6):968-74.

101. Taylor BA, Phillips SJ. Detection of obesity QTLs on mouse chromosomes 1 and 7 by selective DNA pooling. Genomics. 1996;34(3):389-98.

102. Johnson MM, Peters JP. Technical note: an improved method to quantify nonesterified fatty acids in bovine plasma. J Anim Sci. 1993;71(3):753-6. 
103. Levin BE, Richard D, Michel C, Servatius R. Differential stress responsivity in dietinduced obese and resistant rats. Am J Physiol Regul Integr Comp Physiol. 2000;279(4):R1357-64.

104. Lauterio TJ, Barkan A, DeAngelo M, DeMott-Friberg R, Ramirez R. Plasma growth hormone secretion is impaired in obesity-prone rats before onset of diet-induced obesity. Am J Physiol. 1998;275(1 Pt 1):E6-11.

105. Nascimento AF, Sugizaki MM, Leopoldo AS, Lima-Leopoldo AP, Nogueira CR, Novelli EL, et al. Misclassification probability as obese or lean in hypercaloric and normocaloric diet. Biol Res. 2008;41(3):253-9.

106. Dobrian AD, Davies MJ, Prewitt RL, Lauterio TJ. Development of hypertension in a rat model of diet-induced obesity. Hypertension. 2000;35(4):1009-15.

107. Boustany CM, Bharadwaj K, Daugherty A, Brown DR, Randall DC, Cassis LA. Activation of the systemic and adipose renin-angiotensin system in rats with dietinduced obesity and hypertension. Am J Physiol Regul Integr Comp Physiol. 2004;287(4):R943-9.

108. Smith AD, Brands MW, Wang MH, Dorrance AM. Obesity-induced hypertension develops in young rats independently of the renin-angiotensin-aldosterone system. Exp Biol Med. 2006;231(3):282-7.

109. Akiyama T, Tachibana I, Shirohara H, Watanabe N, Otsuki M. High-fat hypercaloric diet induces obesity, glucose intolerance and hyperlipidemia in normal adult male Wistar rat. Diabetes Res Clin Pract. 1996;31(1-3):27-35.

110. Dourmashkin JT, Chang GQ, Gayles EC, Hill JO, Fried SK, Julien C, et al. Different forms of obesity as a function of diet composition. Int J Obes. 2005; 29(11):1368-78.

111. Woods SC, Seeley RJ, Rushing PA, D'Alessio DA, Tso P. A controlled high-fat diet induces an obese syndrome in rats. J Nutr. 2003;133(4):1081-7. 
112. Nivoit P, Morens C, Van Assche FA, Jansen E, Poston L, Remacle C, et al. Established diet-induced obesity in female rats leads to offspring hyperphagia, adiposity and insulin resistance. Diabetologia. 2009;52(6):1133-42.

113. de Assis AM, Rieger DK, Longoni A, Battu C, Raymundi S, da Rocha RF, et al. High fat and highly thermolyzed fat diets promote insulin resistance and increase DNA damage in rats. Exp Biol Med. 2009;234(11):1296-304.

114. Matthews DR, Hosker JP, Rudenski AS, Naylor BA, Treacher DF, Turner RC. Homeostasis model assessment: insulin resistance and beta-cell function from fasting plasma glucose and insulin concentrations in man. Diabetologia 1985;28(7):412-9.

115. Ono K, Masuyama T, Yamamoto K, Doi R, Sakata Y, Nishikawa N, et al. Echodoppler assessment of left ventricular function in rats with hypertensive hypertrophy. J Am Soc Echocardiogr. 2002;15(2):109-17.

116. Sjaastad I, Sejersted OM, Ilebekk A, Bjornerheim R. Echocardiographic criteria for detection of postinfarction congestive heart failure in rats. $J$ Appl Physiol. 2000;89(4):1445-54.

117. Tanaka N, Dalton N, Mao L, Rockman HA, Peterson KL, Gottshall KR, et al. Transthoracic echocardiography in models of cardiac disease in the mouse. Circulation. 1996;94(5):1109-17.

118. Okoshi K, Ribeiro HB, Okoshi MP, Matsubara BB, Gonçalves G, Barros R, et al. Improved systolic ventricular function with normal myocardial mechanics in compensated cardiac hypertrophy. Jpn Heart J. 2004;45(4):647-56.

119. du Toit EF, Nabben M, Lochner A. A potential role for angiotensin II in obesity induced cardiac hypertrophy and ischaemic/reperfusion injury. Basic Res Cardiol. 2005;100(4):346-54. 
120. Matsubara LS, Narikawa S, Ferreira AL, Paiva SA, Zornoff LM, Matsubara BB. Myocardial remodeling in chronic pressure or volume overload in the rat heart. Arq Bras Cardiol. 2006;86(2):126-30.

121. Matsubara LS, Matsubara BB, Okoshi MP, Cicogna AC, Janicki JS. Alterations in myocardial collagen content affect rat papillary muscle function. Am J Physiol Heart Circ Physiol. 2000;279(4):H1534-9.

122. Schwint OA, Labraga M, Cervino CO, Haffar M, Sequeiros PH, Marcos HJ. A modification of the staining technique of reticular fibres for image analysis of the cardiac collagen network. Cardiovasc Pathol. 2004;13(4):213-20.

123. Cicogna AC, Padovani CR, Okoshi K, Aragon FF, Okoshi MP. Myocardial function during chronic food restriction in isolated hypertrophied cardiac muscle. Am J Med Sci. 2000;320(4):244-8.

124. Cicogna AC, Robinson KG, Conrad CH, Squire R, Okoshi MP, Bing OH. Role of myocardial contractile status and relaxation in ventricular dysfunction during the transition of the heart hypertrophy to failure. Arq Bras Cardiol. 1997;69(6):381-4.

125. Gut AL, Okoshi MP, Padovani CR, Aragon FF, Cicogna AC. Myocardial dysfunction induced by food restriction is related to calcium cycling and beta-adrenergic system changes. Nutr Res 2003; 23(7):911-9.

126. Krebs HA, Henseleit K. Studies on urea formation in the animal organism. HoppeSeylers Z. Physiol. Chem. 1932;210:33-66,

127. Yamato T, Yamasaki S, Misumi Y, Kino M, Obata T, Aomine M. Postrest contraction in the ventricular papillary muscle of spontaneously diabetic WBN/Kob rat. Exp Anim. 2001;50(1):19-31.

128. Riou B, Lecarpentier Y, Viars P. Inotropic effect of ketamine on rat cardiac papillary muscle. Anesthesiology. 1989;71(1):116-25. 
129. Urthaler F, Walker AA, Reeves DN, Hefner LL. Maximal twitch tension in intact lengthclamped ferret papillary muscles evoked by modified postextrasystolic potentiation. Circ Res. 1988;62(1):65-74.

130. David JS, Vivien B, Lecarpentier Y, Coriat P, Riou B. Interaction of protamine with alpha- and beta-adrenoceptor stimulations in rat myocardium. Anesthesiology. 2002;96(2):521.

131. Prabhu SD, Azimi A, Frosto T. Nitric oxide effects on myocardial function and forceinterval relations: regulation of twitch duration. J Mol Cell Cardiol. 1999;31(12):207785.

132. Layland J, Kentish JC. Positive force- and $\left[\mathrm{Ca}^{2+}\right]$ i-frequency relationships in rat ventricular trabeculae at physiological frequencies. Am J Physiol. 1999;276(1 Pt 2):H9H18.

133. Cicogna AC, Padovani CR, Brooks WW, Schine L, Robinson KG, Conrad CH, et al. Protective effects of diltiazem on the mechanical performance of the hypoxic myocardium. Braz J Med Biol Res 1993;26(8):859-68.

134. Miller CD, Richard JL, Hembrough FB, Osweiler GD, Cox DF. In vitro effects of cyclopiazonic acid mycotoxin on turkey papillary muscles. Am J Vet Res. 1990;51(5):836-8.

135. Dettbarn C, P Palade. Effects of three sarcoplasmic/endoplasmic reticulum $\mathrm{Ca}++$ pump inhibitors on release channels of intracellular stores. J Pharmacol Exp Ther. 1998;285(2):739-45.

136. Budriesi R, Cosimelli B, Ioan P, Ugenti MP, Carosati E, Frosini M, et al. L-Type calcium channel blockers: from diltiazem to 1,2,4-oxadiazol-5-ones via thiazinooxadiazol-3-one derivatives. J Med Chem. 2009;52(8):2352-62. 
137. Klitzner TS, Chen FH, Raven RR, Wetzel GT, Friedman WF. Calcium current and tension generation in immature mammalian myocardium: effects of diltiazem. J Mol Cell Cardiol. 1991;23(7):807-15.

138. Yamazaki M, Kamitani K, Ito Y, Momose Y. Effects of halothane and diltiazem on ltype calcium currents in single smooth muscle cells from rabbit portal veins. Br J Anaesth. 1994;73(2):209-13.

139. Hockerman GH, Dilmac N, Scheuer T, Catterall WA. Molecular determinants of diltiazem block in domains IIIS6 and IVS6 of L-type $\mathrm{Ca}^{(2+)}$ channels. Mol Pharmacol. 2000;58(6):1264-70.

140. Periasamy M, Huke S. SERCA pump level is a critical determinant of $\mathrm{Ca}^{2+}$ homeostasis and cardiac contractility. J Mol Cell Cardiol. 2001;33(6):1053-63.

141. Schwinger RH, Brixius K, Bavendiek U, Hoischen S, Müller-Ehmsen J, Bölck B, et al. Effect of cyclopiazonic acid on the force-frequency relationship in human nonfailing myocardium. J Pharmacol Exp Ther. 1997;283(1):286-92.

142. du Toit EF, Opie LH. Inhibitors of $\mathrm{Ca}^{2+}$ ATPase pump of sarcoplasmic reticulum attenuate reperfusion stunning in isolated rat heart. $\mathbf{J}$ Cardiovasc Pharmacol. 1994;24(4):678-84.

143. DeFronzo RA, Ferrannini E. Insulin resistance. A multifaceted syndrome responsible for NIDDM, obesity, hypertension, dyslipidemia, and atherosclerotic cardiovascular disease. Diabetes Care. 1991;14(3):173-94.

144. Norman GR, Streiner DI. Biostatistics: The bare essentials. St. Louis (Mosby) 1994.

145. Bayley BJR. Tables of the Bonferroni "t" statistic. J Am Stat Assoc. 1977;72:469-78.

146. Johnson RA, Wichern DW. Applied multivariate statistical analysis. New Jersey; Prefice-Hall 1998; $4^{\text {th }}$ ed: p.816. 
147. Draper NR, Smith H. Applied regression analysis. New York: John Wiley; 1998; $3^{\text {rd }}$ ed: p.736.

148. Levin BE, Triscari J, Sullivan AC. Altered sympathetic activity during development of diet-induced obesity in rat. Am J Physiol. 1983;244(3):R347-55.

149. Ghibaudi L, Cook J, Farley C, van Heek M, Hwa JJ. Fat intake affects adiposity, comorbidity factors, and energy metabolism of sprague-dawley rats. Obes Res. 2002;10(9):956-63.

150. Gao J, Ghibaudi L, van Heek M, Hwa JJ. Characterization of diet-induced obese rats that develop persistent obesity after 6 months of high-fat followed by 1 month of low-fat diet. Brain Res. 2002;936(1-2):87-90.

151. Tentolouris N, Pavlatos S, Kokkinos A, Perrea D, Pagoni S, Katsilambros N. Dietinduced thermogenesis and substrate oxidation are not different between lean and obese women after two different isocaloric meals, one rich in protein and one rich in fat. Metabolism. 2008;57(3):313-20.

152. Schrauwen P, Westerterp KR. The role of high-fat diets and physical activity in the regulation of body weight. Br J Nutr. 2000;84(4):417-27.

153. Passadore MD, Griggio MA, Nunes MT, Luz J. Effects of ageing on the energy balance of food-restricted rats. Acta Physiol Scand. 2004;181(2):193-8.

154. Pausova Z. From big fat cells to high blood pressure: a pathway to obesity-associated hypertension. Curr Opin Nephrol and Hypertens. 2006;15(2):173-8.

155. Gower BA, Nagy TR, Goran MI.Visceral fat, insulin sensitivity, and lipids in prepubertal children. Diabetes. 2001;50(2):477-8.

156. Quon MJ. Limitations of the fasting glucose to insulin ratio as an index of insulin sensitivity. J Clin Endocrinol Metab. 2001;86(10):4615-7. 
157. Kahn SE, Prigeon RL, Schwartz RS, Fujimoto WY, Knopp RH, Brunzell JD, et al. Obesity, body fat distribution, insulin sensitivity and Islet beta-cell function as explanations for metabolic diversity. J Nutr. 2001;131(2):354S-60S.

158. Pessin JE, Saltiel AR. Signaling pathways in insulin action: molecular targets of insulin resistance. J Clin Invest. 2000;106(2):165-9.

159. Jellinger PS. Metabolic consequences of hyperglycemia and insulin resistance. Clin Cornerstone. 2007;8(7):S30-42.

160. Field CJ, Ryan EA, Thomson AB, Clandinin MT. Diet fat composition alters membrane phospholipid composition, insulin binding, and glucose metabolism in adipocytes from control and diabetic animals. J Biol Chem. 1990;265(19):11143-50.

161. Maegawa H, Kobayashi M, Ishibashi O, Takata Y, Shigeta Y. Effect of diet change on insulin action: difference between muscles and adipocytes. Am J Physiol. 1986;251(5 Pt 1):E616-23.

162. Shepherd PR, Kahn BB. Glucose transporters and insulin action--implications for insulin resistance and diabetes mellitus. N Engl J Med. 1999;341(4):248-57.

163. Klip A, Tsakiridis T, Marette A, Ortiz PA. Regulation of expression of glucose transporters by glucose: a review of studies in vivo and in cell cultures. FASEB J. 1994;8(1):43-53.

164. Storlien LH, Jenkins AB, Chisholm DJ, Pascoe WS, Khouri S, Kraegen EW. Influence of dietary fat composition on development of insulin resistance in rats. Relationship to muscle triglyceride and omega-3 fatty acids in muscle phospholipid. Diabetes. 1991;40(2):280-9.

165. Huang BW, Chiang MT, Yao HT, Chiang W. The effect of high-fat and high-fructose diets on glucose tolerance and plasma lipid and leptin levels in rats. Diabetes Obes Metab. 2004;6(2):120-6. 
166. Li L, Yang G, Li Q, Tang Y, Li K. High-fat- and Lipid-induced insulin resistance in rats: the comparison of glucose metabolism, plasm resistin and adiponectin levels. Ann Nutr Metab. 2006;50(6):499-505.

167. Winzell MS, Ahrén B. The high-fat diet-fed mouse: a model for studying mechanisms and treatment of impaired glucose tolerance and type 2 diabetes. Diabetes. 2004;53(Suppl 3):S215-9.

168. Mantzoros CS. The role of leptin in human obesity and disease: a review of current evidence. Ann Int Med. 1999;130(8):671-80.

169. Ainslie DA, Proietto J, Fam BC, Thorburn AW. Short-term, high-fat diets lower circulating leptin concentrations in rats. Am J Clin Nutr. 2000;71(2):438-42.

170. Frederich RC, Hamann A, Anderson S, Lollmann B, Lowell BB, Flier JS. Leptin levels reflect body lipid content in mice: evidence for diet-induced resistance to leptin action. Nat Med. 1995;1(12):1311-4.

171. Sinitskaya N, Gourmelen S, Schuster-Klein C, Guardiola-Lemaitre B, Pévet P, Challet E. Increasing the fat-to-carbohydrate ratio in a high-fat diet prevents the development of obesity but not a prediabetic state in rats. Clin Sci (Lond). 2007;113(10):417-25.

172. Reilly MP, Rader DJ. The metabolic syndrome: more than the sum of its parts? Circulation. 2003;108(13):1546-51.

173. Moller DE, Kaufman KD. Metabolic syndrome: a clinical and molecular perspective. Annu Rev Med. 2005;56:45-62.

174. Zammit VA, Waterman IJ, Topping D, McKay G. Insulin stimulation of hepatic triacylglycerol secretion and the etiology of insulin resistance. $J$ Nutr. 2001;131(8):2074-7.

175. Holmes JH, Lambourne LJ. The relation between plasma free fatty acid concentration and the digestible energy intake of cattle. Res Vet Sci. 1970;11(1):27-36. 
176. Birnbaum MJ. Lipolysis: more than just a lipase. J Cell Biol. 2003;161(6):1011-2.

177. Mahan LK, Escott-Stump S. Alimentos, nutrição e dietoterapia. $9^{a}$ ed. São Paulo: Roca, 1998. p.1179.

178. Djoussé L, Pankow JS, Eckfeldt JH, Folsom AR, Hopkins PN, Province MA, et al. Relation between dietary linolenic acid and coronary artery disease in the National Heart, Lung, and Blood Institute Family Heart Study. Am J Clin Nutr. 2001;74(5):6129.

179. Dewailly EE, Blanchet C, Gingras S, Lemieux S, Sauvé L, Bergeron J, et al. Relations between n-3 fatty acid status and cardiovascular disease risk factors among Quebecers. Am J Clin Nutr. 2001;74(5):603-11.

180. Schaefer EJ. Lipoproteins, nutrition, and heart disease. Am J Clin Nutr. 2002;75(2):191212.

181. Mustad VA, Etherton TD, Cooper AD, Mastro AM, Pearson TA, Jonnalagadda SS, et al. Reducing saturated fat intake is associated with increased levels of LDL receptors on mononuclear cells in healthy men and women. J Lipid Res. 1997;38(3):459-68.

182. Cohn JN, Ferrari R, Sharpe N. Cardiac remodeling--concepts and clinical implications: a consensus paper from an international forum on cardiac remodeling. Behalf of an International Forum on Cardiac Remodeling. J Am Coll Cardiol. 2000;35(3):569-82.

183. Lu MC, Tzang BS, Kuo WW, Wu FL, Chen YS, Tsai CH, et al. More activated cardiac mitochondrial-dependent apoptotic pathway in obese Zucker rats. Obesity. 2007;15(11):2634-42.

184. Yin FC, Spurgeon HA, Rakusan K, Weisfeldt ML, Lakatta EG. Use of tibial length to quantify cardiac hypertrophy: application in the aging rat. Am $\mathrm{J}$ Physiol. 1982;243(6):H941-7. 
185. Voltera AF, Cesaretti ML, Ginoza M, Kohlmann O Jr. Effects of neuroendocrine obesity induction on systemic hemodynamics and left ventricular function of normotensive rats. Arq Bras Endocrinol Metabol. 2008;52(1):47-54.

186. Okoshi K. Estrutura e função do coração de ratos normotensos e hipertensos submetidos à restrição da ingestão alimentar: estudo in vivo pelo ecocardiograma e in vitro do coração isolado [tese]. Botucatu: Faculdade de Medicina, UNESP; 2000.

187. Skurk C, Izumiya Y, Maatz H, Razeghi P, Shiojima I, Sandri M, et al. The FOXO3a transcription factor regulates cardiac myocyte size downstream of AKT signaling. J Biol Chem. 2005;280(21):20814-23.

188. Fiedler B, Wollert KC. Targeting calcineurin and associated pathways in cardiac hypertrophy and failure. Expert Opin Ther Targets. 2005;9(5):963-73.

189. Cicogna AC, Okoshi MP, Okoshi K. História natural da remodelação miocárdica: da agressão aos sintomas. Rev Soc Cardiol Estado de São Paulo. 2000;10:8-16.

190. Kershaw EE, Flier JS. Adipose tissue as an endocrine organ. J Clin Endocrinol Metab 2004;89(6):2548-56.

191. Rondinone CM. Adipocyte-derived hormones, cytokines, and mediators. Endocrine. 2006;29(1):81-90.

192. Brownsey RW, Boone AN, Allard MF. Actions of insulin on the mammalian heart: metabolism, pathology and biochemical mechanisms. Cardiovasc Res. 1997;34(1):3-24.

193. McNulty PH, Jacob R, Deckelbaum LI, Young LH. Effect of hyperinsulinemia on myocardial aminoacid uptake in patients with coronary artery disease. Metabolism. 2000;49(10):1365-9.

194. Young LH, Dahl DM, Rauner D, Barrett EJ. Physiological hyperinsulinemia inhibits myocardial protein degradation in vivo in the canine heart. Circ Res. 1992;71(2):393400. 
195. Davis CL, Kapuku G, Snieder H, Kumar M, Treiber FA. Insulin resistance syndrome and left ventricular mass in healthy young people. Am J Med Sci. 2002;324(2):72-5.

196. Ilercil A, Devereux RB, Roman MJ, Paranicas M, O’Grady MJ, Lee ET, et al. Associations of insulin levels with left ventricular structure and function in American Indians: the strong heart study. Diabetes. 2002;51(5):1543-7.

197. Levine TB, Levine AB. Metabolic Syndrome and Cardiovascular disease. $1^{\text {st }}$ ed. Philadelphia: Saunders Elsevier; 2006.

198. Brands MW, Hall JE, Van Vliet BN, Alonso-Galicia M, Herrera GA. Obesity and hypertension: roles of hyperinsulinimia, sympathetic nervous system and intrarenal mechanisms. J Nutr 1995;125(6 Suppl):1725S-31S.

199. Pugliese G, Pricci F, Menè P, Romeo G, Nofroni I, Giannini S, et al. High glucose level unmasks a genetic predisposition of enhanced extracellular matrix production in mesangial cells from the milan normotensive strain. J Am Soc Nephrol 1997;8:406-14.

200. Lijnen PJ, Petrov VV, Fagard RH. Induction of cardiac fibrosis by angiotensin II. Methods Find Exp Clin Pharmacol. 2000;22(10):709-23.

201. Fang CX, Dong F, Thomas DP, Ma H, He L, Ren J. Hypertrophic cardiomyopathy in high-fat diet-induced obesity: role of suppression of forkhead transcription factor and atrophy gene transcription. Am J Physiol Heart Circ Physiol. 2008;295(3):H1206-5.

202. Jessup M, Brozena S. Heart failure. N Engl J Med. 2003;348(20):2007-18.

203. Boluyt MO, Bing OH, Lakatta EG. The ageing spontaneously hypertensive rat as a model of the transition from stable compensated hypertrophy to heart failure. Eur Heart J. 1995;16(Suppl N):19-30.

204. Sasson Z, Rasooly Y, Gupta R, Rasooly I. Left atrial enlargement in healthy obese: prevalence and relation to left ventricular mass and diastolic function. Can J Cardiol. 1996;12(3):257-63. 
205. Jain A, Avendano G, Dharamsey S, Dasmahapatra A, Agarwal R, Reddi A, et al. Left ventricular diastolic function in hypertension and role of plasma glucose and insulin. Comparison with diabetic heart. Circulation. 1996;93(7):1396-402.

206. Sugizaki MM, Carvalho RF, Aragon FF, Padovani CR, Okoshi K, Okoshi MP, et al. Myocardial dysfunction induced by food restriction is related to morphological damage in normotensive middle-aged rats. J Biomed Sci. 2005;12(4):641-9.

207. Bregagnollo EA, Zornoff LA, Okoshi K, Sugizaki M, Mestrinel MA, Padovani CR, et al. Myocardial contractile dysfunction contributes to the development of heart failure in rats with aortic stenosis. Int J Cardiol. 2007;117(1):109-14.

208. Joseph T, Coirault C, Dubourg O, Lecarpentier Y. Changes in crossbridge mechanical properties in diabetic rat cardiomyopathy. Basic Res Cardiol. 2005;100(3):231-9.

209. Bing OH, Wiegner AW, Brooks WW, Fishbein MC, Pfeffer JM. Papillary muscle structure-function relations in the aging spontaneously hypertensive rat. Clin Exp Hypertens A. 1988;10(1):37-58.

210. Young ME, Guthrie PH, Razeghi P, Leighton B, Abbasi S, Patil S, et al. Impaired longchain fatty acid oxidation and contractile dysfunction in the obese zucker rats heart. Diabetes. 2002;51(8):2587-92.

211. Carroll JF, Jones AE, Hester RL, Reinhart GA, Cockrell K, Mizelle HL. Reduced cardiac contractile responsiveness to isoproterenol in obese rabbits. Hypertension. 1997;30(6):1376-81.

212. Bers DM. Ca regulation in cardiac muscle. Med Sci Sports Exerc. 1991;23(10):1157-62.

213. Catterall WA. Structure and function of voltage-gated ion channels. Annu Rev Biochem. 1995;64:493-531.

214. Bean BP. Two kinds of calcium channels in canine atrial cells. Differences in kinetics, selectivity, and pharmacology. J Gen Physiol. 1985;86(1):1-30. 
215. Nilius B, Hess P, Lansman JB, Tsien RW. A novel type of cardiac calcium channel in ventricular cells. Nature. 1985;316(6027):443-6.

216. Mewes T, Ravens U. L-type calcium currents of human myocytes from ventricle of nonfailing and failing hearts and from atrium. J Mol Cell Cardiol. 1994;26(10):1307-20.

217. Catterall WA. Modulation of sodium and calcium channels by protein phosphorylation and G proteins. Adv Second Messenger Phosphoprotein Res. 1997;31:159-81.

218. Hartzell HC. Regulation of cardiac ion channels by catecholamines, acetylcholine and second messenger systems. Prog Biophys Mol Biol. 1988;52(3):165-247.

219. Shuba YM, McDonald TF, Trautwein W, Pelzer S, Pelzer D. Direct up-regulating effect of Gs on the whole-cell L-type Ca current in cardiac cells. Gen Physiol Biophys. 1991;10(2):105-10.

220. Brum G, Osterrieder W, Trautwein W. Beta-adrenergic increase in the calcium conductance of cardiac myocytes studied with the patch clamp. Pflugers Arch. 1984;401(2):111-8.

221. Sipido KR, Callewaert G, Carmeliet E. Inhibition and rapid recovery of $\mathrm{Ca}^{2+}$ current during $\mathrm{Ca}^{2+}$ release from sarcoplasmic reticulum in guinea pig ventricular myocytes. Circ Res. 1995;76(1):102-9.

222. Davidoff AJ, Maki TM, Ellingsen O, Marsh JD. Expression of calcium channels in adult cardiac myocytes is regulated by calcium. J Mol Cell Cardiol. 1997;29(7):1791-803.

223. Agata N, Tanaka H, Shigenobu K. Possible action of cyclopiazonic acid on myocardial sarcoplasmic reticulum:inotropic effects neonatal and adult rat heart. Br J Pharmacol. 1993;108(3):571-2. 
224. Badaoui A, Huchet-Cadiou C, Leoty C. Effects of cyclopiazonic acid on membrane currents contraction and intracellular calcium transients in frog hearts. J Mol Cell Cardiol. 1995;27(11):2495-505.

225. Baudet S, Shaoulian R, Bers DM. Effects of thapsigargin and cyclopiazonic acid on twitch force and sarcoplamic reticulum $\mathrm{Ca}^{2+}$ content of rabbit ventricular muscle. Circ Res. 1993;73(5):813-9.

226. Takahashi S, Kato Y, Adachi M, Agata N, Tanaka H, Shigenobu K. Effects of cyclopiazonic acid on rat miocardium: inhibition of calcium uptake into sarcoplasmic reticulum. J Pharmacol Exp Ther. 1995;272(3):1095-100.

227. Philip-Couderc P, Smih F, Hall JE, Pathak A, Roncalli J, Harmancey R, et al. Kinetic analysis of cardiac transcriptome regulation during chronic high-fat diet in dogs. Physiol Genomics. 2004;19(1):32-40.

228. Watanabe A, Arai M, Yamazaki M, Koitabashi N, Wuytack F, Kurabayashi M. Phospholamban ablation by RNA interference increases $\mathrm{Ca}^{2+}$ uptake into rat cardiac myocyte sarcoplasmic reticulum. J Mol Cell Cardiol. 2004;37(3):691-8.

229. Mattiazzi A, Mundiña-Weilenmann C, Guoxiang C, Vittone L, Kranias E. Role of phospholamban on Thr17 in cardiac physiological and pathological conditions. Cardiovasc Res. 2005;68(3):366-75.

230. Kranias EG, Bers DM. Calcium and cardiomyopathies. Subcell Biochem. 2007;45:52337.

231. Bassani JW, Bassani RA, Bers DM. Relaxation in rabbit and rat cardiac cells: speciesdependent differences in cellular mechanisms. J Physiol. 1994;476(2):279-93.

232. Kiss E, Jakab G, Kranias EG, Edes I. Thyroid hormone-induced alterations in phospholamban protein expression. Regulatory effects on sarcoplasmic reticulum $\mathrm{Ca} 2+$ transport and myocardial relaxation. Circ Res. 1994;75(2):245-51. 
233. Algenstaedt P, Antonetti DA, Yaffe MB, Kahn CR. Insulin receptor substrate proteins create a link between the tyrosine phosphorylation cascade and the $\mathrm{Ca}^{2+}$-ATPases in muscle and heart. J Biol Chem. 1997;272(38):23696-702.

234. Viner RI, Ferrington DA, Williams TD, Bigelow DJ, Schöneich C. Protein modification during biological aging: selective tyrosine nitration of the SERCA2a isoform of the sarcoplasmic reticulum $\mathrm{Ca}^{2+}$-ATPase in skeletal muscle. Biochem J. 1999;340 (Pt 3):657-69. 